\title{
Seizure-mediated iron accumulation and dysregulated iron metabolism after status epilepticus and in temporal lobe epilepsy
}

Till S. Zimmer ${ }^{1} \cdot$ Bastian David $^{2}$. Diede W. M. Broekaart ${ }^{1} \cdot$ Martin Schidlowski $^{2,3} \cdot$ Gabriele Ruffolo $^{4}$. Anatoly Korotkov ${ }^{1} \cdot$ Nicole N. van der Wel ${ }^{5,6} \cdot$ Peter C. van Rijen $^{7} \cdot$ Angelika Mühlebner $^{1,8} \cdot$ Wim van Hecke ${ }^{8}$. Johannes C. Baayen ${ }^{9}$. Sander Idema ${ }^{9} \cdot$ Liesbeth François $^{10}$. Jonathan van Eyll ${ }^{10}$. Stefanie Dedeurwaerdere ${ }^{10}$. Helmut W. Kessels ${ }^{11}$ - Rainer Surges ${ }^{2}$. Theodor Rüber ${ }^{2} \cdot$ Jan A. Gorter ${ }^{11}$ - James D. Mills $s^{1,12,13}$. Erwin A. van Vliet ${ }^{1,11}$. Eleonora Aronica ${ }^{1,14}$

Received: 21 April 2021 / Revised: 2 July 2021 / Accepted: 12 July 2021 / Published online: 22 July 2021

(c) The Author(s) 2021

\begin{abstract}
Neuronal dysfunction due to iron accumulation in conjunction with reactive oxygen species (ROS) could represent an important, yet underappreciated, component of the epileptogenic process. However, to date, alterations in iron metabolism in the epileptogenic brain have not been addressed in detail. Iron-related neuropathology and antioxidant metabolic processes were investigated in resected brain tissue from patients with temporal lobe epilepsy and hippocampal sclerosis (TLE-HS), postmortem brain tissue from patients who died after status epilepticus (SE) as well as brain tissue from the electrically induced SE rat model of TLE. Magnetic susceptibility of the presumed seizure-onset zone from three patients with focal epilepsy was compared during and after seizure activity. Finally, the cellular effects of iron overload were studied in vitro using an acute mouse hippocampal slice preparation and cultured human fetal astrocytes. While iron-accumulating neurons had a pyknotic morphology, astrocytes appeared to acquire iron-sequestrating capacity as indicated by prominent ferritin expression and iron retention in the hippocampus of patients with SE or TLE. Interictal to postictal comparison revealed increased magnetic susceptibility in the seizure-onset zone of epilepsy patients. Post-SE rats had consistently higher hippocampal iron levels during the acute and chronic phase (when spontaneous recurrent seizures are evident). In vitro, in acute slices that were exposed to iron, neurons readily took up iron, which was exacerbated by induced epileptiform activity. Human astrocyte cultures challenged with iron and ROS increased their antioxidant and iron-binding capacity, but simultaneously developed a pro-inflammatory phenotype upon chronic exposure. These data suggest that seizure-mediated, chronic neuronal iron uptake might play a role in neuronal dysfunction/loss in TLE-HS. On the other hand, astrocytes sequester iron, specifically in chronic epilepsy. This function might transform astrocytes into a highly resistant, pro-inflammatory phenotype potentially contributing to pro-epileptogenic inflammatory processes.
\end{abstract}

Keywords Iron - Glutathione metabolism - Status epilepticus - Temporal lobe epilepsy with hippocampal sclerosis · Astrocytes

\begin{tabular}{|c|c|c|c|}
\hline \multicolumn{2}{|c|}{ Abbreviations } & BBB & Blood-brain barrier \\
\hline 4-AP & 4-Aminopyridine & BCA & Bicinchoninic acid assay \\
\hline 4-HNE & 4-Hydroxynonenal & $\mathrm{C} 1 \mathrm{ORF} 43$ & Chromosome 1 open reading frame 43 \\
\hline ACSF & Artificial cerebrospinal fluid & CA1 & Cornu ammonis 1 \\
\hline $\mathrm{AEC}$ & 3'-Amino 9'-ethylcarbazole & $\mathrm{CP}$ & Ceruloplasmin \\
\hline AP & Alkaline phosphatase & CSF & Cerebrospinal fluid \\
\hline & & CycA & Cyclin A \\
\hline Erwin A. & Vliet, Eleonora Aronica are joint senior author. & $\begin{array}{l}\text { DAB } \\
\text { DG }\end{array}$ & $\begin{array}{l}\text { Diaminobenzidine } \\
\text { Dentate gyrus }\end{array}$ \\
\hline & & DMT-1 & Divalent metal transporter 1 (SLC11A2) \\
\hline $\begin{array}{l}\Delta \text { Eleon } \\
\text { e.aror }\end{array}$ & $\begin{array}{l}\text { Aronica } \\
@ \text { @amsterdan }\end{array}$ & $\mathrm{EC}$ & Entorhinal cortex \\
\hline ended & information ayaits & $\mathrm{EF} 1-\alpha$ & Elongation factor $1 \alpha$ \\
\hline
\end{tabular}




$\begin{array}{ll}\text { FAC } & \text { Ferric ammonium citrate } \\ \text { FCS } & \text { Fetal calf serum } \\ \text { FPN-1 } & \text { Ferroportin 1 (SLC40A1) } \\ \text { FTH-1 } & \text { Ferritin heavy chain 1 } \\ \text { FTL } & \text { Ferritin light chain } \\ \text { GAPDH } & \text { Glyceraldehyde 3-phosphate dehydrogenase } \\ \text { GCLC } & \text { Glutamate cysteine ligase catalytic subunit } \\ \text { GFAP } & \text { Glial fibrillary acidic protein } \\ \text { Glu } & \text { L-glutamate } \\ \text { GO } & \text { Glucose oxidase } \\ \text { GPx1 } & \text { Glutathione peroxidase 1 } \\ \text { GSR } & \text { Glutathione disulfide reductase } \\ \text { HMGB-1 } & \text { High-mobility group box 1 } \\ \text { HO-1 } & \text { Heme oxygenase 1 } \\ \text { HRP } & \text { Horse radish peroxidase } \\ \text { Hrpt } & \text { Hypoxanthine phosphoribosyltransferase 1 } \\ \text { Iba-1 } & \text { Ionized calcium-binding adapter molecule 1 } \\ \text { IHC } & \text { Immunohistochemistry } \\ \text { IRS } & \text { Immunoreactivity score } \\ \text { MEA } & \text { Multi-electrode arrays } \\ \text { MTT } & \text { 3-(4,5-Dimethylthiazol-2-yl)-2,5-diphenyl } \\ & \text { tetrazolium bromide } \\ \text { NADPH } & \text { Nicotinamide adenine dinucleotide phosphate } \\ \text { Nrf-2 } & \text { Nuclear factor erythroid 2 like 2 } \\ \text { OS } & \text { Oxidative stress } \\ \text { PBS } & \text { Phosphate buffered saline } \\ \text { PCR } & \text { Polymerase chain reaction } \\ \text { PHC } & \text { Parahippocampal cortex } \\ \text { PLL } & \text { Poly-L-lysine } \\ \text { PRX6 } & \text { Peroxiredoxin 6 } \\ \text { PV } & \text { Parvalbumin } \\ \text { PVDF } & \text { Polyvinylidene difluoride } \\ \text { QSM } & \text { Quantitative susceptibility mapping } \\ \text { ROS } & \text { Reactive oxygen species } \\ \text { SE } & \text { Status epilepticus } \\ \text { SRS } & \text { Spontaneous recurrent seizures } \\ \text { TBI } & \text { Traumatic brain injury } \\ \text { Tbp } & \text { TATA box-binding protein } \\ \text { TBS-T } & \text { Tris-buffered saline with 0.1\% Tween20 } \\ \text { TFRC } & \text { Transferrin receptor 1 } \\ \text { TLE-HS } & \text { Temporal lobe epilepsy with hippocampal } \\ \text { TMM } & \text { sclerosis } \\ \text { xCT } & \text { Trimmed mean of M-values } \\ & \text { Glutamate/cysteine antiporter system Xc }{ }^{-} \\ \text {light subunit (SLC7A11) } \\ \end{array}$

\section{Introduction}

Epilepsy is a common neurological disease that is characterized by "an enduring predisposition to generate epileptic seizures, and by the neurobiologic, cognitive, psychological, and social consequences of this condition" $[18,19]$.
Epileptogenesis describes the pathogenic process by which physiological and structural changes in the brain are induced, leading to increased seizure susceptibility and enhanced likelihood of spontaneous recurrent seizures (SRS) to occur [61]. A major pathogenic mechanism of epileptogenesis in epilepsies of various etiology is oxidative stress (OS) [58, $75,81]$.

OS is defined as an imbalance between the antioxidant capacity of a cell or tissue and the generation of reactive oxygen species (ROS) with a shift towards the latter leading to cell damage or even cell death. During acute seizure activity, excessive ROS are generated due to i.e. mitochondrial dysfunction and/or increased activity of nicotinamide adenine dinucleotide phosphate (NADPH) oxidase [37, 69, 81]. Targeting OS by providing ROS scavenging antioxidants or by boosting endogenous antioxidant systems, specifically the activity of the antioxidant transcription factor nuclear factor erythroid 2 like 2 (Nrf-2), was shown to have a beneficial disease-modifying effect in models of acquired epilepsy, delaying onset and progression of seizures [45, 58, 74, 76]. These effects were likely facilitated by proteins involved in the production and recycling of the primary intracellular antioxidant glutathione [7].

In this context, recent evidence from congenital epilepsies due to focal cortical dysplasia and tuberous sclerosis complex indicates that OS and iron metabolism are tightly linked and could act synergistically to exacerbate cell dysfunction and damage in epilepsy [97]. Accordingly, high concentrations of unbound $\mathrm{Fe}^{2+}$ iron could act as catalyst in the Haber-Weiss and Fenton reactions to enhance the potency of hydrogen peroxide from cellular processes to more reactive ROS like the hydroxyl radical or hydroxide ion, thereby facilitating cell dysfunction or death [22, 82]. Besides congenital epilepsies, intracerebral hemorrhages resulting from traumatic brain injury (TBI) and sequential post-traumatic epilepsy are characterized by brain iron deposition and intracortical iron injections evoke seizures and epilepsy in experimental models [1, 35, 40, 42, 50, 71, 77, 89]. Additionally, independent of large-scale hemorrhages, dysfunction of the BBB is a hallmark of a variety of epileptogenic pathologies in which iron concentrations could increase locally by non-specific leakage of iron-rich blood components into the brain parenchyma and subsequent iron release $[20,85]$. In line with this, previous microarray studies of brain tissue from low-grade epilepsy-associated tumors and a rat model of acquired epilepsy point towards a critical role of iron metabolism in epilepsy [3, 24]. However, up to now, alterations in iron metabolism and its consequences have not been assessed in detail in brain tissue from patients with temporal lobe epilepsy (TLE).

This study aims to investigate (1) if iron accumulation and iron metabolism are altered after status epilepticus (SE) and in TLE per se in conjunction with OS and antioxidant 
capacity, (2) which cell types are involved in iron regulation and (3) whether iron has ictogenic effects and could be involved in epileptogenesis. To this end, we evaluated OS and iron metabolism in post-mortem brain tissue of patients who died after SE and in surgically resected brain tissue from patients suffering from intractable TLE with hippocampal sclerosis (TLE-HS) to elucidate the effects of acute seizure activity and chronic epilepsy in iron metabolism, respectively. These findings were further validated by assessing the transcriptome of a cohort of TLE-HS hippocampal tissue. Furthermore, by employing quantitative susceptibility mapping (QSM) of three patients with focal epilepsies, spatial and temporal changes in iron in the seizure-onset zone were assessed. Consequently, iron overload and affected cell types were studied during different stages of epileptogenesis in the electrical post-SE model of TLE. To elucidate the cellular response to iron-mediated OS hippocampal brain slices and human fetal astrocytes were stimulated with iron in vitro.

\section{Materials and methods}

\section{Subjects}

Surgical and post-mortem brain tissue included in this study was obtained from the archives of the departments of Neuropathology of the Amsterdam UMC, (Amsterdam, The Netherlands) and the UMC Utrecht (Utrecht, The Netherlands). Hippocampal brain samples were obtained from patients undergoing surgery for intractable epilepsy and diagnosed with TLE-HS. All cases were reviewed independently by two neuropathologists. The classification of HS was determined as described by the International League against Epilepsy [4]. The hippocampus and cortex of age-matched controls without a history of seizures or other neurological diseases and cortical brain tissue from patients who died after SE, stroke or traumatic brain injury (TBI) was obtained at autopsy. All autopsies were performed within $24 \mathrm{~h}$ after death. Clinical details of patient cohorts and number of samples for experiments used in this study are summarized in Tables 1, 2, 3 and 4 and Online resource 7. Tissue was obtained with informed consent for the use in research and access to medical records in accordance with the Declaration of Helsinki and the Amsterdam UMC Research Code provided by the Medical Ethics Committee.

\section{Immunohistochemistry on paraffin-embedded brain tissue}

Human brain tissue was fixed in $10 \%$ buffered formalin and embedded in paraffin. Paraffin-embedded tissue was sectioned at $6 \mu \mathrm{m}$, mounted on pre-coated glass slides (Star
Table 1 Summary of experimental groups

\begin{tabular}{lllll}
\hline $\begin{array}{l}\text { Experimental } \\
\text { group }\end{array}$ & Diagnosis & $N \begin{array}{l}\text { Median age } \\
\text { in years } \\
\text { (range) }\end{array}$ & Gender (m/f) \\
\hline RNA & Autopsy control & 10 & $71(25-79)$ & $6 / 4$ \\
& TLE-HS & 13 & $42(29-66)$ & $6 / 7$ \\
Protein & Autopsy control & 6 & $48(35-63)$ & $3 / 3$ \\
& TLE-HS & 9 & $38(6-66)$ & $4 / 5$ \\
CSF & CSF control & 6 & $61(38-70)$ & $3 / 3$ \\
& TLE-HS & 8 & $43(32-57)$ & $6 / 2$ \\
IHC & Autopsy control & 5 & $39(25-67)$ & $1 / 4$ \\
& Status epilep- & 5 & $79(31-87)$ & $3 / 2$ \\
& ticus & & & \\
\multirow{2}{*}{$\begin{array}{l}\text { RNA sequenc- } \\
\text { ing }\end{array}$} & ALE-HS & 6 & $36(29-60)$ & $3 / 3$ \\
& Autopsy control & 11 & $62(30-72)$ & $7 / 4$ \\
\hline
\end{tabular}

TLE-HS temporal lobe epilepsy with hippocampal sclerosis, $m$ male, $f$ female, CSF cerebrospinal fluid, IHC immunohistochemistry, $N$ number of cases

Mann-Whitney $U$ test of age-matched status: RNA $p=0.0586$; Protein $p=0.3156$; CSF $p=0.0526$; IHC $p=0.9307$; RNA sequencing $p=0.0526$

Frost, Waldemar Knittel Glasbearbeitungs, Braunschweig, Germany) and processed for immunohistochemical stainings. Sections were deparaffinated in xylene, rinsed in ethanol $(100 \%, 95 \%, 70 \%)$ and incubated for $20 \mathrm{~min}$ in $0.3 \%$ $\mathrm{H}_{2} \mathrm{O}_{2}$ diluted in methanol to block endogenous peroxidase activity. Antigen retrieval was performed using a pressure cooker in $0.01 \mathrm{M}$ sodium citrate buffer $(\mathrm{pH} 6.0)$ at $121^{\circ} \mathrm{C}$ for $10 \mathrm{~min}$. Slides were washed with phosphate-buffered saline (PBS; 0.1 M, pH 7.4) and incubated overnight with primary antibodies against phosphorylated 4-hydroxynonenal (4-HNE; rabbit polyclonal, Abcam, Cambridge, UK; 1:500), heme oxygenase 1 (HO-1; rabbit polyclonal, Abcam, Cambridge, UK; 1:200), DMT-1 (SLC11A2; rabbit polyclonal, Proteintech, Rosemont, IL, USA; 1:500), anti-horse spleen ferritin (against rat tissue; polyclonal rabbit, SigmaAldrich, St. Louis, MO, USA; 1:2000), anti-human ferritin (rabbit polyclonal, DAKO, Glostrup, Denmark; 1:750), peroxiredoxin 6 (PRX6; rabbit polyclonal, Merck-Millipore, Burlington, MA, USA; 1:100) or TFRC (rabbit polyclonal, Proteintech, Rosemont, IL, USA; 1:200) in antibody diluent (VWR International, Radnor, PA, USA) at $4{ }^{\circ} \mathrm{C}$. Thereafter, slides were washed in PBS and then stained with a polymerbased horse radish peroxidase (HRP) immunohistochemistry detection kit (Brightvision plus kit, ImmunoLogic, Duiven, The Netherlands) according to the manufacturer's instructions. After washing in PBS, sections were stained using 3,3'-diaminobenzidine (DAB) tetrahydrochloride (SigmaAldrich, St. Louis, MO, USA) in the presence of $0.015 \%$ $\mathrm{H}_{2} \mathrm{O}_{2}$ in $0.05 \mathrm{M}$ Tris- $\mathrm{HCl}$ buffer ( $\mathrm{pH}$ 7.6). The reaction was 
Table 2 Clinical information of autopsy control, cerebrospinal fluid control and status epilepticus patients

\begin{tabular}{|c|c|c|c|c|c|c|c|c|}
\hline \multirow{2}{*}{$\begin{array}{l}\text { Group } \\
\text { Autopsy control }\end{array}$} & \multicolumn{2}{|c|}{ Case ID } & \multirow{2}{*}{$\begin{array}{l}\text { Age } \\
71\end{array}$} & \multirow{2}{*}{$\begin{array}{l}\text { Gender } \\
\text { f }\end{array}$} & \multirow{2}{*}{$\begin{array}{l}\text { Cause of death/reason for CSF sampling } \\
\text { bronchopneumonia }\end{array}$} & \multirow{2}{*}{$\begin{array}{l}\text { Post-mor- } \\
\text { tem delay } \\
\text { (h) } \\
10\end{array}$} & \multirow{2}{*}{$\begin{array}{l}\text { Neuropathological conclusion } \\
\text { normal, mild hypoxia }\end{array}$} & \multirow{2}{*}{$\begin{array}{l}\text { SE to } \\
\text { death } \\
\text { delay }\end{array}$} \\
\hline & 4 & $\mathrm{a}$ & & & & & & \\
\hline Autopsy control & 5 & $\mathrm{a}$ & 70 & $\mathrm{f}$ & Peritonitis & 15 & Normal & N/A \\
\hline Autopsy control & 6 & $\mathrm{a}, \mathrm{e}$ & 30 & $\mathrm{~m}$ & Myocardial infarction & 8 & Normal & N/A \\
\hline Autopsy control & 7 & $\mathrm{a}$ & 76 & $\mathrm{~m}$ & Myocardial infarction & 9 & Normal, mild hypoxia & N/A \\
\hline Autopsy control & 8 & $\mathrm{a}$ & 72 & $\mathrm{~m}$ & Respiratory insufficiency & 11 & Normal & N/A \\
\hline Autopsy control & 9 & $\mathrm{a}, \mathrm{d}$ & 25 & f & Arrhythmia & 7 & Normal & N/A \\
\hline Autopsy control & 10 & $\mathrm{a}$ & 79 & $\mathrm{~m}$ & Respiratory insufficiency & 12 & Normal & N/A \\
\hline Autopsy control & 11 & $\mathrm{a}, \mathrm{e}$ & 69 & $\mathrm{~m}$ & Bronchopneumonia & 10 & Normal & N/A \\
\hline Autopsy control & 12 & $a, b, d$ & 35 & $\mathrm{f}$ & Myocarditis & 9 & Normal & N/A \\
\hline Autopsy control & 13 & $\mathrm{a}$ & 75 & $\mathrm{~m}$ & Bronchopneumonia & 11 & Normal & N/A \\
\hline Autopsy control & 14 & $\mathrm{~b}, \mathrm{e}$ & 62 & $\mathrm{~m}$ & Bronchopneumonia & 9 & Normal, mild hypoxia & N/A \\
\hline Autopsy control & 15 & $\mathrm{~b}, \mathrm{e}$ & 63 & $\mathrm{f}$ & Pulmonary embolism & 11 & Normal & N/A \\
\hline Autopsy control & 16 & $\mathrm{~b}$ & 35 & $\mathrm{f}$ & Myocarditis & 8 & Normal & N/A \\
\hline Autopsy control & 17 & $\mathrm{~b}, \mathrm{e}$ & 49 & $\mathrm{~m}$ & Bronchopneumonia & 10 & Normal & N/A \\
\hline Autopsy control & 18 & $\mathrm{~b}, \mathrm{e}$ & 47 & $\mathrm{~m}$ & Cardiac tamponade & 8 & Normal & N/A \\
\hline Autopsy control & 19 & $\mathrm{~b}$ & 38 & $\mathrm{f}$ & Pneumothorax & 11 & Normal & N/A \\
\hline Autopsy control & 20 & $\mathrm{c}$ & 51 & $\mathrm{~m}$ & Chronic headache & N/A & Normal & N/A \\
\hline Autopsy control & 21 & $\mathrm{c}$ & 60 & $\mathrm{~m}$ & Facial hypoesthesia & N/A & Normal & N/A \\
\hline Autopsy control & 22 & $\mathrm{c}$ & 61 & f & Chronic headache & N/A & Normal & N/A \\
\hline Autopsy control & 23 & $\mathrm{c}$ & 70 & $\mathrm{~m}$ & Cranial nerve palsy & N/A & Normal & N/A \\
\hline Autopsy control & 24 & $\mathrm{c}$ & 68 & $\mathrm{f}$ & Myelopathy & N/A & Normal & N/A \\
\hline Autopsy control & 25 & $\mathrm{c}$ & 38 & $\mathrm{f}$ & Suspected Guillain-Barré syndrome & N/A & Normal & N/A \\
\hline Autopsy control & 26 & $\mathrm{~d}$ & 39 & $\mathrm{f}$ & Cardiorespiratory failure & 10 & Normal & N/A \\
\hline Autopsy control & 27 & $\mathrm{~d}$ & 67 & $\mathrm{~m}$ & Cardiorespiratory failure & 9 & Normal & N/A \\
\hline Autopsy control & 28 & d & 25 & $\mathrm{f}$ & Cardiorespiratory failure & 12 & Normal & N/A \\
\hline Autopsy control & 29 & d & 35 & $\mathrm{f}$ & Myocarditis & 10 & Normal & N/A \\
\hline Autopsy control & 30 & $\mathrm{~d}$ & 45 & $\mathrm{f}$ & Arrhythmia & 7 & Normal & N/A \\
\hline Status epilepticus & 31 & d & 58 & $\mathrm{~m}$ & Frontal lobe infarction, thrombosis & 10 & Non-convulsive SE & $3 \mathrm{~d}$ \\
\hline Status epilepticus & 32 & $\mathrm{~d}$ & 79 & $\mathrm{f}$ & Myocardial infarction & 8 & Non-convulsive SE & $7 \mathrm{w}$ \\
\hline Status epilepticus & 33 & $\mathrm{~d}$ & 81 & $\mathrm{~m}$ & Pneumonia & 14 & Convulsive SE & $0 \mathrm{~d}$ \\
\hline Status epilepticus & 34 & $\mathrm{~d}$ & 31 & $\mathrm{~m}$ & Astrocytoma (WHO III) & 9 & Convulsive SE & $5 \mathrm{~d}$ \\
\hline Status epilepticus & 35 & $\mathrm{~d}$ & 87 & $\mathrm{f}$ & Aneurysm arteria cerebri media & 7 & Convulsive SE & $10 \mathrm{~d}$ \\
\hline Autopsy control & 36 & $\mathrm{e}$ & 63 & $\mathrm{f}$ & Arrhythmia—ventricular fibrillation & 8 & Normal, mild Hypoxia & N/A \\
\hline Autopsy control & 37 & e & 67 & $\mathrm{f}$ & Multiple organ failure & 10 & Normal & N/A \\
\hline Autopsy control & 38 & e & 34 & $\mathrm{~m}$ & Arrhythmia—cardiomyopathy & 7 & Normal, mild hypoxia & N/A \\
\hline Autopsy control & 39 & e & 72 & $\mathrm{~m}$ & Bronchopneumonia & 11 & Normal & N/A \\
\hline Autopsy control & 40 & $\mathrm{e}$ & 44 & $\mathrm{f}$ & Bronchopneumonia & 9 & Normal & N/A \\
\hline
\end{tabular}

Letters in case ID indicate applied technique to the respective sample: $a=q P C R, b=$ protein analyses, $c=$ cerebrospinal fluid (CSF) analyses, $\mathrm{d}=$ immunohistochemistry, $\mathrm{e}=$ RNA sequencing

N/A not applicable, $m$ male, $f$ female, $y$ years, $d$ days, $w$ weeks, $h$ hours

stopped by washing in distilled water. Sections were counterstained with Haematoxylin-Mayer solution (Klinipath, Breda, The Netherlands), washed with tap water, dehydrated in alcohol and xylene and coverslipped in Pertex (VWR International, Radnor, PA, USA).

Double labeling was performed with ionized calciumbinding adapter molecule 1 (Iba-1; rabbit polyclonal,
WAKO, Osaka Japan, 1:2000), glial fibrillary acidic protein (GFAP; mouse monoclonal, clone GA5, Sigma-Aldrich, St. Louis, MO, USA; 1:4000), neuronal nuclear protein (NeuN; mouse monoclonal, clone MAB377; Chemicon, Temecula, CA, USA; 1:2000) oligodendrocyte transcription factor 2 (Olig2; rabbit polyclonal, IBL International, Hamburg, Germany; 1:200) or albumin (rabbit polyclonal, 
Table 3 Clinical information of TLE-HS patients who underwent surgical resection for epilepsy therapy

\begin{tabular}{|c|c|c|c|c|c|c|c|c|c|}
\hline \multicolumn{2}{|c|}{ Case ID } & \multirow{2}{*}{$\begin{array}{l}\text { Age (y) } \\
36\end{array}$} & \multirow{2}{*}{$\begin{array}{l}\text { Gender } \\
\mathrm{f}\end{array}$} & \multirow{2}{*}{$\begin{array}{l}\text { TLE-HS type } \\
1\end{array}$} & \multirow{2}{*}{$\begin{array}{l}\text { Duration } \\
\text { epilepsy } \\
\text { (y) }\end{array}$} & \multirow{2}{*}{$\begin{array}{l}\text { Seizures/month } \\
6\end{array}$} & \multirow{2}{*}{$\begin{array}{l}\text { Seizure type } \\
\text { FA, FB/TC }\end{array}$} & \multirow{2}{*}{$\begin{array}{l}\text { ASD } \\
\text { LMT }\end{array}$} & \multirow{2}{*}{$\begin{array}{l}\text { Etiology/comments } \\
\text { N/A }\end{array}$} \\
\hline 1 & $\mathrm{a}$ & & & & & & & & \\
\hline 2 & $\mathrm{a}, \mathrm{b}$ & 66 & $\mathrm{f}$ & 1 & 60 & 8 & FIA & CBZ, CLB & N/A \\
\hline 3 & $\mathrm{a}$ & 50 & $\mathrm{~m}$ & 1 & 22 & 10 & FIA & LMT, CBZ & N/A \\
\hline 4 & $\mathrm{a}$ & 42 & $\mathrm{f}$ & 2 & 28 & 1 & FIA, FB/TC & PHT, OXC & N/A \\
\hline 5 & $\mathrm{a}$ & 29 & $\mathrm{~m}$ & 1 & 11 & 15 & FIA, FB/TC & $\mathrm{CBZ}$ & N/A \\
\hline 6 & $\mathrm{a}$ & 29 & $\mathrm{f}$ & 1 & 16 & 32 & FIA, FB/TC & LMT, TPM & History of febrile convulsions \\
\hline 7 & $\mathrm{a}, \mathrm{c}$ & 57 & $\mathrm{f}$ & 1 & 1 & 1 & FIA & CNP & $\begin{array}{l}\text { Possible history of febrile } \\
\text { convulsions }\end{array}$ \\
\hline 8 & $\mathrm{a}$ & 39 & $\mathrm{~m}$ & 1 & 5 & 32 & FIA & $\mathrm{CBZ}$ & N/A \\
\hline 9 & $\mathrm{a}$ & 43 & $\mathrm{~m}$ & 1 & 40 & 8 & FIA, FB/TC & LEV, LMT & N/A \\
\hline 10 & $\mathrm{a}$ & 31 & $\mathrm{f}$ & 2 & 10 & 4 & FIA & CBZ, CLB & N/A \\
\hline 11 & $\mathrm{a}$ & 49 & $\mathrm{~m}$ & 1 & 41 & 2 & FIA & LEV, CBZ, CLB & $\begin{array}{l}\text { Possible history of CNS } \\
\text { infection }\end{array}$ \\
\hline 12 & $\mathrm{a}$ & 44 & $\mathrm{f}$ & 2 & 22 & 3 & FIA & CBZ, LMT & History of CNS infection \\
\hline 13 & $\mathrm{a}$ & 38 & $\mathrm{~m}$ & 2 & 10 & 6 & FIA & $\mathrm{CBZ}$ & N/A \\
\hline 14 & $\mathrm{~b}$ & 35 & $\mathrm{f}$ & 1 & 33 & 150 & FIA & CBZ, CLB & N/A \\
\hline 15 & $\mathrm{~b}$ & 53 & $\mathrm{~m}$ & 1 & 50 & 60 & FIA & LMT, CBZ & N/A \\
\hline 16 & $\mathrm{~b}$ & 51 & $\mathrm{~m}$ & 1 & 51 & 200 & FIA, FB/TC & LEV & N/A \\
\hline 17 & $\mathrm{~b}$ & 19 & $\mathrm{f}$ & 1 & 12 & 17 & FIA & TPM & N/A \\
\hline 18 & $\mathrm{~b}$ & 6 & $\mathrm{f}$ & 1 & 5 & 20 & FIA & LMT & N/A \\
\hline 19 & $\mathrm{~b}$ & 38 & $\mathrm{f}$ & 1 & 36 & 40 & FIA & LCS, LMT, CLB & N/A \\
\hline 20 & $\mathrm{~b}$ & 14 & $\mathrm{~m}$ & 1 & 7 & 17 & FIA & $\mathrm{LEV}, \mathrm{CBZ}$ & $\begin{array}{l}\text { Posterior reversible encepha- } \\
\text { lopathy (PRES) syndrome }\end{array}$ \\
\hline 21 & $\mathrm{~b}$ & 39 & $\mathrm{~m}$ & 1 & 5 & 4 & FIA, FB/TC & LCS, CLB, CNP & N/A \\
\hline 22 & $\mathrm{c}$ & 32 & $\mathrm{f}$ & 1 & 17 & 4 & FIA & CBZ, LEV & N/A \\
\hline 23 & $\mathrm{c}$ & 55 & $\mathrm{~m}$ & 3 & 7 & 3 & FA, FIA & $\mathrm{CBZ}$ & N/A \\
\hline 24 & $\mathrm{c}$ & 37 & $\mathrm{~m}$ & 1 & 20 & $15-20$ & FIA & $\mathrm{CBZ}$ & N/A \\
\hline 25 & $\mathrm{c}$ & 38 & $\mathrm{~m}$ & 2 & 10 & 6 & FIA & $\mathrm{CBZ}$ & N/A \\
\hline 26 & $\mathrm{c}$ & 57 & $\mathrm{~m}$ & 1 & 7 & $>20$ & FIA & LMT & N/A \\
\hline 27 & $\mathrm{c}$ & 43 & $\mathrm{~m}$ & 1 & 43 & 1 & FIA & LMT, CBZ & N/A \\
\hline 28 & $\mathrm{c}$ & 42 & $\mathrm{~m}$ & 1 & 25 & 20 & FIA & CBZ, PGB & N/A \\
\hline 29 & $\mathrm{~d}$ & 50 & $\mathrm{f}$ & 1 & 40 & 30 & FA, FB/TC & CBZ, LEV, PHT & N/A \\
\hline 30 & $\mathrm{~d}$ & 41 & $\mathrm{f}$ & 1 & 29 & 8 & FIA & CBZ, TPM & N/A \\
\hline 31 & $\mathrm{~d}$ & 31 & $\mathrm{~m}$ & 1 & 28 & 20 & FIA & $\mathrm{CBZ}$ & $\begin{array}{l}\text { Adverse events following } \\
\text { smallpox vaccination }\end{array}$ \\
\hline 32 & $\mathrm{~d}$ & 60 & $\mathrm{f}$ & 1 & 54 & 3 & FIA, FB/TC & CBZ, LEV & $\begin{array}{l}\text { Possible history of CNS } \\
\text { infection }\end{array}$ \\
\hline 33 & $\mathrm{~d}$ & 29 & $\mathrm{~m}$ & 1 & 13 & 36 & FIA & CBZ, CLB & History of febrile convulsions \\
\hline 34 & $\mathrm{~d}$ & 29 & $\mathrm{~m}$ & 1 & 14 & 36 & FIA & CBZ, CLB & History of febrile convulsions \\
\hline 35 & $\mathrm{~d}$ & 29 & $\mathrm{~m}$ & 3 & 25 & 12 & FIA & CBZ, CLB & $\begin{array}{l}\text { Possible history of CNS } \\
\text { infection }\end{array}$ \\
\hline 36 & $\mathrm{e}$ & 41 & $\mathrm{~m}$ & 1 & 26 & 4 & FIA & LEV, LMT, CLB & N/A \\
\hline 37 & $\mathrm{e}$ & 56 & $\mathrm{~m}$ & 1 & 52 & 25 & FIA & CBZ, LEV & N/A \\
\hline 38 & $\mathrm{e}$ & 38 & $\mathrm{f}$ & 2 & 17 & 7 & FIA & LMT, CLB & N/A \\
\hline 39 & $\mathrm{e}$ & 60 & $\mathrm{f}$ & 1 & 54 & 3 & FIA, FB/TC & CBZ, LEV & N/A \\
\hline 40 & $\mathrm{e}$ & 36 & $\mathrm{f}$ & 1 & 32 & 6 & FA, FB/TC & LMT & N/A \\
\hline 41 & $\mathrm{e}$ & 41 & $\mathrm{~m}$ & 1 & 30 & 30 & FIA & CBZ, CLB & N/A \\
\hline 42 & $\mathrm{e}$ & 42 & $\mathrm{f}$ & 2 & 26 & 1 & FIA, FB/TC & PHT, OXC & N/A \\
\hline 43 & $\mathrm{e}$ & 55 & $\mathrm{~m}$ & 3 & 7 & 3 & FIA & CBZ & N/A \\
\hline
\end{tabular}


Table 3 (continued)

\begin{tabular}{|c|c|c|c|c|c|c|c|c|c|}
\hline \multicolumn{2}{|c|}{ Case ID } & \multirow{2}{*}{$\begin{array}{l}\text { Age (y) } \\
39\end{array}$} & \multirow{2}{*}{$\frac{\text { Gender }}{\mathrm{m}}$} & \multirow{2}{*}{$\begin{array}{l}\text { TLE-HS type } \\
1\end{array}$} & \multirow{2}{*}{$\begin{array}{l}\text { Duration } \\
\text { epilepsy } \\
(y)\end{array}$} & \multirow{2}{*}{$\begin{array}{l}\text { Seizures/month } \\
3\end{array}$} & \multirow{2}{*}{$\begin{array}{l}\text { Seizure type } \\
\text { FIA, FB/TC }\end{array}$} & \multirow{2}{*}{$\begin{array}{l}\text { ASD } \\
\text { LMT, OXC }\end{array}$} & \multirow{2}{*}{$\begin{array}{l}\text { Etiology/comments } \\
\text { N/A }\end{array}$} \\
\hline 44 & $\mathrm{e}$ & & & & & & & & \\
\hline 45 & $\mathrm{e}$ & 49 & $\mathrm{~m}$ & 1 & 39 & 2 & FIA & LEV, CBZ, CLB & N/A \\
\hline 46 & $\mathrm{e}$ & 38 & $\mathrm{~m}$ & 2 & 8 & 6 & FIA & CBZ & N/A \\
\hline 47 & $\mathrm{e}$ & 43 & $\mathrm{~m}$ & 1 & 39 & 8 & FIA, FB/TC & LEV, LMT & N/A \\
\hline 48 & $\mathrm{e}$ & 49 & $\mathrm{~m}$ & 1 & 33 & 5 & FIA, FB/TC & $\mathrm{CBZ}$ & N/A \\
\hline 49 & $\mathrm{e}$ & 54 & f & 1 & 33 & 20 & FIA, FB/TC & VPA, OXC & N/A \\
\hline 50 & $\mathrm{e}$ & 43 & $\mathrm{~m}$ & 1 & 19 & 5 & FIA, FB/TC & CBZ, VPA, LMT & N/A \\
\hline 51 & $\mathrm{e}$ & 39 & $\mathrm{f}$ & 1 & 23 & 5 & FIA & ZNS, LMT, CLB & N/A \\
\hline 52 & $\mathrm{e}$ & 43 & $\mathrm{~m}$ & 1 & 37 & 5 & FIA & OXC, LEV & N/A \\
\hline 53 & $\mathrm{e}$ & 32 & $\mathrm{f}$ & 1 & 14 & 5 & FIA & CBZ, LEV, CLB & N/A \\
\hline 54 & $\mathrm{e}$ & 62 & $\mathrm{~m}$ & 1 & 38 & 6 & FIA, FB/TC & PHT, LMT, PB & N/A \\
\hline 55 & $\mathrm{e}$ & 47 & $\mathrm{f}$ & 1 & 12 & 3 & FIA, FB/TC & LEV, LCS & N/A \\
\hline 56 & $\mathrm{e}$ & 53 & $\mathrm{~m}$ & 1 & 50 & 60 & FIA & LMT, CLB & N/A \\
\hline 57 & $\mathrm{e}$ & 41 & $\mathrm{~m}$ & 1 & 39 & 20 & FIA & CBZ, LEV & N/A \\
\hline 58 & $\mathrm{e}$ & 60 & $\mathrm{~m}$ & 1 & 46 & 20 & FIA & LMT, LEV & N/A \\
\hline 59 & $\mathrm{e}$ & 51 & $\mathrm{~m}$ & 1 & 51 & 200 & FIA, FB/TC & LEV, LOR & N/A \\
\hline 60 & $\mathrm{e}$ & 38 & f & 1 & 36 & 40 & FIA & LCS, LMT, CLB & N/A \\
\hline 61 & $\mathrm{e}$ & 38 & $\mathrm{~m}$ & 1 & 26 & 4 & FIA & OXC, TPM & History of febrile convulsions \\
\hline 62 & $\mathrm{e}$ & 46 & $\mathrm{f}$ & 1 & 36 & 4 & FIA, FB/TC & LMT, OXC, CLB & N/A \\
\hline 63 & $\mathrm{e}$ & 44 & $\mathrm{~m}$ & 1 & 11 & 13 & FIA & LMT & N/A \\
\hline 64 & $\mathrm{e}$ & 39 & $\mathrm{~m}$ & 1 & 5 & 4 & FIA, FB/TC & LCS, CLB, CNP & N/A \\
\hline 65 & $\mathrm{e}$ & 58 & $\mathrm{~m}$ & 1 & 40 & 4 & FIA, SE & $\mathrm{CBZ}, \mathrm{LCS}$ & N/A \\
\hline 66 & $\mathrm{e}$ & 58 & $\mathrm{f}$ & 1 & 52 & 6 & FIA, FB/TC & CBZ, LMT, PGB, CLB & N/A \\
\hline 67 & $\mathrm{e}$ & 58 & $\mathrm{~m}$ & 1 & 25 & 30 & FIA & PGB, CLB, PER & N/A \\
\hline 68 & $\mathrm{e}$ & 53 & $\mathrm{~m}$ & 2 & 27 & 30 & FIA & VPA, CBZ, CLB, LEV & N/A \\
\hline
\end{tabular}

Letters in case ID indicate applied technique to the respective sample: $a=q P C R ; b=$ protein analyses; $c=$ cerebrospinal fluid (CSF) analyses; $\mathrm{d}=$ immunohistochemistry; $\mathrm{e}=$ RNA sequencing

$A S D$ antiseizure drug, $m$ male, $f$ female, $y$ years, $F A$ focal aware, $F I A$ focal impaired awareness, $F B / T C$ focal bilateral/tonic clonic, $B R V$ brivaracetam, $C B Z$ carbamazepine, $C L B$ clobazam, $C N P$ clonazepam, ESM ethosuximide, $L C S$ lacosamide, $L E V$ levetiracetam, $L M T$ lamotrigine, $L O R$ lorazepam, $O X C$ oxcarbazepine, $P B$ phenobarbital, $P E R$ perampanel, $P G B$ pregabalin, $P H T$ phenytoin, TPM topiramate, $V P A$ valproate, $Z N S$ zonisamide, $N / A$ not applicable, $C N S$ central nervous system

HS typing performed according to the ILAE consensus classification on hippocampal sclerosis in TLE [4].

Table 4 Summary of clinical information of quantitative susceptibility mapping cohort

\begin{tabular}{lllllll}
\hline & Condition & $\begin{array}{l}\text { Duration } \\
\text { epilepsy (y) }\end{array}$ & Seizures/month & Seizure type & pSOZ & ASD \\
\hline Patient \#1 & Non-lesional & 12 & $3-4$ & FB/TC & Left temporal lobe $\quad$ LEV, LMT, ECB \\
Patient \#2 & Left mesio-temporal GG & 12 & 0.25 & FB/TC & Left temporal lobe $\quad$ BRI, LMT \\
Patient \#3 & FCD 2b & 21 & $30-60$ & FIA & Right frontal lobe $\quad$ OXC, ZNS, CBD
\end{tabular}

$A S D$ antiseizure drug, $F C D 2 b$ focal cortical dysplasia type $2 \mathrm{~b}, G G$ ganglioglioma, $F B / T C$ focal to bilateral tonic-clonic, $p S O Z$ presumed seizure-onset zone, FIA focal impaired awareness, BRI Brivaracetam, CBD Cannabidiol, ECB Eslicarbazepine, LEV Levetiracetam, LMT Lamotrigine, $O X C$ Oxcarbazepine, ZNS Zonisamide, $y$ years

DAKO, Glostrup, Denmark; 1:10,000). Sections were incubated overnight with primary antibody and the next day incubated with BrightVision poly-HRP anti-rabbit (Immunologic, Duiven, The Netherlands) for $30 \mathrm{~min}$ at room temperature and washed with PBS. Staining was developed using 3'-amino 9'-ethylcarbazole (AEC, Sigma-Aldrich, St. Louis, MO, USA) in $0.05 \mathrm{M}$ Acetate buffer with $0.5 \%$ $\mathrm{H}_{2} \mathrm{O}_{2}$ filtered substrate solution. To remove the first primary 
antibody, sections were cooked in citrate buffer and then washed with PBS. Incubation with ferritin as second primary antibody was performed overnight followed by incubation with poly-alkaline phosphatase(AP)-anti-rabbit (Immunologic, Duiven, The Netherlands) for $30 \mathrm{~min}$ at room temperature the next day. AP activity was visualized with the AP substrate kit III Vector Blue (SK-5300, Vector Laboratories Inc., Burlingame, CA, USA). Sections incubated without the primary antibody were essentially blank. Finally, stained sections were air dried and coverslipped using VectaMount (H5000-60, Vector Laboratories Inc., Burlingame, CA, USA).

For DAB-enhanced Perl's iron stain, the modified Meguro method was used [47]. After deparaffinization, tissue slides were incubated in freshly prepared, acidified $1 \%$ potassium ferrocyanide in distilled water ( $\mathrm{pH} \sim 1.0$ to 1.5$)$ solution for $40 \mathrm{~min}$ at room temperature. Afterwards, slides were washed three times in distilled water and incubated in methanol containing $0.01 \mathrm{M} \mathrm{NaN}_{3}$ and $0.3 \% \mathrm{H}_{2} \mathrm{O}_{2}$ for $75 \mathrm{~min}$ at room temperature. Slides were washed three times in $0.1 \mathrm{M}$ PBS ( $\mathrm{pH} 7.4$ ) and then incubated in PBS containing $0.025 \%$ DAB and $0.005 \% \mathrm{H}_{2} \mathrm{O}_{2}$ for $40 \mathrm{~min}$ at room temperature in the dark. For double labelling, slides were incubated with AEC instead of $\mathrm{DAB}$, followed by primary antibody incubation overnight and AP-based color development as described in the preceding text. Color development was stopped by washing slides in distilled water. As negative control, one duplicate slide was incubated with non-acidified ferrocyanide solution $(\mathrm{pH} \sim 8.0)$ which did not show any staining. Additionally, coverslips with cells permeabilized with Triton X-100 prior to Perl's stain as negative control did not show iron staining. Fetal astrocytes were counterstained with Safranin O (Merck-Millipore, Burlington, MA, USA). Finally, slides were dehydrated in ethanol and xylene and coverslipped using Pertex.

\section{Quantification of immunohistochemistry}

Semi-quantitative analysis of surgically resected tissue was performed as described previously [2]. Briefly, tissue sections selected for investigation were evaluated by two independent observers for immunoreactivity (IR) using a scale $0-3(0=$ absent, $1=$ weak, $2=$ moderate, $3=$ strong staining). All areas of the hippocampus (TLE-HS, SE) were examined and the score represents the predominant intensity found in each case. In addition, the number of cells positive for the investigated markers was evaluated $(0=$ absent, $1=$ low, $2=$ moderate, $3=$ high). The product of intensity and number scores was taken to give the overall immunoreactivity score (IRS, Table 5). For iron/ferritin expression in astrocytes, cases were investigated for iron accumulation
Table 5 Immunohistochemical evaluation of 4-HNE, HO-1, ferritin and iron in post-mortem control vs. post-mortem SE and surgical TLE-HS brain tissue

\begin{tabular}{|c|c|c|c|}
\hline & Control & SE & TLE-HS \\
\hline \multicolumn{4}{|l|}{ Iron } \\
\hline CA1 & $0(0)$ & $0(0-3)$ & $3(3-6)^{* * *}$ \\
\hline DG & $0(0-3)$ & $0(0)$ & $3(3)^{*}$ \\
\hline Astrocytes & $0(0)$ & $0(0-2)$ & $3(0-3)^{*}$ \\
\hline \multicolumn{4}{|l|}{ Ferritin } \\
\hline Astrocytes & $0(0)$ & $3(3-9) * *$ & $4.5(3-6)^{* * *}$ \\
\hline \multicolumn{4}{|l|}{ 4-HNE } \\
\hline CA1 & $2(0-6)$ & $6(6-9)^{*}$ & $9(6-9)^{* *}$ \\
\hline DG & $0(0-1)$ & $1(1-2)$ & $3(0-6)^{*}$ \\
\hline \multicolumn{4}{|l|}{ HO-1 } \\
\hline CA1 & $1.5(0-3)$ & $3(3-6)^{*}$ & $9(6-9)^{*}$ \\
\hline DG & $1.5(0-3)$ & $3(3-6)^{*}$ & $7.5(3-9)^{*}$ \\
\hline
\end{tabular}

The immunoreactivity score (IRS) is given as median with the range in brackets. Immunoreactivity was evaluated using a $0-3$ scale $(0=$ absent, $1=$ weak, $2=$ moderate, $3=$ strong staining $)$. In addition, the number of positive cells was evaluated $(0=$ absent, $1=$ low, $2=$ moderate, $3=$ high). The product of these two scores (IRS) was calculated for each case. $n=5$ (control) $n=6$, (TLE-HS), $n=5$ (SE). ${ }^{*} p<0.05,{ }^{*} p<0.01$ using Mann-Whitney $U$ test

Bold values indicate statistical significance

or ferritin expression in cell bodies of cells with astrocytic morphology.

\section{Quantitative susceptibility mapping in epilepsy patients}

Three patients (\#1: male, 32 years old; \#2: male, 29 years old; \#3: male, 25 years old; Table 4) undergoing presurgical evaluation, including inpatient video monitoring, at the Department of Epileptology of the University Hospital Bonn were scanned interictally and postictally using a Siemens Magnetom Trio (3T) MRI-scanner. Seizure to postictal scan intervals for patients \#1, \#2, and \#3 were $245 \mathrm{~min}, 166 \mathrm{~min}$, and $72 \mathrm{~min}$, respectively. Interictal scans were acquired at a minimum of $48 \mathrm{~h}$ after the last seizure and included a T1-weighted structural image (MP-RAGE, TE $=2.54 \mathrm{~ms}$, $\mathrm{TR}=1660 \mathrm{~ms}$, flip angle $=9^{\circ}, \mathrm{FOV}=171 \times 279 \times 206$ $\mathrm{mm}$, voxel size $=0.8 \times 0.8 \times 0.8 \mathrm{~mm}, \mathrm{TA}=6: 32 \mathrm{~min})$. For QSM, T2*-weighted MRI acquisitions were conducted using a gradient-recalled echo sequence with seven echo times (3D-FLASH, phase and magnitude image reconstruction, $\mathrm{TE}=3.98 / 9.8 / 18.27 / 26.74 / 35.21 / 43.68 / 52.15 \mathrm{~m}$ $\mathrm{s}, \mathrm{TR}=59 \mathrm{~ms}$, flip angle $=15^{\circ} \mathrm{FOV}=172.5 \times 230 \times 144 \mathrm{~mm}$, voxel size $=0.9 \times 0.9 \times 1.5 \mathrm{~mm}, \mathrm{TA}=10: 34 \mathrm{~min}$ ). Data processing included the application of the tool SEPIA [8], utilizing Laplacian-based phase unwrapping, Laplacian boundary value guided background field removal, and a final QSM modeling by thresholded K-space division. Susceptibility 
values were normalized by the whole-brain mean. Postictal and interictal images were linearly co-registered with the structural T1-weighted image and subtracted to quantify postictally increased magnetic susceptibility as surrogate marker for postictal iron accumulation. Masks of the presumable seizure-onset zone were manually demarcated according to the information gained in the multimodal presurgical evaluation. Using these masks, absolute susceptibility values were read out voxel-wise for both scans and Cohen's d between the two distributions was assessed as metric of the effect size.

\section{RNA isolation for RNA sequencing}

Total RNA for RNAseq, including the miRNA fraction, was isolated using the miRNeasy Mini kit (Qiagen Benelux, Venlo, The Netherlands) according to the manufacturer's instructions. The concentration and purity of RNA were determined at 260/280 nm using a Nanodrop spectrophotometer (Ocean Optics, Dunedin, FL, USA) and RNA integrity was assessed using a Bioanalyzer 2100 (Agilent, Santa Clara, CA, USA).

\section{RNA-Seq library preparation and sequencing}

All library preparation and sequencing were performed at GenomeScan (Leiden, The Netherlands). The NEBNext Ultra II Directional RNA Library Prep Kit for Illumina (New England Biolabs, Ipswich, MA, USA) was used for sample processing. Sample preparation was performed according to the protocol "NEBNext Ultra II Directional RNA Library prep Kit for Illumina” (NEB \#E7760S/L). Briefly, mRNA was isolated from total RNA using oligo-dT magnetic beads. After fragmentation of mRNA, cDNA synthesis was performed. Next, sequencing adapters were ligated to the cDNA fragments followed by PCR amplification. Clustering and DNA sequencing was performed using the NovaSeq6000 (Illumina, Foster City, CA, USA) in accordance with manufacturers' guidelines. All samples underwent paired-end sequencing of 150 nucleotides in length, the mean read depth per a sample was 47 million reads.

\section{Bioinformatics analysis of RNA-Seq data}

The Bestus Bioinformaticus Decontamination Using Kmers (BBDuk) tool from the BBTools suite was used for adapter removal, quality trimming and removal of contaminant sequences (ribosomal/bacterial) [6]. A phred33 score of 20 was used to assess the quality of the read, any read shorter than 31 nucleotides in length was excluded from the downstream analysis.

Reads were aligned directly to the human GRCh38 reference transcriptome (Gencode version 33) [28] using
Salmon v0.11.3 [57]. Transcript counts were summarized to the gene level and scaled used library size and average transcript length using the $\mathrm{R}$ package tximport [78]. Genes detected in less than $20 \%$ of the samples in any diagnosis and with counts less than six across all samples were filtered out. The gene counts were than normalized using the weighted trimmed mean of $\mathrm{M}$ values (TMM) method using the $\mathrm{R}$ package edgeR [68]. The normalized counts were than $\log 2$ transformed using the voom function from the R package limma [67]. The subsequent differential expression was carried out using the R package limma. Differential expression testing was performed across all genes. Subsequently, a linear model was fit for each gene and moderated $t$-statistic was calculated after applying an empirical Bayes smoothing to the standard errors. Those genes with a Benjamini-Hochberg adjusted $p$ value $<0.05$ were considered differentially expressed. For correlation matrices, normalized counts of genes of interest were analyzed using Spearman's rank correlation with a $p$ value $<0.05$ indicating significance.

To assess the similarities between the expression profiles of the manually curated gene sets from the reactome pathways [12] detoxification of reactive oxygen species (R-HSA-3299685) and glutathione conjugation (R-HSA156590) combined as well as iron uptake and transport (R-HSA-917937) the Euclidean distance was calculated. These results were then visualized as heatmaps in R.

\section{Experimental animals}

Experiments were performed on adult male Sprague Dawley rats (Envigo, Horst, The Netherlands) and were approved by the University Animal Welfare committee and performed in accordance with the guidelines of the European Community Council Directives 2010/63/EU. The rats were housed individually in a controlled environment $\left(21 \pm 1^{\circ} \mathrm{C}\right.$; humidity 60\%; lights on 08:00 a.m.-8:00 p.m.; food and water available ad libitum). Rat brain tissue utilized in this study was retrieved from archived brain tissue from the electrically induced rat post-SE model prepared as described previously [5].

For immunohistochemistry on paraffin-embedded rat tissue against ferritin, iron and HO-1, rats were deeply anesthetized with pentobarbital (Euthasol, AST Farma, Oudewater, The Netherlands, $60 \mathrm{mg} / \mathrm{kg}$ i.p.) and perfused via the ascending aorta $\left(300 \mathrm{~mL} 0.37 \% \mathrm{Na}_{2} \mathrm{~S}\right.$ followed by $300 \mathrm{~mL} \mathrm{4 \%} \mathrm{PFA}$ in $0.1 \mathrm{M}$ phosphate buffer, $\mathrm{pH}$ 7.4). Rats were perfused at three different time points after SE, each corresponding to the early and late stages of epileptogenesis: the acute phase ( 1 day post-SE, $n=5$ ) and the chronic phase $(7$ months post-SE, when recurrent spontaneous electrographic seizures are evident, $n=5$; [25]). Control rats $(n=5)$ that were implanted with EEG electrodes, but not stimulated, were 
also included. The brains were post-fixated overnight, dissected and embedded in paraffin. Tissue was sectioned sagittally at $6 \mu \mathrm{m}$ and mounted on pre-coated glass slides (Star Frost, Waldemar Knittel, Braunschweig, Germany).

For quantitative real-time PCR analysis, protein and iron analysis, a separate cohort of rats were decapitated 1 day after SE (acute phase), 1 week after SE (latent phase) or 3.5 months after SE (chronic phase). Electrode-implanted control rats were also included. The brain was dissected and the parahippocampal cortex [PHC; protein analysis $n=5$ (control, chronic), $n=6$ (acute); RNA $n=5$ (control, acute, chronic), $n=6$ (latent)], which includes mainly the entorhinal cortex (EC) and parts of the peri-rhinal and posterior piriform cortex, was removed by incision at the ventro-caudal part underneath the rhinal fissure until approximately $5 \mathrm{~mm}$ posterior to bregma. Additionally, the whole hippocampus was removed as well and used for iron assays [ $n=3$ (acute), $n=4$ (control), $n=6$ (chronic)] or dissected into CA1 [ $n=5$ (control, latent, chronic), $n=6$ (acute) and dentate gyrus (DG; $n=4$ (control, latent), $n=5$ (acute, chronic)] for RNA analysis. Animals sacrificed during the chronic phase and used for protein and iron determination had daily SRS. All material was frozen on dry ice and stored at $-80{ }^{\circ} \mathrm{C}$ until use.

\section{Mouse slice preparation and analysis}

Mouse brain slices were prepared from wild-type C57/BL6 mice ranging from 4 to 6 weeks of age. Mouse rather than rat brain slices were chosen due to their improved experimental utility in this experimental set-up as described elsewhere [51]. The protocol was approved by the University Animal Welfare committee and performed in accordance with the guidelines of the European Community Council Directives 2010/63/EU. Mice were decapitated, the brain was dissected within $1 \mathrm{~min}$ and placed in ice-cold slicing artificial cerebrospinal fluid (ACSF; $208 \mathrm{mM}$ sucrose, $2 \mathrm{mM} \mathrm{KCl}, 0.5 \mathrm{mM}$ $\mathrm{CaCl}_{2}, 2 \mathrm{mM} \mathrm{MgSO}_{4}, 5 \mathrm{mM} \mathrm{MgCl} 2,1.25 \mathrm{mM} \mathrm{KH}_{2} \mathrm{PO}_{4}$, $10 \mathrm{mM}$ D-glucose, $26 \mathrm{mM} \mathrm{NaHCO}_{3}, 3 \mathrm{mM}$ pyruvate, $1 \mathrm{mM}$ L-ascorbic acid $\mathrm{pH}$ 7.4) bubbled with carbogen $\left(95 \% \mathrm{O}_{2} / 5 \%\right.$ $\mathrm{CO}_{2}$ ). Horizontal hippocampal brain slices were cut at a $10^{\circ}$ angle using a vibratome (Leica VT1200S, Leica, Germany) at $400 \mu \mathrm{m}$ (for recording and assay lysates) or $100 \mu \mathrm{m}$ (for stainings) and submerged in ice-cold slicing ACSF, bubbled with carbogen. For 4-aminopyridine (4-AP) recordings, partially disconnected slices were prepared to restrain fast CA3 driven interictal-like activity spreading to the parahippocampal cortices by cutting the Shaffer collaterals with a microblade as described previously [52]. Thereafter, slices were washed and allowed to recover in holding ACSF (115 mM $\mathrm{NaCl}, 2 \mathrm{mM} \mathrm{KCl}, 1.25 \mathrm{mM} \mathrm{KH} \mathrm{PO}_{4}, 1.3 \mathrm{mM} \mathrm{MgSO}_{4}$, $2 \mathrm{mM} \mathrm{CaCl}_{2}, 25 \mathrm{mM}$ D-glucose, $26 \mathrm{mM} \mathrm{NaHCO}_{3}, 1 \mathrm{mM}$
L-ascorbic acid pH 7.4 in distilled water at $300 \mathrm{mOsm} / \mathrm{kg}$ ), bubbled with carbogen for 45-60 min at room temperature.

For multi-electrode array (MEA) recordings, brain slices were prewarmed in holding ACSF at $30-32{ }^{\circ} \mathrm{C}$ for $30 \mathrm{~min}$. For 4-AP recordings, slices were additionally pre-incubated another $30 \mathrm{~min}$ in holding ACSF with $250 \mu \mathrm{M} 4$-AP. For recordings, slices were transferred to the recording setup and placed in the recording chamber, held down via a custom-made platinum anchor. The recording chamber was perfused with prewarmed recording ACSF $(115 \mathrm{mM}$ $\mathrm{NaCl}, 2 \mathrm{mM} \mathrm{KCl}, 1.25 \mathrm{mM} \mathrm{KH}_{2} \mathrm{PO}_{4}, 1 \mathrm{mM} \mathrm{MgSO}_{4}, 2 \mathrm{mM}$ $\mathrm{CaCl}_{2}, 25 \mathrm{mM}$ D-glucose, $26 \mathrm{mM} \mathrm{NaHCO}_{3}, 1 \mathrm{mM}$ L-ascorbic acid pH 7.4 in distilled $\mathrm{H}_{2} \mathrm{O}$ at $300 \mathrm{mOsm} / \mathrm{kg}$ ) via a PH01 heating cannula (Multichannel systems, MCS, Reutlingen, Germany) at $37{ }^{\circ} \mathrm{C}$ before entering the $32{ }^{\circ} \mathrm{C}$ MEA bath, creating a fluid temperature in the bath of roughly $32-34{ }^{\circ} \mathrm{C}$. Slices were allowed to equilibrate for $10 \mathrm{~min}$ and subsequently recorded for 1-2 $\mathrm{h}$. The MEA consisted of $60 \mathrm{TiN} /$ SiN planar electrodes, including the reference electrode, with $200 \mu \mathrm{m}$ between the center of each electrode and was placed in a MEA mini 1200 system head-stage (Multichannel systems, Reutlingen, Germany). Signals were recorded at $10 \mathrm{kHz}$, with a $200 \mathrm{~Hz}$ low-pass filter using the Multichannel experimenter program (v 2.17.2) and analyzed using the Multichannel analyzer program (v 2.17.2) (Multichannel systems, Reutlingen, Germany). For analysis of spike frequency upon 4-AP stimulation, automated spike counting with a cut-off of five standard deviations in a 30 min timewindow of stable recording was applied. Spikes from 2 to 3 channels per area (CA3, EC) were quantified and averaged to yield the average frequency per minute per brain area.

Slices that were not used for MEA recordings were incubated in recording ACSF with $250 \mu \mathrm{M}$ 4-AP, $1 \mathrm{mM}$ monosodium L-glutamate, $200 \mu \mathrm{M} \mathrm{FAC}, 10 \mu \mathrm{M}$ Hemin or a combination and optionally $10 \mu \mathrm{M}$ nifedipine or $20 \mu \mathrm{M}$ MK801 (Merck-Millipore, Burlington, MA, USA) for $1 \mathrm{~h}$ at $37^{\circ} \mathrm{C}$. Afterwards, slices were washed in distilled water and either lysed in $5 \mathrm{M} \mathrm{NaCl}$ with $1 \%$ Tween-20 (iron assay), Qiazol (RNA analysis) or fixed for $24 \mathrm{~h}$ in $4 \%$ PFA in $0.1 \mathrm{M}$ phosphate buffer, $\mathrm{pH} 7.4$ (stainings). If not stated otherwise, all chemicals were purchased from Sigma-Aldrich (MerckMillipore, Burlington, MA, USA).

\section{Cell culture and stimulation}

Primary fetal astrocyte-enriched cell cultures were obtained from human fetal brain tissue (cortex, 14-19 gestational weeks) from medically induced abortions. All material was collected from donors from whom written informed consent for the use of the material for research purposes was obtained by the Bloemenhove kliniek (Heemstede, The Netherlands). Tissue was obtained in accordance with the Declaration of Helsinki and the 
Amsterdam UMC Research Code provided by the Medical Ethics Committee. Cell isolation was performed as described previously [83]. Briefly, large blood vessels were removed, after which the tissue was mechanically minced into smaller fragments and enzymatically digested by incubating at $37{ }^{\circ} \mathrm{C}$ for $30 \mathrm{~min}$ with $2.5 \%$ trypsin (Sigma-Aldrich, St. Louis, MO, USA). Tissue was washed with incubation medium containing Dulbecco's modified Eagle's medium (DMEM)/HAM F10 (1:1) medium (Thermo Fisher Scientific, Waltham, MA, USA), supplemented with 100 units $/ \mathrm{mL}$ penicillin, $100 \mu \mathrm{g} / \mathrm{mL}$ streptomycin, $1 \%$ glutamine (Thermo Fisher Scientific, Waltham, MA, USA) and $10 \%$ fetal calf serum (FCS; Thermo Fisher Scientific, Waltham, MA, USA) and triturated by passing through a $70 \mu \mathrm{m}$ mesh filter. Cell suspension was incubated at $37^{\circ} \mathrm{C}, 5 \% \mathrm{CO}_{2}$ for $48 \mathrm{~h}$ to let glial cells adhere to the culture flask before it was thoroughly washed with PBS to remove excess myelin and cell debris. Cultures were subsequently refreshed twice a week. Cultures reached confluence after 2-3 weeks. SHSY5Y neuroblastoma cells (ATCC CRL-2266 ${ }^{\mathrm{TM}}$; gift from Prof. M. Perluigi) were cultured in DMEM/F-12 (Thermo Fisher Scientific, Waltham, MA, USA) with 5\% Glutamine, 100 units $/ \mathrm{mL}$ penicillin, $100 \mu \mathrm{g} / \mathrm{mL}$ streptomycin, $1 \%$ glutamine and $10 \%$ FCS.

Cell cultures for experiments were obtained by trypsinizing and sub-plating cells onto 96-well $\left(1 \times 10^{4}\right.$ cells/ well for MTT assay) and poly-L-lysine (PLL, $15 \mu \mathrm{g} / \mathrm{mL}$, Sigma-Aldrich, St. Louis, MO, USA)-pre-coated 12- and 24-well plates (Greiner Bio-One, Kremsmünster, Austria; $5 \times 10^{4}$ cells/well for RNA isolation and PCR, $5 \times 10^{4}$ cells/well with coverslips for immunocytochemistry). Fetal astrocyte cultures were used at passage 2-5 for all experiments and SHSY5Y cells at passage $\geq 13$. Stimulation was done either with chronic OS (1 mU (SHSY5Y)/2.5 mU (astrocytes) glucose oxidase (GO) for $72 \mathrm{~h}$ with exchange of stimulation medium every $24 \mathrm{~h}$ to ensure sufficient glucose concentration), acute OS $(100 \mu \mathrm{M}$ (SHSY 5Y)/500 $\mu \mathrm{M}$ (astrocytes) $\mathrm{H}_{2} \mathrm{O}_{2}$ for $3 \mathrm{~h}$ ), iron ( $200 \mu \mathrm{M}$ ferric ammonium citrate (FAC) for $24 \mathrm{~h})$, hemin $(1 \mu \mathrm{M}$ (SHSY 5Y) $/ 10 \mu \mathrm{M}$ (astrocytes) for $24 \mathrm{~h}$ ) or a combination at $37{ }^{\circ} \mathrm{C}, 5 \% \mathrm{CO}_{2}$. For albumin stimulation, human fetal astrocytes were subplated in PLL-coated 12-well plates and serum-starved by incubation in DMEM/HAM F10 (1:1) medium with 100 units $/ \mathrm{mL}$ penicillin, $100 \mu \mathrm{g} / \mathrm{mL}$ streptomycin, $1 \%$ glutamine supplemented with G5 (Thermo Fisher Scientific, Waltham, MA, USA) for $48 \mathrm{~h}$. Thereafter, fetal astrocytes were exposed to $300 \mu \mathrm{M}$ bovine serum albumin (BSA; Roche Applied Science, Basel, Switzerland) or $300 \mu \mathrm{M}$ recombinant human serum albumin (HSA; SigmaAldrich, St Louis, MO, USA) for $24 \mathrm{~h}$ or $48 \mathrm{~h}$. After stimulation cells were washed with PBS and lysed in $700 \mu \mathrm{L}$ Qiazol for RNA analysis or washed with PBS, fixed for
15 min in 4\% PFA at room temperature and washed again with PBS for immunocytochemistry. For high-mobility group box 1 (HMGB-1) and interleukin 6 (IL-6) analysis, cell supernatant was collected, centrifuged at $12,000 \times \mathrm{g}$ for 5 min at $4{ }^{\circ} \mathrm{C}$ and kept at $-80{ }^{\circ} \mathrm{C}$ until analysis.

\section{MTT viability assay}

Cell viability was determined by the 3-(4,5-dimethylthiazol-2-yl)-2,5-diphenyl tetrazolium bromide (MTT; SigmaAldrich, St Louis, MO, USA) cell viability assay. Subsequent to stimulation, $0.5 \mathrm{mg} / \mathrm{ml}$ MTT in complete medium was added to each well and the plate was incubated for $1 \mathrm{~h}$ at $37{ }^{\circ} \mathrm{C}$ in $5 \% \mathrm{CO}_{2}$. The reaction mixture was aspirated and $100 \mu \mathrm{L}$ lysis buffer $(4 \mathrm{mM} \mathrm{HCl}, 0.1 \%$ Nonidet P-40 in isopropanol) was added to each well to stop color development and disrupt cells. Plates were agitated to ensure complete lysis of MTT crystals and cell viability was determined by measuring optical density at $570 \mathrm{~nm}$ wavelength using a microplate reader (BMG Labtech, Ortenberg, Germany). Absorbance of treated cells was plotted relative to control cells.

\section{Human astrocyte and SHSY5Y cell culture supernatant immunoassays}

For analysis of HMGB-1 (IBL International, Hamburg, Germany) or IL-6 (Sanquin, Amsterdam, The Netherlands) concentration in cell culture supernatant, procedures were performed according to the manufacturer's instructions. Absorbance of samples was read at $450 \mathrm{~nm}$ using a microplate reader and concentration was determined using a HMGB-1/IL-6 standard curve.

\section{Electron microscopy}

SHSY5Y neuroblastoma cell cultures were fixed after stimulation using 2\% paraformaldehyde (PFA) and $0.2 \%$ glutaraldehyde in $0.4 \mathrm{M}$ PHEM buffer [240 mM piperazine- $N, N^{\prime}$-bis(2-ethanesulfonic acid) (PIPES), $100 \mathrm{mM}$ 4-(2-hydroxyethyl)-1-piperazineethanesulfonic acid (HEPES), $8 \mathrm{mM} \mathrm{MgCl} 2,40 \mathrm{mM}$ ethylene glycol-bis( $\beta$ aminoethyl ether)- $N, N, N^{\prime}, N^{\prime}$-tetraacetic acid (EGTA)] for $24 \mathrm{~h}$. Subsequently, cells were washed twice with $0.1 \mathrm{M}$ PBS containing $0.15 \mathrm{M}$ glycine and stained with $1 \%$ osmium tetroxide for $1 \mathrm{~h}$. Thereafter, cells were dehydrated in a series of 50, 70, 80, 96 and 100\% ethanol. Then, cells were carefully detached from plastic wells and placed in 50\% epoxy resin for $1 \mathrm{~h}$ at room temperature, then $100 \%$ resin at $65^{\circ} \mathrm{C}$ overnight. Samples were polymerized and sectioned in ultrathin sections $(70 \mathrm{~nm})$ which were placed on copper grids and visualized with a FEI Tecnai T12 Transmission 
Electron Microscope and G2 Spirit Biotwin using Veleta and Xarosa camera plus integrated Radius software.

\section{RNA isolation and quantitative real-time PCR}

For RNA isolation, human, rat, mouse and cell culture material was homogenized in $700 \mu \mathrm{L}$ Qiazol Lysis Reagent (Qiagen Benelux, Venlo, The Netherlands). Total RNA was isolated using phenol/chloroform extraction. To this end, $140 \mu \mathrm{L}$ chloroform was mixed with Qiazol lysate and centrifuged at $12,000 \times g$ for $15 \mathrm{~min}$ at $4{ }^{\circ} \mathrm{C}$. The aqueous phase was collected and mixed 1:1 with ice-cold isopropanol and 1 $\mu \mathrm{L}$ of glycogen blue (GlycoBlue, Thermo Fisher Scientific, Waltham, MA, USA) and incubated at $-20^{\circ} \mathrm{C}$ overnight followed by centrifugation at $20,000 \times g$ for $35 \mathrm{~min}$ at $4{ }^{\circ} \mathrm{C}$. RNA pellets were washed two times with ice-cold $80 \%$ ethanol, air-dried and dissolved in RNase-free water.

Concentration and purity of RNA were determined at 260/280 nm using a Nanodrop 2000 spectrophotometer (Thermo Fisher Scientific, Waltham, MA, USA). To evaluate mRNA expression, $250 \mathrm{ng}$ of cell culture derived total RNA or 500 ng tissue-derived total RNA were reverse-transcribed into cDNA using oligo-dT primers. PCRs were run on a Roche Lightcycler 480 thermocycler (Roche Applied Science, Basel, Switzerland) using the reference genes chromosome 1 open reading frame 43 (C1ORF43) and elongation factor $1 \alpha(E F 1-\alpha)$ for human, Cyclin A $(C y c A)$ and glyceraldehyde 3-phosphate dehydrogenase $(G A P D H)$ for rat and TATA box-binding protein $(T b p)$ and hypoxanthine phosphoribosyltransferase 1 (Hrpt-1) for mouse mRNA (see Online resource 8 for primer sequences). The PCR mix contained $1 \mu \mathrm{L}$ cDNA, $2.5 \mu \mathrm{L}$ SensiFAST SYBR Green NoROX kit (Bioline Reagents Limited, London, UK), $0.4 \mu \mathrm{M}$ of forward/reverse primers plus water to a final volume of $5 \mu \mathrm{L} /$ well. PCR reactions were run in duplicates and a negative control containing water instead of cDNA was included for each gene in each run. Cycling conditions were as follows: initial denaturation at $95^{\circ} \mathrm{C}$ for $5 \mathrm{~min}$, followed by 45 cycles of denaturation at $95{ }^{\circ} \mathrm{C}$ for $15 \mathrm{~s}$, annealing at $65^{\circ} \mathrm{C}$ for $5 \mathrm{~s}$ and extension at $72{ }^{\circ} \mathrm{C}$ for $10 \mathrm{~s}$. Fluorescence of the sample was measured via single acquisition mode at $72{ }^{\circ} \mathrm{C}$ after each cycle. Quantification of data was performed using LinRegPCR as described elsewhere [83].

\section{Western blot analysis}

For protein analysis, rat $\mathrm{PHC}$ or $40-50 \mathrm{mg}$ of frozen human hippocampal tissue was mixed with lysis buffer containing $10 \mathrm{mM}$ Tris ( $\mathrm{pH} 8.0$ ), $150 \mathrm{mM} \mathrm{NaCl}, 10 \%$ glycerol, $1 \%$ NP-40, $0.4 \mathrm{mg} / \mathrm{ml}$ sodium orthovanadate, $5 \mathrm{mM}$ EDTA ( $\mathrm{pH}$ 8.0), $5 \mathrm{mM} \mathrm{NaF}$, and protease inhibitors (Protease inhibitor cocktail tablets, Roche Diagnostics, Mannheim, Germany) and homogenized by pottering and subsequent trituration.
Homogenates were centrifuged at $12,000 \times \mathrm{g}$ for $10 \mathrm{~min}$ at $4{ }^{\circ} \mathrm{C}$ and the supernatant was used for further analysis. Protein concentrations were estimated using the bicinchoninic acid assay (BCA) (Sigma-Aldrich, St. Louis, MO, USA).

For western blotting, rat/human protein extract was boiled at $100{ }^{\circ} \mathrm{C}$ for $8 \mathrm{~min}$. Equal amounts of protein lysate $(15 \mu \mathrm{g} /$ lane) were then separated using sodium dodecyl sulfate polyacrylamide gel electrophoresis on a gradient Bolt 4-12\% Bis-Tris gel (Thermo Fisher Scientific, Waltham, MA, USA) and electrotransferred for $90 \mathrm{~min}$ at $100 \mathrm{~V}$ to polyvinylidene difluoride (PVDF) membranes (Immobilon-P; Merck, Darmstadt, Germany). Blots were then blocked with $5 \%$ skim milk in Tris-buffered saline with $0.1 \%$ Tween 20 (TBS-T; $20 \mathrm{mM}$ Tris, $150 \mathrm{mM} \mathrm{NaCl}, 0.1 \%$ Tween20, $\mathrm{pH}$ 7.5) for $1 \mathrm{~h}$ at room temperature. Membranes were cut and incubated with primary antibodies overnight at $4{ }^{\circ} \mathrm{C}$ in $5 \%$ skim milk in TBS-T and subsequently washed $3 \times 10 \mathrm{~min}$ in TBS-T. This was followed by incubation with horseradish peroxidase-coupled secondary antibodies for $1 \mathrm{~h}$ at room temperature in 5\% skim milk in TBS-T. After three washes, the membranes were incubated with ECL (PLUS) Western blotting detection reagent (GE Healthcare Europe, Diegen, Belgium). Blots were digitized using an ImageQuant LAS 4000 system (GE Healthcare Europe, Eindhoven, The Netherlands). $\beta$-tubulin was used as loading control. Precision Plus Protein Dual Color Standard (Bio-Rad, Richmond, CA, USA) was used to determine the molecular weight of proteins. Blots were probed with the same antibodies as for IHC unless otherwise specified: ferritin (1:1000), HO-1 (1:1000), 4-HNE (1:1000), FPN-1 (SLC40A1; rabbit polyclonal, Novus Biologicals, Abingdon, UK; 1:1000), glutamate cysteine ligase catalytic subunit $(\gamma \mathrm{GCSc}$ referred to as GCLC; polyclonal rabbit, Santa Cruz Biotechnology, Dallas, TX, USA; 1:1000), $\beta$-tubulin (mouse monoclonal, clone D66, Sigma-Aldrich, St. Louis, MO, USA; 1:30,000), anti-mouse/HRP (SouthernBiotech, Birmingham, AL, USA; 1:2500) or anti-rabbit/HRP (Agilent Technologies, Middelburg, The Netherlands; 1:2500). To quantify the blots, band intensities of individual proteins were measured densitometrically using ImageJ (v. 1.51; U.S. National Institute of Health, Bethesda, MD, USA) and normalized to $\beta$-tubulin.

\section{Iron determination in tissue lysates}

For determination of total cell culture or tissue iron, lysates in protein lysis buffer were mixed 1:10 with assay working buffer (0.2 M L-ascorbic acid (Sigma-Aldrich, St. Louis, MO, USA) in $0.4 \mathrm{M}$ acetate buffer, $\mathrm{pH} 4-4.5$ ) containing 25 mM 3-(2-Pyridyl)-5,6-di(2-furyl)-1,2,4-triazine-5',5"disulfonic acid disodium (Ferene-S; Merck, Darmstadt, Germany). Samples were mixed and incubated $\geq 20 \mathrm{~h}$ at room temperature. Thereafter, samples were mixed and centrifuged at $20,000 \times g$ for $5 \mathrm{~min}$ and $50 \mu \mathrm{L}$ supernatant 


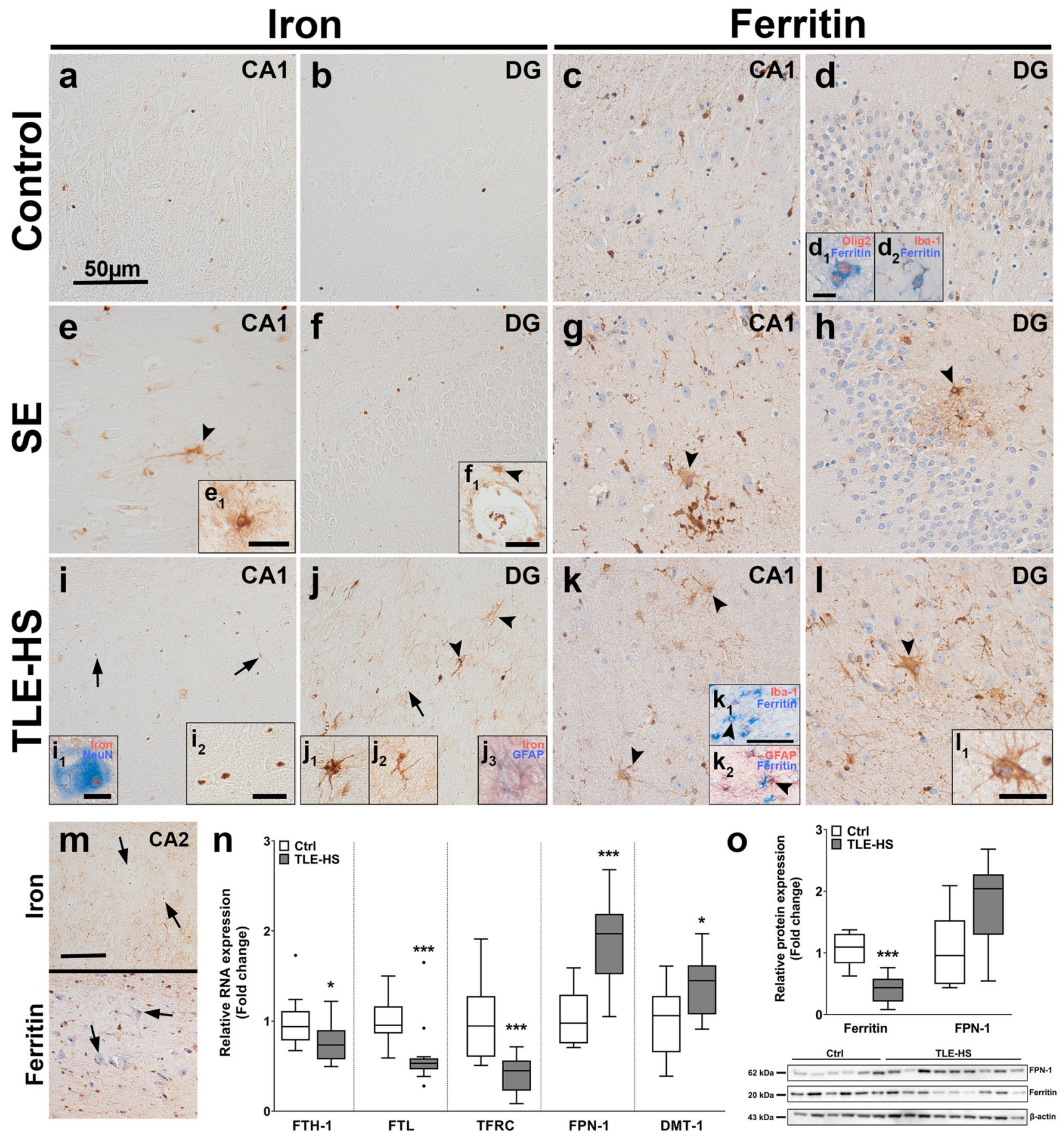

was transferred in duplicates to a 96-well flat-bottom plate (Greiner Bio-One, Kremsmünster, Austria) and measured at $595 \mathrm{~nm}$ in a microplate reader. For quantification of total iron, FAC standards (0-50 $\mu \mathrm{g}$ iron) were used (1 M FAC corresponding to $\sim 45.846 \mathrm{mg}$ iron). Iron concentrations were plotted relative to protein input as determined by the BCA method.

\section{Statistical analysis}

Statistical analysis was performed with GraphPad Prism software version 5.01 (Graphpad software Inc., La Jolla, CA, USA) using a non-parametric Mann-Whitney $U$ test or Kruskal-Wallis test followed by Dunn post hoc or Two-way ANOVA followed by Bonferroni correction for analysis for multiple groups. $p$ value $<0.05$ was assumed to indicate a significant difference. Data are displayed as bar graphs with 
४Fig. 1 SE and TLE-HS hippocampal tissue is characterized by iron accumulation in pyknotic neurons, glial iron and ferritin accumulation and altered iron metabolism. a-d Iron could be sparsely detected, predominantly in white matter inside oligodendrocytes, while ferritin protein expression in autopsy control hippocampus could be detected exclusively in oligodendrocytes $\left(\mathrm{d}_{1}\right)$ and microglia $\left(\mathrm{d}_{2}\right)$ in CA1 and DG. e, f In SE tissue, iron accumulation could be detected perivascularly $\left(f_{1}\right)$ and in cells with glial morphology $\left(e, e_{1}\right.$, arrowhead). $\mathbf{g}$, h Ferritin was primarily detected in microglia but also cells with astrocytic morphology (arrowheads). $\mathbf{i}, \mathbf{j}$ Iron accumulation in TLE-HS hippocampi was detected in neuronal nuclei and specifically nucleoli in CA1 (arrows) and hilar neurons $\left(i_{1,2}\right)$, especially in pyknotic neurons. Moreover, iron accumulation could also be found in cells with astrocytic $\left(\mathrm{j}_{1}\right)$ and microglial $\left(\mathrm{j}_{2}\right)$ morphology (arrowheads). Double labeling revealed co-localization of GFAP and iron in some astrocytes $\left(\mathrm{j}_{3}\right)$. k, I Surgically resected hippocampi from TLE-HS patients displayed ferritin expression in microglia, but also cells with astrocyte morphology $\left(l_{1}\right.$, arrowheads). Double labelling revealed GFAP-positive Iba-1-negative cells that expressed ferritin $\left(\mathrm{k}_{1,2}\right.$, arrowheads). $\mathbf{m}$ In the CA2 subfield with preserved neurons, iron was detected in glial processes and neuronal nucleoli (arrows), while ferritin localized to microglia. n FTH-1 RNA expression did not differ from autopsy control in TLE-HS hippocampal tissue, while FTL and TFRC were reduced. Moreover, FPN-1 and DMT-1 RNA expression were elevated. o Downregulation of ferritin was also confirmed via Western blot, while FPN-1 was not different. Sections c, $\mathbf{d}, \mathbf{g}, \mathbf{h}, \mathbf{k}, \mathbf{l}$ were counterstained with hematoxylin. Scale bars: $50 \mu \mathrm{m}$ in a (representative for $\mathbf{a}-\mathbf{l}), \mathrm{m}$ and $\mathrm{k}_{1}$ (representative for $\mathrm{k}_{2}$ ), $15 \mu \mathrm{m}$ in inserts $e_{1}, f_{1}, i_{2}, l_{1} ; 10 \mu \mathrm{m}$ in $i_{1}$ (representative for $j_{1-3}$ ), $5 \mu \mathrm{m}$ in $\mathrm{d}_{1,2}$; arrows $=$ neurons, arrowheads $=$ glia. $\mathbf{n}, \mathbf{o}$ Mann - Whitney $U$ test. Data are expressed relative to expression observed in autopsy controls and displayed as Tukey box plots; $* * p<0.01, * * * p<0.001$. n: $n=10$ autopsy control vs. $n=13$ TLE-HS; $\mathbf{0}: n=6$ autopsy control vs. $n=9$ TLE-HS

standard deviation (SD) or Tukey style box plot with interquartile range from 25 to 75 th percentile plus outliers. Correlation analysis was performed using Spearman's rank correlation.

\section{Results}

\section{Neuronal and astrocytic iron accumulation in the hippocampus of SE or TLE-HS patients are accompanied by changes in iron metabolism}

To determine iron content in the hippocampus of patients with SE or TLE, the distribution of tissue iron as well as the expression of the primary iron storage protein ferritin were assessed (see also Online resource 1a-f for lower magnification overview). In the hippocampus of control tissues (Fig. 1a, b), iron was mainly present in white matter and cells with oligodendroglial morphology (Online resource $1 \mathrm{a}, \mathrm{m})$. Since formalin fixation might induce changes in iron ionization [27] and promote leaching of iron from tissue upon fixation $[11,73]$ iron staining between frozen and paraffin-embedded tissue was compared. While the overall staining intensity for iron was slightly higher in fresh frozen tissue, the iron localization was preserved in formalin-fixed paraffin-embedded tissue (Online resource 1n), indicating that these tissues are suitable for analyzing tissue iron. SE tissue had a higher iron load (Fig. 1e, f) as compared to control tissue, with occasional iron accumulation in glial processes (Fig. 1e, arrowhead) and cells with astrocyte morphology (Fig. 1 $\mathrm{e}_{1}$ ). Additionally, punctate iron staining could be detected perivascularly and occasional iron accumulation was observed in perivascular glia (Fig. $11 f_{1}$, arrowhead). Iron in TLE-HS tissue was detected in the nucleus and even stronger in the nucleolus of CA1 and hilar neurons, especially with pyknotic morphology (Fig. $1 \mathrm{i}, \mathrm{i}_{1,2}, \mathrm{j}$, arrows). Iron accumulation could also be detected in microglia and astrocytes (Fig. $1 \mathrm{j}$ arrowheads, $\mathrm{j}_{1-3}$ ) as well as the neuropil. Iron also accumulated in glia around preserved neurons in the CA2 area as well as in neuronal nuclei (Fig. 1m).

Ferritin expression in hippocampi of autopsy control tissue was detected in oligodendrocytes and microglia (Fig. $1 d_{1}, d_{2}$ ). Ferritin-positive neurons could not be detected in the CA1 or the DG, while fine ferritin-positive astrocyticlike processes could be detected in the hippocampus and EC (Fig. 1c, d; Online resource 1o). In all SE cases, ferritin was detected in the hippocampus in microglia and astrocytes (Fig. 1g, h arrowheads), as well as in the EC (Online resource 10). Ferritin expression in the hippocampus of TLE-HS cases could be detected predominantly in microglia and more frequently in astrocytes compared to control and SE tissue (Fig. 1k, 1, $1_{1}$ ). Though not all TLE-HS hippocampi contained adjacent EC and, thus, could not be quantified, those cases with EC displayed a similar high expression of ferritin in astrocytes (Online resource 10). Double labeling revealed ferritin expression in astrocytes and microglia (Fig. $1 \mathrm{k}_{1}, \mathrm{k}_{2}$, arrowheads). Ferritin expression around preserved neurons in the CA2 was primarily found in microglia (Fig. $1 \mathrm{~m}$ ). A summary of the immunohistochemical evaluation for SE and TLE-HS tissue compared to autopsy control can be found in Table 5. Quantification of gene expression revealed alterations in iron metabolism in TLE-HS brain tissue, with lower RNA expression of ferritin heavy (FTH-1) and light chain (FTL) (Fig. 1n). On the protein level, ferritin expression was markedly lower as compared to control (Fig. 1o). These results indicate increased iron deposition and marked changes in iron metabolism in SE and TLE-HS tissue.

Expression of iron transporters was also altered in TLEHS; RNA expression was lower for FPN-1 and DMT-1, while TFRC showed higher expression (Fig. 1n), although FPN-1 protein levels were not significantly higher (Fig. 10). TFRC in control cases was found mostly in endothelium of vessels and DG neurons (Online resource 2a, $\mathrm{a}_{1}, \mathrm{~d}$ ). In SE cases, TFRC could be found in some neuronal inclusions in the CA1 as well as in astrocytes, while TLE-HS tissue revealed overall weak neuronal expression with occasional strong expression in some neurons and astrocytes (Online 


\section{4-HNE}
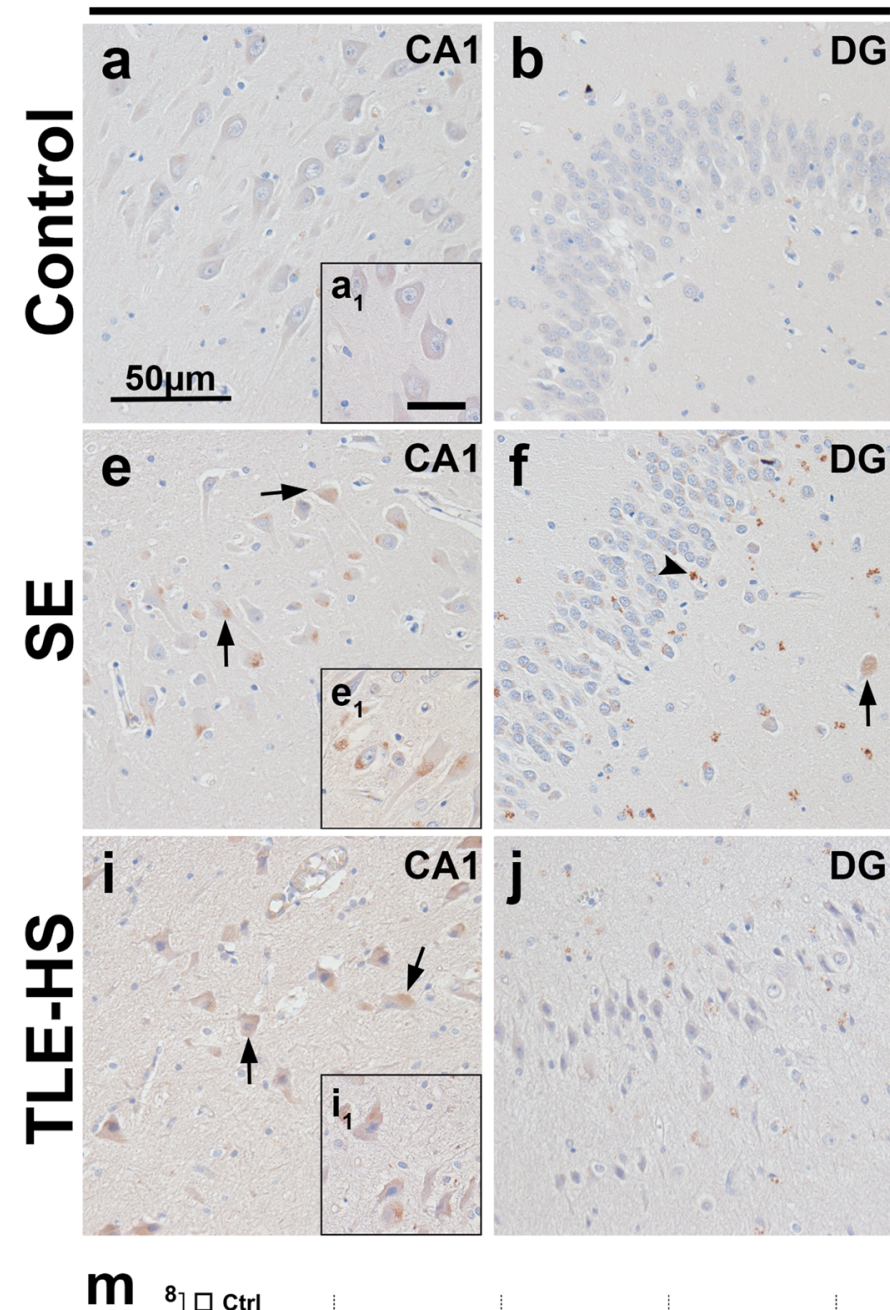

m

b

DG

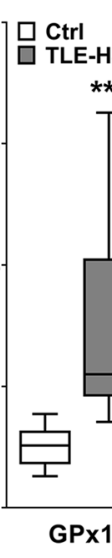

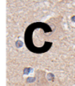

DG

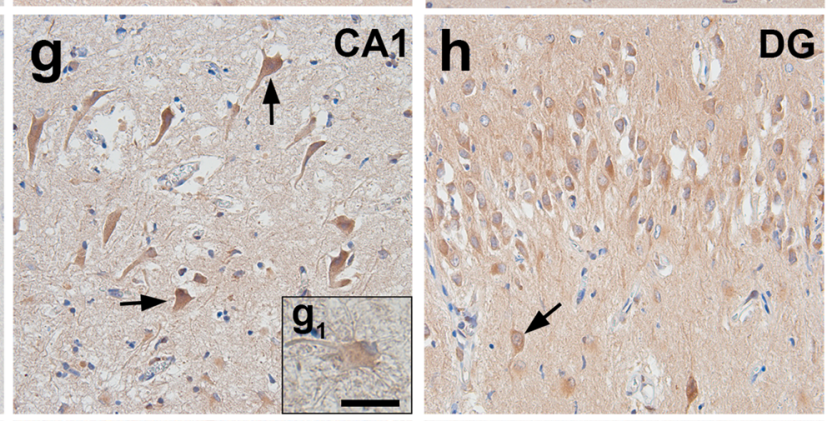

CA1 d

\section{HO-1}
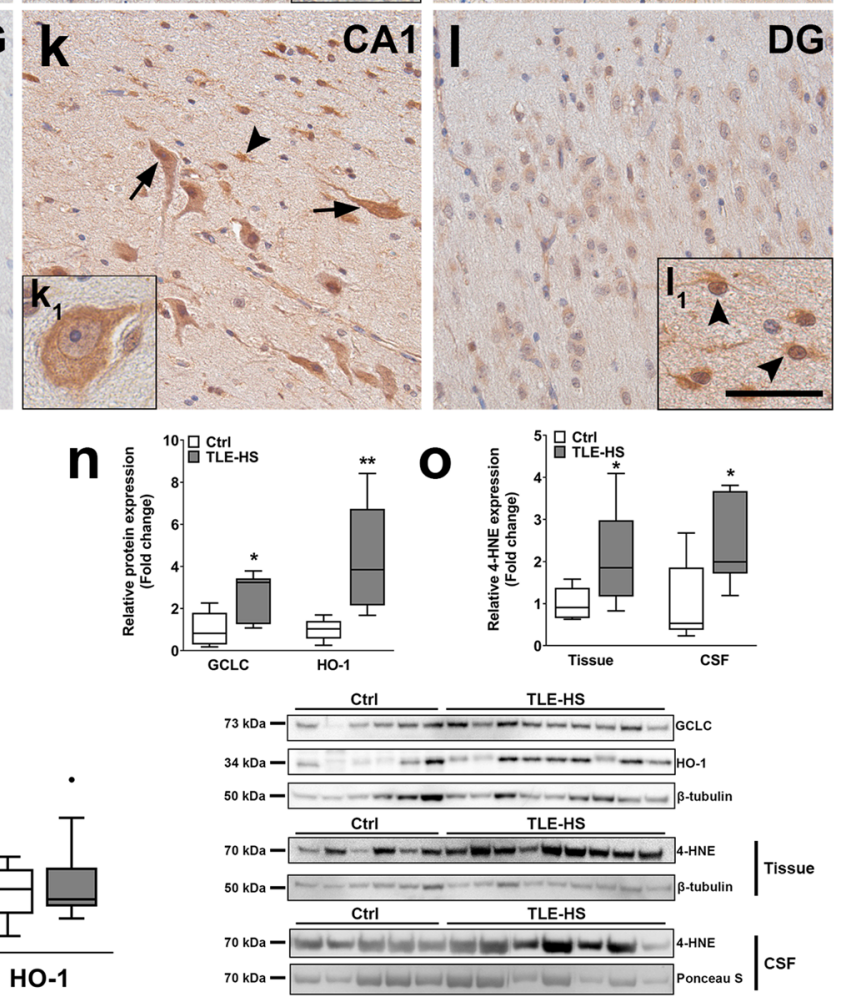

resource 2b, c, e, f). DMT-1 displayed perinuclear staining as well as reactivity in intracellular inclusions and cell membranes in neurons in control tissue (Online resource $2 \mathrm{~g}, \mathrm{j}$ ). In SE tissue, DMT-1 expression was stronger perinuclear in neurons compared to controls (Online resource $2 \mathrm{~h}, \mathrm{k}$ ). In TLE-HS tissue, a markedly higher DMT-1 expression could be found as compared to controls, primarily in some CA1 neurons, but predominantly in astrocytes (Online resource $2 \mathrm{i}, 1)$.

To determine if iron accumulation is associated with BBB leakage in TLE-HS hippocampi, iron and albumin co-labeling was performed. Perivascular iron accumulation in glial processes could be detected and co-localized with albumin in cells with astrocyte morphology (Online resource $2 \mathrm{~m}, \mathrm{o}, \mathrm{p}$ arrowheads). In addition, albumin could 
४Fig. 2 SE and TLE-HS hippocampus tissue display higher reactivity for the oxidative damage marker 4-HNE, higher expression of glutathione synthesis enzymes and the oxidative stress marker HO-1. a, b Expression of 4-HNE in the hippocampus of autopsy control hippocampi was restricted primarily to CA1 neurons $\left(a_{1}\right)$ displaying very low reactivity in intracellular deposits. c, d Similarly, very low expression of HO-1 could be detected in CA1 neurons but not the DG. e, $\mathbf{f}$ In the hippocampus of SE patients, neurons in CA1 $\left(\mathrm{e}_{1}\right)$ and DG displayed more reactive intracellular deposits (arrows). Additionally, some glial cells revealed intracellular deposits in the DG (arrowhead). g, h HO-1 in SE tissue was strongly expressed in CA1, DG as well as hilar interneurons ( $h$, arrow). In addition, cells with astrocyte morphology showed high HO-1 expression $\left(\mathrm{g}_{1}\right)$. $\mathbf{i}, \mathbf{j}$ The hippocampus of surgically resected TLE-HS brain tissue revealed 4-HNE deposits in CA1 neurons $\left(\mathrm{i}_{1}\right)$ and DG glia (arrows). k, 1 HO-1 expression in TLE-HS brain tissue was markedly higher, primarily in CA1 and DG neurons (arrows), but also hilar interneurons $\left(\mathrm{k}_{1}\right)$ and cells with glial morphology ( $\mathrm{l}_{1}$, arrowheads). m RNA quantification of TLE-HS hippocampi showed higher expression of glutathione metabolic genes GPx1, GCLC, GSR and xCT, while HO-1 RNA was not different from autopsy control. $\mathbf{n}$ Total protein quantification of TLE-HS hippocampi revealed higher GCLC and HO-1 expression compared to autopsy control. o Additionally, 4-HNE expression was higher in tissue and cerebrospinal fluid (CSF) of TLE-HS patients compared to control. Sections a-l were counterstained with hematoxylin. Scale bars: $50 \mu \mathrm{m}$ in a (representative for $\mathbf{a}-\mathbf{l}), 20 \mu \mathrm{m}$ in inserts $a_{1}$ (representative for $b_{1}, c_{1}$ ) and $l_{1}, 20 \mu \mathrm{m}$ in $g_{1}$ (representative for $\mathrm{k}_{1}$ ); arrows = neurons, arrowheads = glia. $\mathbf{m}, \mathbf{n}$ Mann-Whitney $U$ test. Data are expressed relative to expression observed in autopsy controls and displayed as Tukey box plots; ${ }^{*} p<0.05$, $* * p<0.01$, $* * * p<0.001$. m: $n=10$ autopsy control vs. $n=13$ TLE-HS; $\mathbf{n}: n=6$ autopsy/CSF control vs. $n=9$ TLE-HS; o: $n=6$ autopsy/CSF control vs. $n=9$ TLE-HS

be found in neurons which also co-localized with iron (Online resource $2 \mathrm{~m}_{1}, 2, \mathrm{p}$, arrows). However, there were also areas of strong extracellular albumin reactivity with nuclear iron accumulation in neurons as well as areas with iron but no albumin (Online resource 2n, p).

In addition to SE and TLE-HS brain tissue, autopsy tissue from patients who died following TBI and stroke were investigated in a small cohort of patients with varying post-injury delays before death. Though these tissues were retrieved from cortical lesions, the general response of cells to the injury and consequent iron loading of the tissue serving as reference were of interest. Blood extravasation acutely after trauma $(<48 \mathrm{~h})$ was followed $(>48 \mathrm{~h})$ by iron accumulation in some neurons, but predominantly perivascular cells with microglial and macrophage morphology (Online resource 3a, b). This was mirrored by strong perivascular ferritin expression in morphologically similar cells (Online resource 3d, e). Lesions from patients who developed epilepsy after TBI ( $>6$ months) contained areas of high iron reactivity in the neuropil and glia around vessels as well as neuronal iron accumulation in cytoplasm and nucleolus (Online resource 3c). Ferritin expression could be detected primarily in microglia, whereas ferritin expression in cells with astrocyte morphology was apparent in older lesions (Online resource $3 f, \mathrm{f}_{1}$ ). Similar to TBI tissue, acute stroke lesions (2-4 days) displayed perivascular iron related to bleeding with little ferritin expression (Online resource $3 \mathrm{~g}, \mathrm{j}$ ). Older lesions (5-6 days) displayed iron accumulation and ferritin expression in glia and macrophages, as well as cytoplasmic iron accumulation in neurons (Online resource $3 \mathrm{~h}, \mathrm{k}$ ). Even older lesions ( 2 weeks) showed iron mostly contained in cells with glial and macrophage morphology and ferritin-expressing glia and macrophages around vessels, some shaped like astrocytes (Online resource 3i, 1).

\section{Neuronal oxidative damage and oxidative stress response are elevated in the hippocampus of patients with SE or TLE-HS}

Since OS and iron metabolism are intimately related, we next investigated which cell types are affected most by OS in SE and TLE-HS brain tissue by examining 4-HNE and HO-1 expression (respective markers of lipid peroxidation and ROS response; a low magnification overview can be found in Online resource $1 \mathrm{~g}-\mathrm{l}$ ). For 4-HNE, low-to-no expression was detected in nuclei of CA1 neurons, while the DG was almost blank in control hippocampus (Fig. 2a, $\left.\mathrm{a}_{1}, \mathrm{~b}\right)$. HO-1 expression in CA1 and DG neurons of control tissue displayed low, but detectable expression (Fig. 2c, d). In SE tissue, we found many 4-HNE-positive perinuclear intracellular deposits, predominantly in CA1 neurons and occasionally also in interneurons and glial cells in the DG (Fig. 2e, $\mathrm{e}_{1}, \mathrm{f}$ ). HO-1 expression in SE tissue was markedly higher in CA1 and DG as compared to controls, especially in pyknotic neurons and hilar interneurons (Fig. $2 \mathrm{~g}$, h, arrows). In addition, HO-1 expression could also be detected in astrocytes (Fig. $2 \mathrm{~g}_{1}$ ). In TLE-HS tissue, not only 4-HNE reactive deposits, similar to $\mathrm{SE}$, but also cell membrane reactivity was found mostly in CA1 neurons, especially within pyknotic neurons (Fig. 2i, $\mathrm{i}_{1}$ ). DG neurons also displayed higher 4-HNE reactivity but much less than CA1 neurons (Fig. 2j). Similar to SE tissue, HO-1 expression in TLEHS was very high in CA1 and DG neurons, as well as hilar interneurons (Fig. 2k, $\mathrm{k}_{1}$, 1). Additionally, glial cells also displayed higher HO-1 expression in some cases of TLE-HS (Fig. 21 ${ }_{1}$ ). A summary of the immunohistochemical evaluation for SE and TLE-HS tissue compared to autopsy control can be found in Table 5. Quantification of gene expression revealed a marked increase in glutathione metabolism indicated by higher RNA expression of glutathione peroxidase 1 (GPx1), GCLC, glutathione disulfide reductase (GSR) and the glutamate/cysteine antiporter system $\mathrm{Xc}^{-}$light subunit (xCT [SLC7A11]) in TLE-HS as compared to control, while HO-1 expression remained unchanged (Fig. 2m). Higher expression of not only GCLC but also HO-1 was detected upon investigation of total protein (Fig. 2n). This 


\section{a}

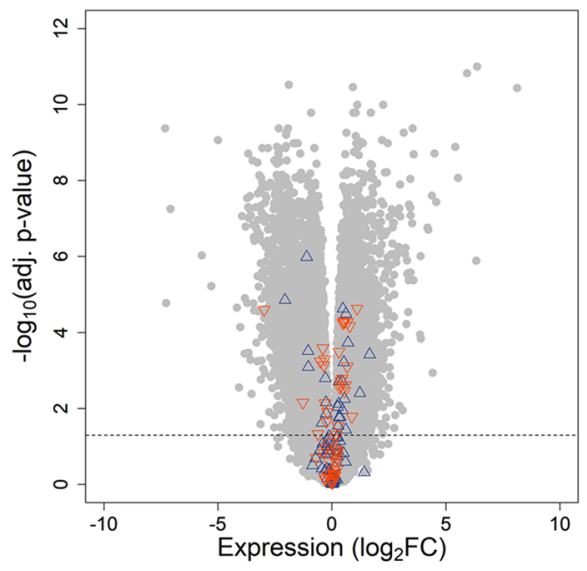

$\triangle$ Detoxification of ROS/GSH conjugation $\nabla$ Iron uptake and transport
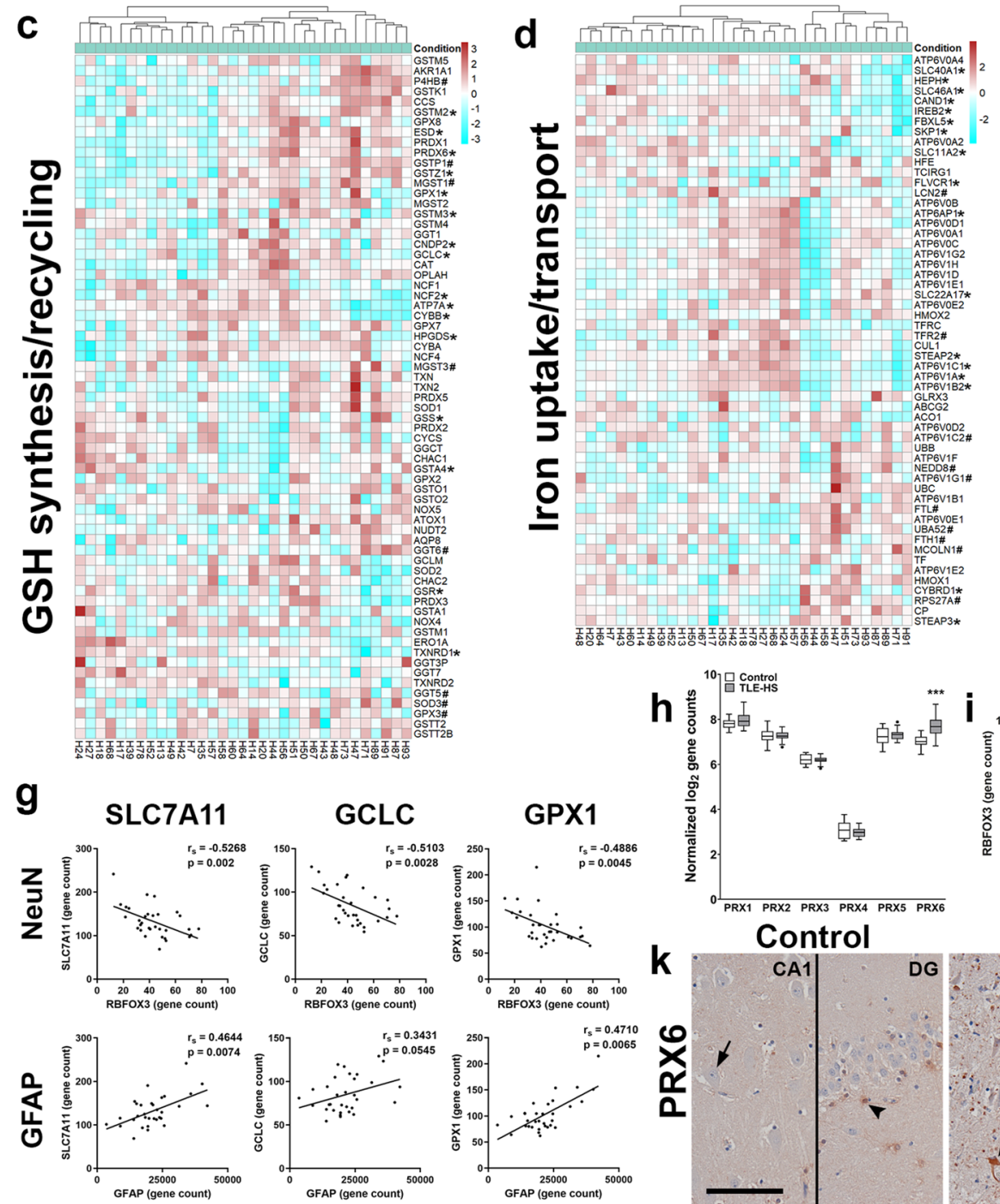

e s

$\operatorname{scc} 2000.71$

$\operatorname{cos4} 0,430,51$

occor $0,660,0,350,33$

$\operatorname{cocm} 0.460 .540 .660 .20$

css $0.170 .220 .02 \quad 0.170 .03$

asR $0,060,0,35 \quad 0,36 \quad 0,37 \quad 0,40 \quad 0,39$

GPx1 $\begin{array}{lllllll}0.48 & 0.42 & 0.57 & 0.51 & 0.52 & -0.04 & 0.25\end{array}$

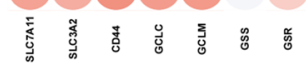

f $\quad$ Trec -0.39

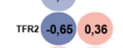

WFE $0,20-0,08-0,0,31$

STteAs $0,13-0,09-0,560,0,26$

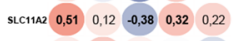

FFrt $0,11 \quad 0,27 \quad 0,07-0,01-0.18-0,12$

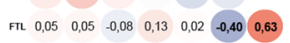

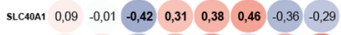

cP $0,08 \quad 0,10-0,31 \quad 0,34 \quad 0,47-0,14 \quad 0,41 \quad 0,62-0.09$

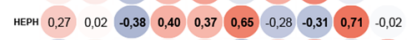

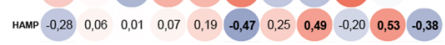
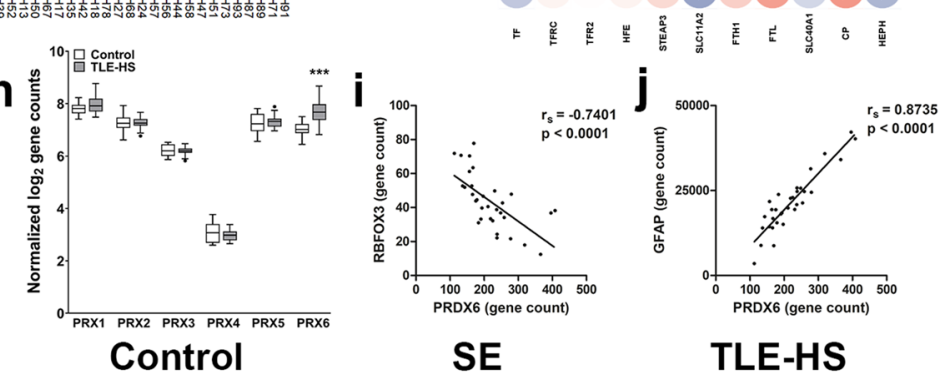

SE

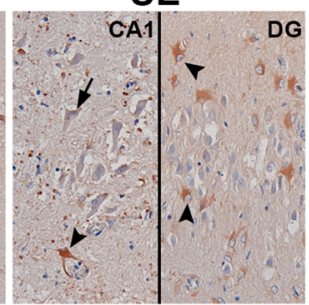

TLE-HS

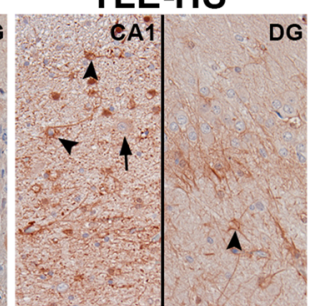

was accompanied by a higher 4-HNE reactivity of the most prominent protein band at $70 \mathrm{kDa}$ in TLE-HS tissue and cerebrospinal fluid (CSF) compared to control (Fig. 2o). Combined, these results suggest higher OS and elevated glutathione metabolism in the hippocampus of epileptic patients. 
4Fig. 3 The transcriptome of TLE-HS hippocampus tissue confirms alterations in iron metabolism and glutathione metabolism, revealing strong correlations between genes of similar function, but also heterogeneity between patients. a Volcano plot of TLE-HS hippocampi compared to autopsy control tissue yielded 5937 upregulated and 6125 downregulated genes, many of them being involved in either detoxification of ROS and glutathione conjugation or iron uptake and transport. b A more focused visualization of principal components of glutathione synthesis/recycling (left) and iron uptake and transport (right). c, d Clustering of samples (Euclidean distance) using genes involved in glutathione recycling/synthesis and iron uptake/ transport revealed heterogeneity between TLE-HS patients. e Correlation analysis revealed a strong correlation between glutathione synthesis/recycling genes, except GSS. f Correlation analysis of genes involved in iron uptake and transport revealed positive correlations between i.e. iron binding (FTH-1/FTL), iron export (HEPH/FPN1 [SLC40A1]), while iron uptake (TFR2/TF) was negatively correlated. g While NeuN [RBFOX3] was negatively correlated, GFAP correlated positively with XCT [SLC7A11], GCLC and GPX1. h-j Of the family of PRX proteins, PRX6 displayed strong upregulation in TLEHS (h) and was negatively correlated with NeuN [RBFOX3] (i), but positively correlated with GFAP $(\mathbf{j})$. k Immunohistochemical analysis of PRX6 revealed a predominantly astrocytic staining. Sections in $\mathrm{k}$ were counterstained with hematoxylin. a Dashed line represents a cut-off of Benjamini-Hochberg corrected $p<0.05$. b bold $=\mathrm{p}<0.05$. c, d Euclidean distance clustering. Genes differentially expressed compared to control are indicated with *(upregulated, adjusted $p$-value $<0.05$ ) and \# (downregulated, adjusted $p$-value $<0.05$ ), respectively. e, f Numbers represent Spearman $r\left(r_{\mathrm{s}}\right)$ with bold numbers $p<0.05$. $\mathbf{e}-\mathbf{g}, \mathbf{i}, \mathbf{j}$ Spearman's rank test. RNA sequencing: $n=11$ control autopsy hippocampi vs. $n=33$ TLE-HS hippocampi. SLC $3 \mathrm{~A} 2=4 \mathrm{~F} 2$ cell-surface antigen heavy chain, SLC7A11 $=\mathrm{xCT}$, SLC11A2 = DMT-1, SLC40A1 $=$ FPN-1

\section{The transcriptome of TLE-HS hippocampi confirms higher glutathione metabolism and altered iron trafficking}

To validate the current findings and utilize the advantages of high-throughput analysis, transcriptomic data from TLEHS hippocampi compared to autopsy control tissue was employed. In total, 6125 downregulated and 5937 upregulated genes were identified, containing a multitude of genes involved in functions related to antioxidant capacity and iron metabolism (Fig. 3a). Two sets of genes relating to different functional modules were sub-selected for analysis: 1. a combined list of genes involved in detoxification of ROS and glutathione conjugation and 2. genes involved in iron uptake and transport. Investigation of a subset of genes involved in glutathione metabolism revealed upregulation of cysteine import (xCT [SLC7A11], SLC3A2, CD44), glutathione synthesis (GCLC, GSS) as well as recycling (GSR) and glutathione-dependent peroxidation (GPx1). A subset of genes involved in iron metabolism revealed lower expression of iron uptake (TFR2), iron binding (FTH1, FTL) and iron export suppression (HAMP), while genes involved in endosomal iron reduction and export (STEAP3, DMT-1 [SLC11A2]) as well as cellular iron export (FPN-1 [SLC40A1], HEPH) were overexpressed compared to autopsy control tissue. Besides its endosomal function, DMT-1 located at the membrane (not depicted) could potentially also facilitate cellular iron uptake depending on the cell type (Fig. 3b). Visualization of genes involved in glutathione synthesis/recycling and iron uptake/transport revealed distinct subgrouping of TLE-HS cases (Fig. 3c, d). A correlation analysis of the subset of glutathione genes revealed positive correlations between genes involved in glutathione synthesis and recycling, except for GSS (Fig. 3e). Correlation analysis of the gene subset involved in iron uptake and transport revealed negative correlations between TFR2 and genes involved in intracellular iron uptake (HFE, STEAP3, SLC11A2/DMT-1) and cellular export (HEPH, CP, SLC40A1/FPN-1). Moreover, strongest positive correlations were detected i.e. in genes involved in iron binding (FTH-1, FTL) and iron cycling (HEPH, SLC11A2/DMT-1, SLC40A1/FPN-1) (Fig. 3f). To investigate the relationships between cytopathology and the transcriptional changes of glutathione metabolism, a correlation analysis was conducted of XCT [SLC7A11], GCLC and GPX1 with either the astrocyte marker GFAP or neuronal marker RBFOX3 (NeuN). All three genes correlated negatively with RBFOX3 (xCT [SLC7A11]: $r_{\mathrm{s}}=-0.5268$, $p=0.002 ;$ GCLC: $r_{\mathrm{s}}=-0.5103, \mathrm{p}=0.0028$; GPX 1 : $\left.r_{\mathrm{s}}=-0.4886, p=0.0045\right)$, while they correlated positively with GFAP (xCT [SLC7A11]: $r_{\mathrm{s}}=0.4644, p=0.0074$; GCLC: $r_{\mathrm{s}}=0.3431, p=0.0545 ;$ GPX1: $r_{\mathrm{s}}=0.4710$, $p=0.0065$ ) (Fig. 3g). Moreover, of the family of peroxiredoxins (PRX), we found specifically PRX6 to be upregulated in TLE-HS, which revealed negative correlation with RBFOX3 $\left(r_{\mathrm{s}}=-0.7401, p<0.0001\right)$ and positive correlation with GFAP $\left(r_{\mathrm{s}}=0.8735, \mathrm{p}<0.0001\right)$ (Fig. 3h-j). This strong co-expression with GFAP was validated on tissue, revealing strong astrocytic PRX6 expression in SE and TLE-HS (Fig. 3k). These data validate substantial alterations in iron metabolism and suggest that predominantly astrocytes are responsible for antioxidant gene expression in hippocampi of epilepsy patients.

\section{Postictally increased magnetic susceptibility in epilepsy patients}

Evidence from experimental epilepsy models suggest seizure-dependent opening of the $\mathrm{BBB}$, which is hypothesized to promote the extravasation and intracerebral accumulation of iron-rich blood components such as protein-bound iron. However, thus far, this hypothesis has not been tested in human subjects. To this end, the magnetic susceptibility of the electroencephalographically determined seizure-onset zone of three patients diagnosed with focal epilepsy were compared inter- and postictally. Patients \#1 and \#2 showed a temporomesial seizure onset as ascertained by ictal EEG, while patient \#3 presented with a radiologically diagnosed 
Fig. 4 Postictal quantitative susceptibility in three epilepsy patients with focal seizures QSM scans of three epilepsy patients showed an increase in postictal magnetic susceptibility, indicative for an increased iron accumulation within the presumable seizure-onset zone. QSM difference images have been thresholded, visualized according to the indicated color scale, and superimposed on the structural T1-weighted image. The presumable seizure-onset zone is schematically indicated by white dashed ellipses. Voxelwise distributions were read out within manually demarcated masks of the seizure-onset zone, visualized as letter-value plots (midline indicating the median), and compared using Cohen's $\mathrm{d}$ $(* * * d>0.8, * d>0.2)$

\section{Patient \#1 - left temporomesial seizure onset}
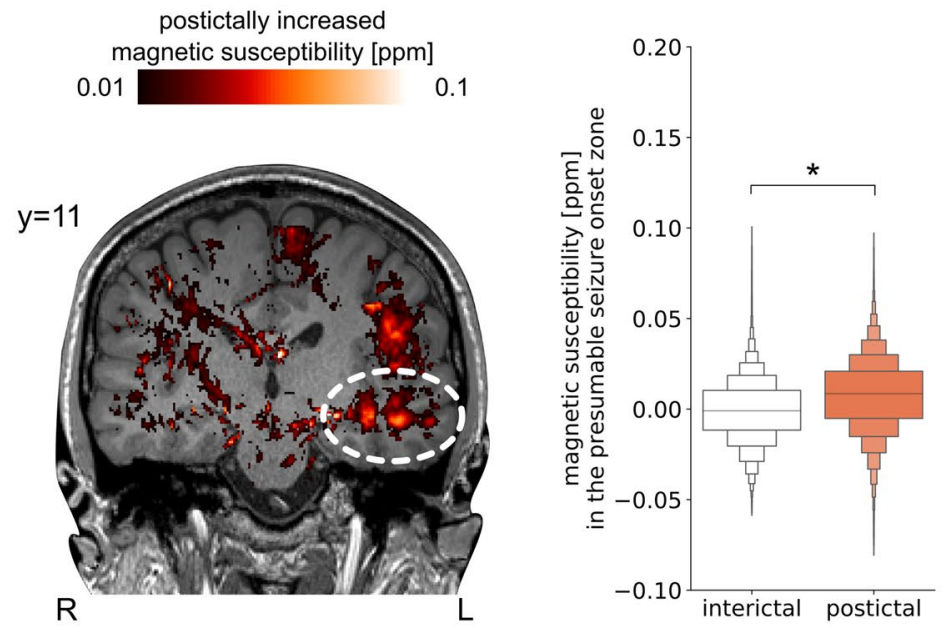

\section{Patient \#2 - left temporomesial seizure onset}

postictally increased magnetic susceptibility [ppm] 0.01
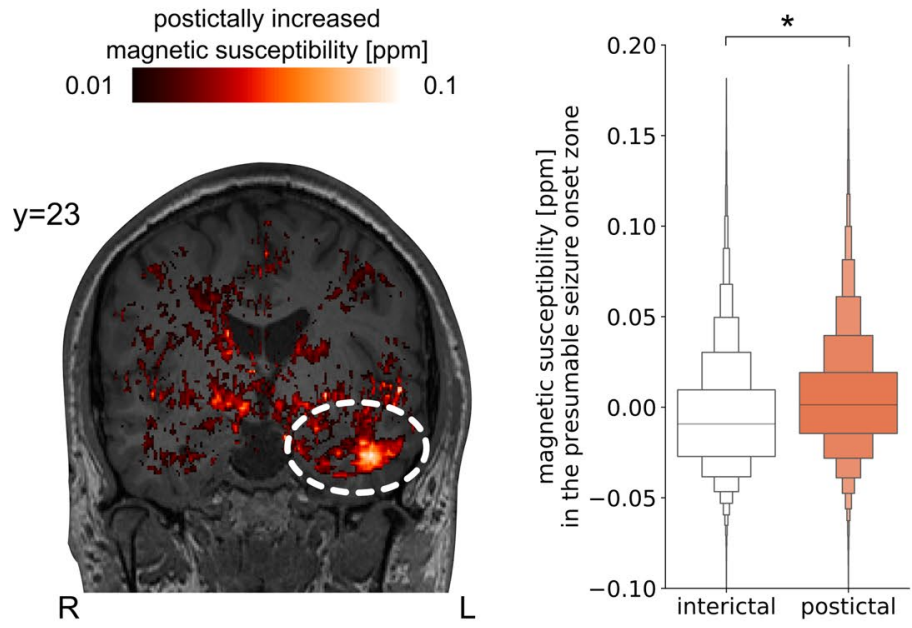

\section{Patient \#3 - right frontal seizure onset}
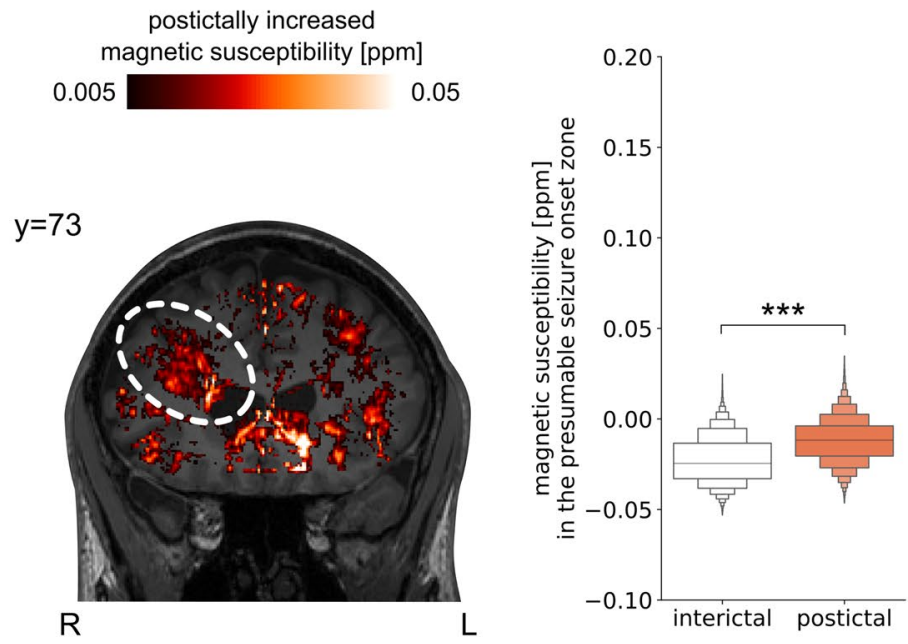
focal cortical dysplasia type $2 \mathrm{~b}$ located in the right frontal lobe (Fig. 4). In all three patients, a postictally (compared to interictally) increased magnetic susceptibility in the immediate vicinity of the presumable seizure-onset zone can be visually appreciated in the QSM difference image (Fig. 4). Comparisons of the voxel-wise magnetic susceptibility distributions showed higher postictal susceptibility values as compared to interictal susceptibility values within the seizure-onset zone with small effect sizes in the two temporomesial cases (Cohen's d $>0.2$ ) and a large effect size (Cohen's $d>0.8$ ) for patient \#3. In conclusion, these results support higher iron accumulation in the seizure-onset zone after seizure activity.

\section{Prominent changes in iron accumulation and iron metabolism acutely after electrically induced SE and after development of spontaneous recurrent seizures in post-SE rats}

To corroborate our findings from human tissue and better understand the time-course of the observed changes, RNA and protein expression of iron metabolism molecules as well as iron concentrations were measured in the hippocampus of post-SE rats at different stages after electrically induced SE (low magnification overviews can be found in Online resource $4 a-i)$. Similar to humans, ferritin expression was predominantly found in microglia (arrowheads) of control animals (Fig. 5a, $\mathrm{a}_{1}$ ) and low HO-1 expression in few neurons (arrow), while very low iron reactivity could be detected in oligodendrocytes and occasionally neuronal nucleoli (Fig. 5d, g). During the acute phase (1 day post$\mathrm{SE})$, ferritin expression was evident in activated microglia (Fig. 5b, $b_{1}$ ), while a lot of iron accumulated in microglia (Fig. 5e ${ }_{1}$ ), some neuronal nuclei (Fig. $5 \mathrm{e}_{2}, \mathrm{e}_{3}$ ) and in the neuropil (Fig. 5e). Moreover, HO-1 expression was markedly higher in glia (Fig. 5h). During the chronic phase (7 months post-SE), when animals had SRS, ferritin was detected in microglia, a few astrocytes as well as across the dendritic tree of some neurons (Fig. 5c). Iron accumulation was less pronounced than 1 day post-SE, but could still be detected in microglia (Fig. $5 f_{1}, f_{2}$ ) and the neuropil (Fig. 5f). HO-1 expression was still detected in not only astrocytes, but also CA1 neurons and hilar interneurons (Fig. 5i, $\mathrm{i}_{1}$ ).

RNA expression in the PHC of post-SE rats at different stages revealed higher XCT, FTH-1, FPN-1 and DMT-1 expression during the latent phase ( 1 week post-SE), while HO-1 was higher during the acute phase (1 day post-SE) (Fig. $5 \mathrm{j}, \mathrm{k}$ ) as compared to controls. In hippocampal subfields $\mathrm{CA} 1$ and DG higher $\mathrm{xCT}$ expression during the latent phase could also be found (Online resource $4 \mathrm{k}$ ). Higher HO-1 expression in the acute phase was found in both CA1 and DG, while HO-1 expression in the latent phase was higher only in the CA1 during the latent phase (Online resource $4 \mathrm{k}, \mathrm{m}$ ). Lower expression of TFRC in the DG in the chronic phase was the only detectable difference in iron metabolism in the hippocampal subfields (Online resource $41, \mathrm{n})$. On protein level, HO- 1 and FTH-1 expression in the PHC were higher during the acute phase (Fig. 51) as compared to controls. Iron concentrations in hippocampal lysates were found to be higher in rats during the chronic phase (Fig. 5m), while lysates of the PHC revealed higher iron concentrations both during the acute and chronic phase (Fig. 5n). These results indicate that electrically induced SE triggers iron accumulation and promotes chronic changes in iron metabolism and OS in the hippocampus.

\section{Effects of ferric iron overload on epileptiform activity in acute hippocampal slices}

To mimic the acute effect of seizure-mediated iron leakage and iron exposure on brain tissue, acute hippocampal brain slices were exposed to hemin or FAC for $1 \mathrm{~h}$. Of note, $200 \mu \mathrm{M}$ FAC correspond to $8.6-9.7 \mu \mathrm{g} / \mathrm{mL}$ iron assuming a reference range of $5-17.5 \mu \mathrm{g} / \mathrm{mL}$ serum iron, implying a physiologically relevant iron load upon BBB leakage. While iron reactivity in control and hemin-treated slices could be detected in cells with microglial and oligodendroglial morphology (arrowheads), FAC treatment led to prominent iron staining in neurons, particularly in neuronal processes as well as neuronal nuclei and nucleoli (Fig. 6a-g, arrows). Treatment with FAC did not induce spontaneous epileptiform activity in hippocampal slices nor did it exacerbate 4-AP-induced epileptiform activity (Fig. 6h-i). However, total iron concentration in hippocampal slices was elevated upon co-treatment with either 4-AP or L-glutamate (Glu, which induced brief paroxysmal activity in the slice, Fig. 6j) which was not reduced by the voltage-gated calcium channel (VGCC) inhibitor nifedipine or the $N$-methyl-D-aspartate (NMDA) receptor inhibitor MK801 (Fig. 6k). Immunohistochemically, no prominent visual differences between FAC and FAC/4-AP or FAC/Glu-treated slices could be detected (not shown). Measurement of RNA expression in hippocampal slices after exposure to FAC, 4-AP, Glu or a combination did not alter expression of iron metabolism genes (Fig. 61). On the contrary, HO-1, IL-1 $\beta$ and IL- 6 expression were induced by FAC, FAC/4-AP, Glu and Glu/FAC treatment, while 4-AP stimulation alone did not induce changes. Overall, co-stimulation of FAC combined with either 4-AP or Glu induced more robust changes (Fig. 6m). Finally, as marker for neuronal activation, we found higher cFOS expression in 4-AP and FAC/4-AP, and Glu/FAC-treated slices (Online resource $4 \mathrm{j}$ ). These data indicate that ferric iron overload does not induce epileptiform activity but leads to activitydependent iron uptake in neurons and amplifies upregulation of pro-inflammatory genes. 

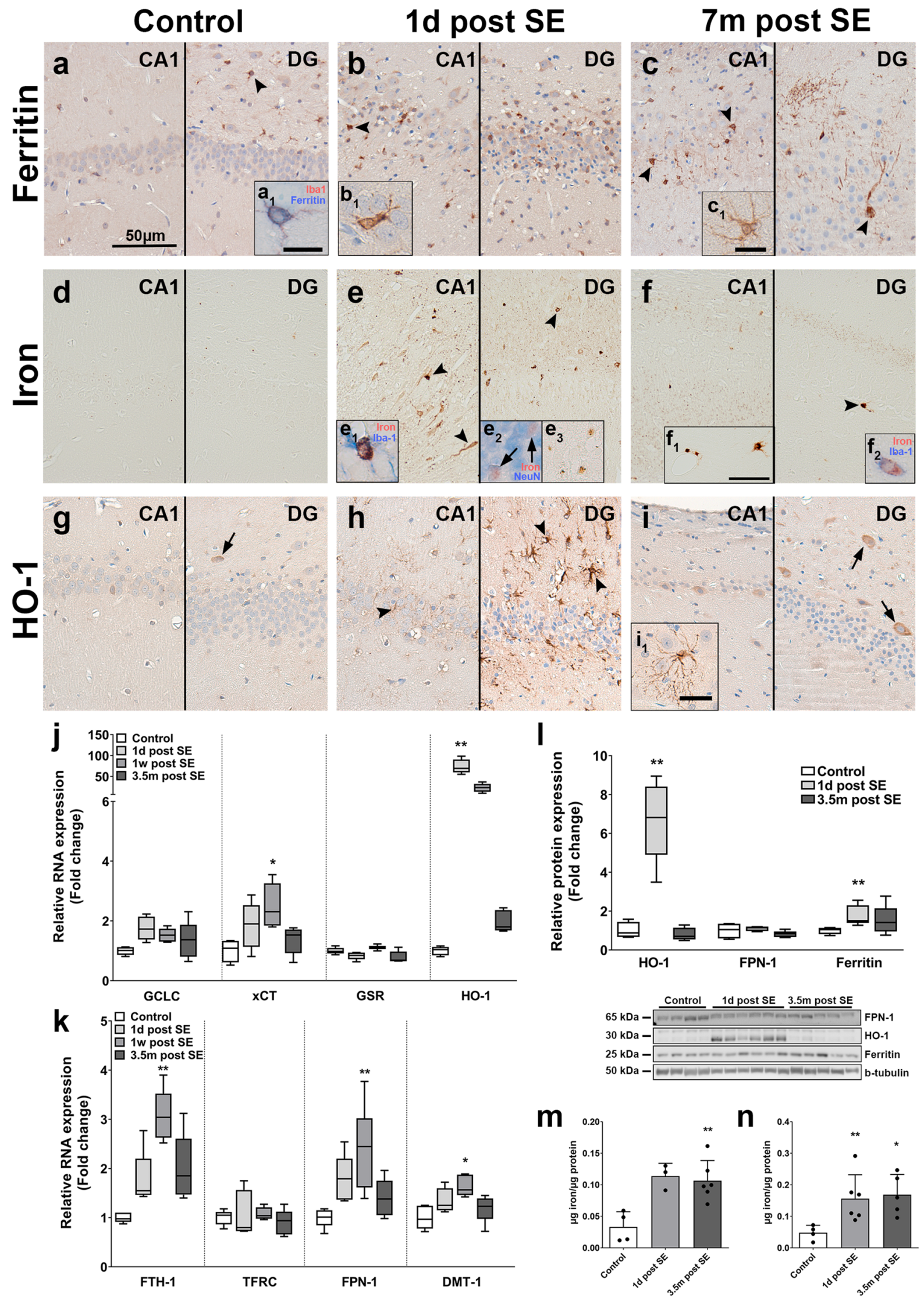
४Fig. 5 Hippocampal tissue of SE rats displays ferritin expression and iron accumulation in microglia, acute HO-1 expression in astrocytes and higher expression of OS response and iron metabolism genes after electrically induced status epilepticus. a-c Control rat hippocampus revealed ferritin expression in CA1 and DG in microglia $\left(\mathbf{a}, \mathrm{a}_{1}\right.$, arrowhead). Distribution of ferritin expression was not altered during the acute stage (1 day after electrically induced SE), being present in microglia with activated morphology and neurons. However, overall, more ferritin-positive microglia could be detected (b, $b_{1}$, arrowhead). During the chronic phase ( 7 months post-SE), when rats have SRS, ferritin expression localized to microglia but also occasionally in astrocytes $\left(c_{1}\right)$ and the dendritic tree of neurons (c, arrowheads). d-f Iron in control hippocampi was detected in oligodendroglia and some neuronal nucleoli (d). Iron accumulation during the acute stage was markedly higher, accumulating in microglia (e, $\mathrm{e}_{1}$, arrowheads), neurons $\left(\mathrm{e}_{1}, \mathrm{e}_{2}\right)$ and in the neuropil (e). In hippocampi of rats with SRS (chronic stage), iron could be detected in microglia $\left(\mathrm{f}_{1}, \mathrm{f}_{2}\right)$ and in the neuropil $(\mathbf{f})$. $\mathbf{g}-\mathbf{i}$ HO- 1 expression in control rats was restricted to few hilar interneurons (g, arrow). During the acute phase, strong expression of HO-1 was observed in astrocytes ( $h$, arrowheads), which persisted in astrocytes with less reactive morphology during the chronic stage $\left(i, i_{1}\right)$. In addition, HO- 1 expression in hilar neurons was elevated in animals suffering from SRS (i, arrows). $\mathbf{j}, \mathbf{k}$ RNA expression in the PHC of TLE rats displayed most modulation during the latent phase with higher xCT, FTH-1, FPN-1 and DMT-1 expression. Moreover, HO-1 expression was higher during the acute stage as compared to control. I On the protein level, HO-1 and ferritin expression were higher during the acute stage compared to control, but not during the chronic stage. $\mathbf{m}, \mathbf{n}$ Iron concentrations in the hippocampus (m) and the PHC (n) were higher in animals during the acute and chronic stages. Sections $\mathbf{a}-\mathbf{c}$ and $\mathbf{g}-\mathbf{i}$ were counterstained with hematoxylin. Scale bar $=50 \mu \mathrm{m}$ in $\mathrm{a}, \mathrm{f}_{1}, 25 \mu \mathrm{m}$ in $\mathrm{i}_{1}, 10 \mu \mathrm{m}$ in $\mathrm{a}_{1}$ (representative for $\mathrm{b}_{1}, \mathrm{e}_{1}, \mathrm{e}_{2}, \mathrm{f}_{2}$ ), $\mathrm{c}_{1}$; arrows $=$ neurons, arrowheads $=$ glia. $\mathbf{j}, \mathbf{k}$ Kruskal-Wallis test followed by post hoc Dunn's test. I-n Mann-Whitney $U$ test. Data are expressed relative to expression observed in controls as Tukey box plots $(\mathbf{j}-\mathbf{l})$ or bar graphs with $\mathrm{SD}(\mathbf{p}, \mathbf{q}) ;{ }^{*} p<0.05, * * p<0.01 . \mathbf{j}, \mathbf{k} n=5$ (control, 1 day, 7 months) or $n=6$ ( 1 week); $\mathbf{l}, \mathbf{n} n=4$ (control), $n=6$ (1 day) or $n=5$ (3.5 months) animals per group. $\mathbf{m} n=4$ (control), $n=3$ (1 day) or $n=6$ (3.5 months) animals per group

\section{Human fetal astrocytes in vitro resist chronic OS and iron overload, but respond with a pro-inflammatory phenotype}

Since prominent ferritin expression was found specifically in astrocytes in tissues from epilepsy patients, human fetal astrocytes were stimulated with OS and iron to further explore iron's effect in vitro. Here, two paradigms were chosen: 1 . modeling chronic OS and iron overload by stimulating with $\mathrm{GO}$ and FAC for $72 \mathrm{~h}$ and 2. modeling acute seizure-induced extravasation of iron-rich blood components combined with acute $\mathrm{OS}$ via hemin $/ \mathrm{H}_{2} \mathrm{O}_{2}$ for $24 \mathrm{~h}$. RNA expression of glutathione metabolic genes GPx1, GCLC, GSR and xCT as well as HO-1 was higher in fetal astrocytes stimulated with GO compared to control and this difference was higher when cells were co-stimulated with FAC (Fig. 7a). Stimulation with hemin-induced HO-1 and xCT expression while co-stimulation with $\mathrm{H}_{2} \mathrm{O}_{2}$ had no additional effect (Fig. 7b). Expression of FTH-1 and FTL was higher upon FAC and GO/FAC stimulation, while FPN-1 was only elevated compared to control in cells exposed to GO/FAC (Fig. 7c). Similar changes were observed for hemin stimulation, which led to upregulation of FTL. Co-treatment of hemin $/ \mathrm{H}_{2} \mathrm{O}_{2}$ induced FTH-1 FTL, FPN-1 and DMT-1 upregulation (Fig. 7d). Time-dependent changes in RNA expression of glutathione and iron metabolism genes in response to $\mathrm{FAC}, \mathrm{GO}$ or $\mathrm{H}_{2} \mathrm{O}_{2}$ in astrocytes were investigated as well (Online resource 5a-f). These experiments revealed prominent changes in iron metabolism genes predominantly in response to OS, not iron overload (Online resource 5b, d, f). Positive Perl's iron stain and quantification of iron in fetal astrocytes exposed to GO/FAC or hemin/ $\mathrm{H}_{2} \mathrm{O}_{2}$, indicated an uptake of iron (Fig. 7e, f, h, i). Moreover, without compromising cell viability (Online resource 5i, j), HMGB-1 in the supernatant was higher in chronic GO/FAC stimulation, while it was lower in hemin $/ \mathrm{H}_{2} \mathrm{O}_{2}$-treated astrocytes (Fig. $7 \mathrm{~g}$, j). Since astrocytes are important mediators of neuroinflammation in TLE-HS, expression of pro-inflammatory mediators upon FAC and GO/FAC or hemin and hemin $/ \mathrm{H}_{2} \mathrm{O}_{2}$ were assessed as well. RNA expression of interleukin $1 \beta$ (IL-1 $\beta$ ) was not different and IL- 6 expression was increased in both conditions with FAC alone and GO/FAC. Contrary, C3 expression was specifically induced in cells exposed to GO/FAC (Fig. 7k). Hemin treatment for $24 \mathrm{~h}$ alone did not have an effect while hemin $/ \mathrm{H}_{2} \mathrm{O}_{2}$ treatment induced IL-6 expression (Fig. 7l), although IL-6 in cell culture supernatant was not different (Online resource $5 \mathrm{~g}, \mathrm{~h}$ ). To investigate if proinflammatory gene expression in response to iron accumulation in astrocytes is complemented by other factors resulting from BBB dysfunction that also co-localize in TLE-HS hippocampi (Online resource $2 \mathrm{~m}-\mathrm{p}$ ), human fetal astrocytes were stimulated with BSA and HSA. IL- $1 \beta$ was elevated after $24 \mathrm{~h}$ and $\mathrm{C} 3$ and COX-2 after $48 \mathrm{~h}$ stimulation with BSA while HO-1 did not change (Online resource $5 \mathrm{k}$, l). A similar trend was observed for $24 \mathrm{~h}$ stimulation with HSA. Matrix metalloproteinase 9 (MMP9) served as positive control, as expression of MMP9 was previously demonstrated to be induced by albumin.

Finally, SHSY5Y neuroblastoma cells were investigated to mimic the neuronal response to OS and iron. GO stimulation induced $\mathrm{xCT}$ and FTL expression, whereas GO/FAC induced GPx1, GSR, xCT, HO-1, FTH-1, FTL and lowered TFRC expression (Online resource 6a, b). Exposure to GO/FAC and hemin $/ \mathrm{H}_{2} \mathrm{O}_{2}$ led to iron uptake and elevated HMGB-1 secretion into the supernatant, while compromising cell viability only when stimulated with hemin $/ \mathrm{H}_{2} \mathrm{O}_{2}$ (Online resource $6 \mathrm{c}-\mathrm{h}$ ). Lastly, while not compromising viability, stress-related alterations like reduced electron density and occasional calcium pits, without dramatic morphological alterations in SHSY5Y mitochondria could be observed after FAC challenge (Online resource 6i). In conclusion, astrocytes in vitro are capable of taking up and detoxifying iron upon ferric iron challenge, but secrete pro-inflammatory 

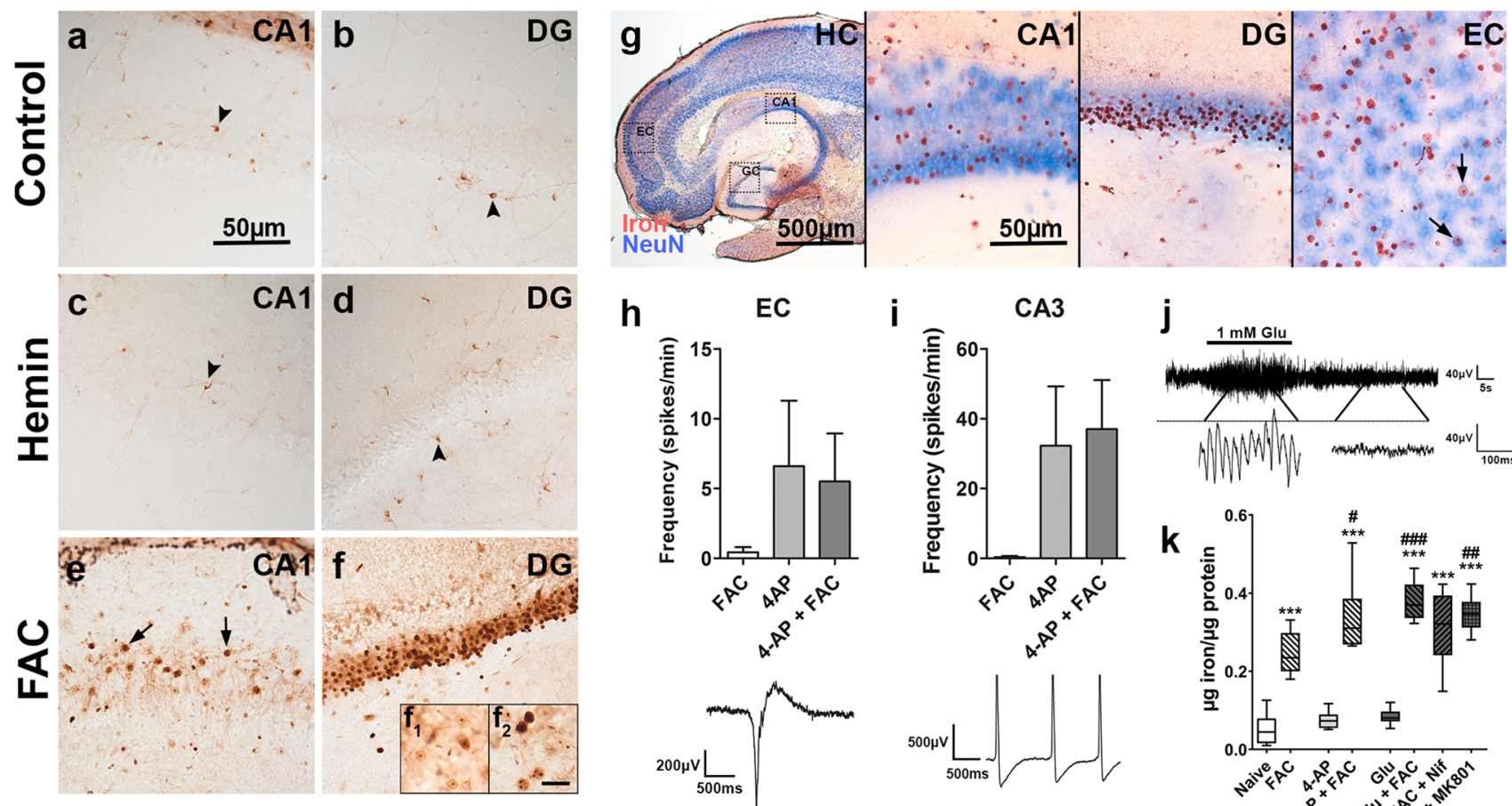

h
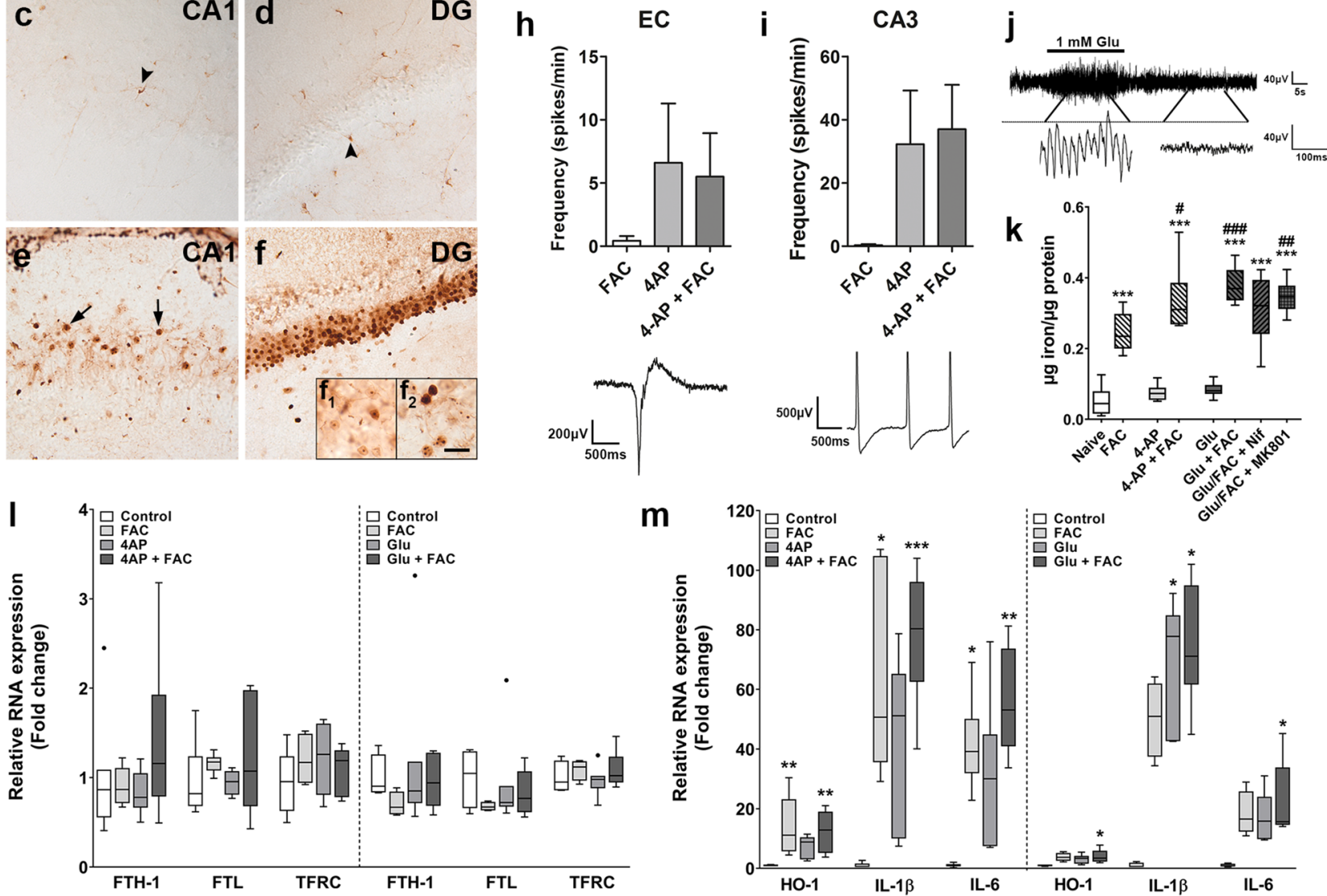

m

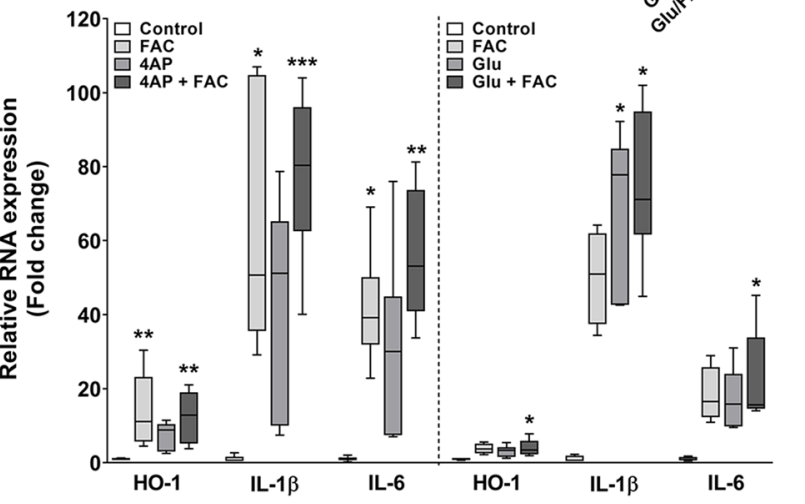

Fig. 6 Iron accumulation upon exposure of acute hippocampal slices to ferric iron is exacerbated by epileptiform activity and induces pro-inflammatory gene expression. a, b Iron in the hippocampus of naive mouse slices could be detected in cells with oligodendroglial morphology (arrowheads) but was absent in neurons. c, d Exposure of mouse slices to hemin $(10 \mu \mathrm{M})$ did not induce iron accumulation, revealing iron in cells with oligodendrocyte morphology similar to control (arrowheads). e, f In contrast, hippocampal slices exposed to FAC $(200 \mu \mathrm{M})$ displayed marked iron accumulation in CA1 and DG neurons and their processes (arrows). $\mathbf{g}$ Co-labelling of iron with NeuN in FAC-treated slices revealed iron accumulation in a subset of neurons (EC, arrows). $\mathbf{h}, \mathbf{i}$ The frequency of epileptiform discharges (example traces underneath) in the EC (h) and CA3 (i) did not differ between brain slices treated with 4-AP $(100 \mu \mathrm{M})$ alone versus 4-AP/ FAC. FAC alone did not induce any spontaneous activity. $\mathbf{j}$ Exposure of hippocampal brain slices to L-glutamate (Glu,1 mM)-induced brief paroxysmal activity for approximately $1 \mathrm{~min}$ after which activity returned back to baseline. k Quantification of total iron showed iron accumulation in brain slices exposed to FAC compared to untreated,

naïve brain slices. Co-treatment with FAC plus either 4-AP or Glu led to an even higher iron accumulation in brain slices compared to FAC alone, that was not reduced by co-treatment with either $10 \mu \mathrm{M}$ nifedipine or $20 \mu \mathrm{M}$ MK801. I Assessment of RNA expression of hippocampal slices did not reveal modulation of FTH-1, FTL or TFRC after treatment with FAC, 4-AP, Glu or a combination. (m) In contrast, expression of HO-1, IL-1 $\beta$ and IL- 6 was upregulated after treatment with FAC or FAC/4-AP, but not 4-AP alone (m, left). Treatment with Glu and Glu/FAC induced higher expression of HO-1, IL-1 $\beta$ and IL-6 (m, right). Scale bars: $500 \mu \mathrm{m}$ in $\mathrm{g}, 50 \mu \mathrm{m}$ in a (representative for $\mathbf{a}-\mathbf{f}$ ) and $\mathrm{g}$ (CA1 representative for DG, EC), $10 \mu \mathrm{m}$ in $\mathrm{f}_{2}$ (representative for $\mathrm{f}_{1}$ ); arrows $=$ neurons, arrowheads=glia. $\mathbf{1}$, m KruskalWallis test followed by post hoc Dunn's test. Data are expressed relative to expression observed in controls as bar graphs with SD (h, i) or Tukey box plots $(\mathbf{k}-\mathbf{m}) ; * p<0.05, * * p<0.01$, *** $p<0.001$ versus control; ${ }^{\#} p<0.05,{ }^{\# \# \#} p<0.001$ vs. FAC. h, i $n=2$ (FAC) or $4-5$ (4-AP, 4-AP/FAC), mean from 2 to 3 electrodes per brain area (EC or CA3); $\mathbf{k} n=8$ slices from 4 animals per condition; $\mathbf{l}, \mathbf{m} n=6-7$ slices from 3 to 4 animals per condition 
factors, while neurons secrete damage-associated signaling molecules and display signs of mitochondrial stress.

\section{Discussion}

The presented data demonstrate that brain tissue from epilepsy patients and rodent epilepsy models respond with iron accumulation as well as changes in iron and glutathione metabolism. Moreover, seizures appear to promote iron accumulation in brain tissue of epilepsy patients in the seizure-onset zone, while ictogenic substances increase iron uptake into acute hippocampal slices. Finally, astrocytes seem to acquire the capacity to sequester iron, while not only upregulating their antioxidant capacity but also producing pro-inflammatory signals.

\section{Nuclear iron accumulation and lipid peroxidation in neurons in SE and TLE-HS brain tissue implicate iron in cell stress}

A prerequisite for iron-catalyzed neuronal dysfunction is the accumulation of intracellular iron. Indeed, iron accumulation in CA1 neurons of SE and TLE-HS tissue could be found specifically in neuronal nuclei and nucleoli. Iron in neuronal nuclei was previously demonstrated upon ultrastructural analysis in the rat brain, supposedly playing important physiological roles e.g. in the synthesis of ribosomal RNA $[31,48,64,92]$. Notably, very strong iron accumulation in neuronal nuclei was detected in TLE-HS and SE in pyknotic neurons. Since pyknosis is a feature of degenerating neurons, this finding indicates that nuclear iron accumulation accompanies neuronal cell death in TLE-HS. Furthermore, ferritin was not expressed in neurons, indicating a low iron storage capacity. In agreement with this finding, elevated nuclear iron accumulation was previously found in degenerating neurons in the context of hereditary iron storage disorders and Alzheimer's disease [86, 94]. Although total neuronal iron load in SE and TLE-HS tissue was low, the DAB-enhanced Perl's method detects $\mathrm{Fe}^{3+}$ [47]. Hence, the visualized iron likely represents non-reactive, protein-bound $\mathrm{Fe}^{3+}$ iron. Unbound, soluble $\mathrm{Fe}^{2+}$, which represents the more Fenton-reactive pool, could also accumulate and more readily react with ROS in neurons.

Higher 4-HNE reactivity was detected in neurons in SE and TLE-HS tissue. Additionally, high 4-HNE adducts could be detected in the CSF and overexpression of glutathione metabolic enzymes in the hippocampus of TLE-HS patients, indicating a more global state of OS in the brain. 4-HNE represents a marker of lipid peroxidation, a process previously implicated in iron-catalyzed regulated necrosis, termed ferroptosis $[16,80]$. Ferroptosis is prevented via system $\mathrm{Xc}^{-}$-mediated cysteine import, the key metabolite in glutathione synthesis required for lipid-ROS detoxification by lipid peroxidases. In turn, system $\mathrm{Xc}^{-}$is a glutamate/ cysteine antiporter, hence elevated extracellular glutamate concentrations in epilepsy could not only promote excitotoxicity but also facilitate ferroptosis [80]. While the exact cell-death mechanism of pyknotic neurons in TLE-HS is unclear, previous studies demonstrated that specifically hilar GABAergic neurons, a neuronal subtype whose dysfunction is supposed to play a pro-epileptogenic role in patients with TLE and animal models of acquired epilepsy, seem to be highly sensitive to ferroptosis $[16,32,66,90]$. A protective response of the brain might require upregulation of the catalytic subunit of system $\mathrm{Xc}^{-}, \mathrm{xCT}$, for sufficient glutathione synthesis. This is in line with the detected overexpression of glutathione metabolism on total hippocampal RNA and protein in TLE-HS tissue. Moreover, only a fraction of 4-HNE-positive neurons exhibited pyknotic morphology, suggesting elevated lipid peroxidation does not automatically predestine cells for necrosis. Besides 4-HNE, neurons also showed high expression of HO-1, an acute stress protein whose transcription is regulated by antioxidant defense systems like the Nrf-2 signaling pathway [53]. Importantly, HO- 1 represents a key enzyme in the acute antioxidant response releasing iron in the process [72]. Consequently, acute $\mathrm{HO}-1$ expression is involved in detoxification, while chronic Nrf-2-dependent HO-1 overexpression induces iron release [97] and paradoxically was shown to accelerate oxidative damage and ferroptosis [38, 72, 79]. Thus, in addition to extrinsic seizure-mediated iron ingress via BBB leakage, neurons might also be confronted with iron overload via intrinsic enzyme-mediated iron release.

\section{Iron accumulation and ferritin expression in glia implicate increased iron-binding capacity of astrocytes in SE and TLE-HS tissue}

A principle finding in SE and TLE-HS brain tissue was a prominent shift in the localization of ferritin expression from microglia and oligodendrocytes in autopsy control tissue to markedly higher expression in astrocytes. Microglia were shown to upregulate ferritin expression in experimental epilepsy models [23, 29]. In addition, astrocytes appear to dynamically acquire the capacity to sequester iron in SE and TLE-HS. Interestingly, astrocytic ferritin overexpression was accompanied by a decrease in total ferritin gene and protein expression in TLE-HS hippocampi. One explanation for the reduction of total ferritin might be that iron sequestration via microglia is dysfunctional or overloaded in epilepsy, either because of higher brain iron load due to seizures or altered microglial iron homeostasis. In this context, recent developments in single cell transcriptomics revealed that microglial subtypes show more distinct changes in homeostatic functions during pathological situations, which could 

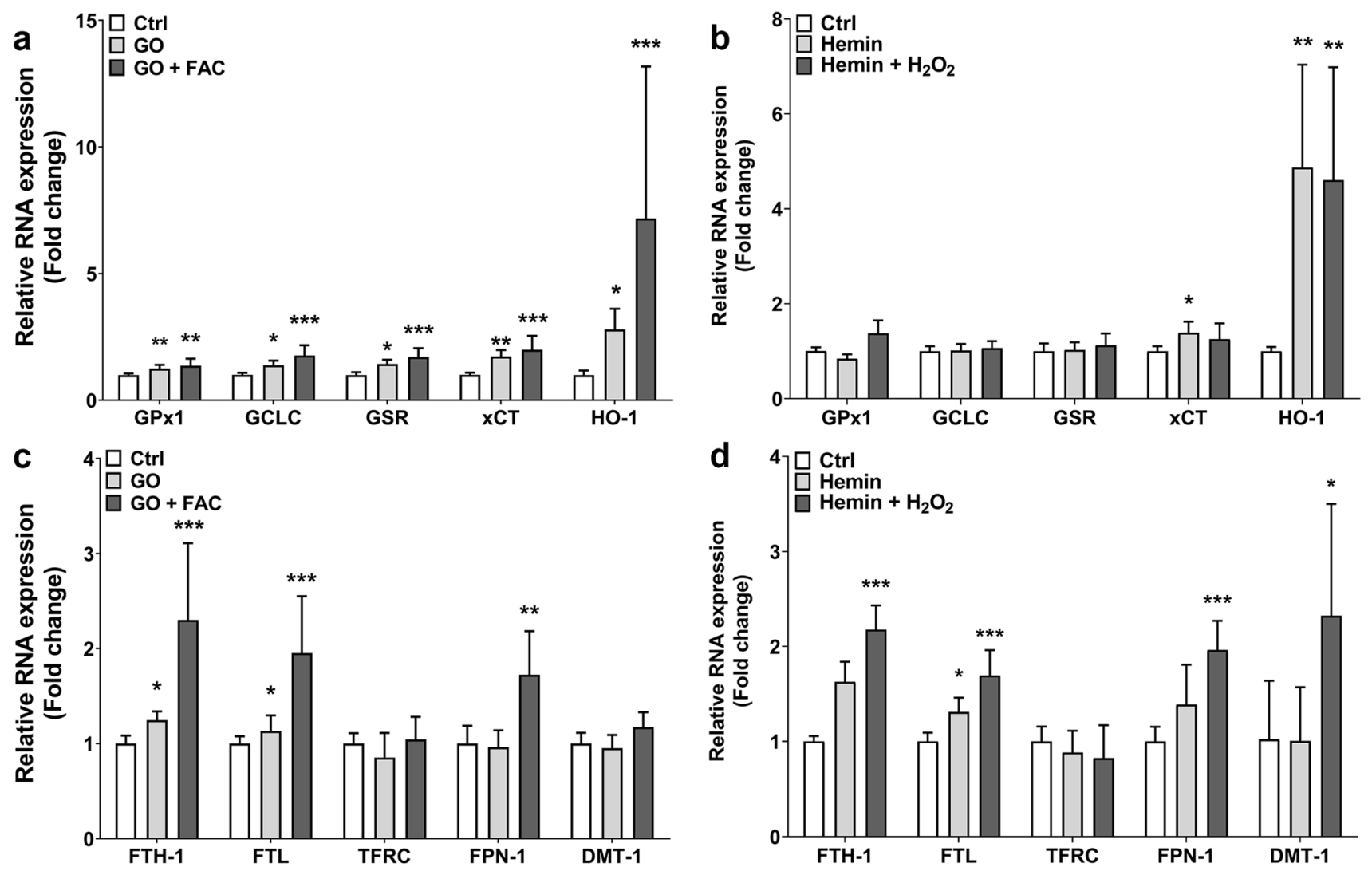
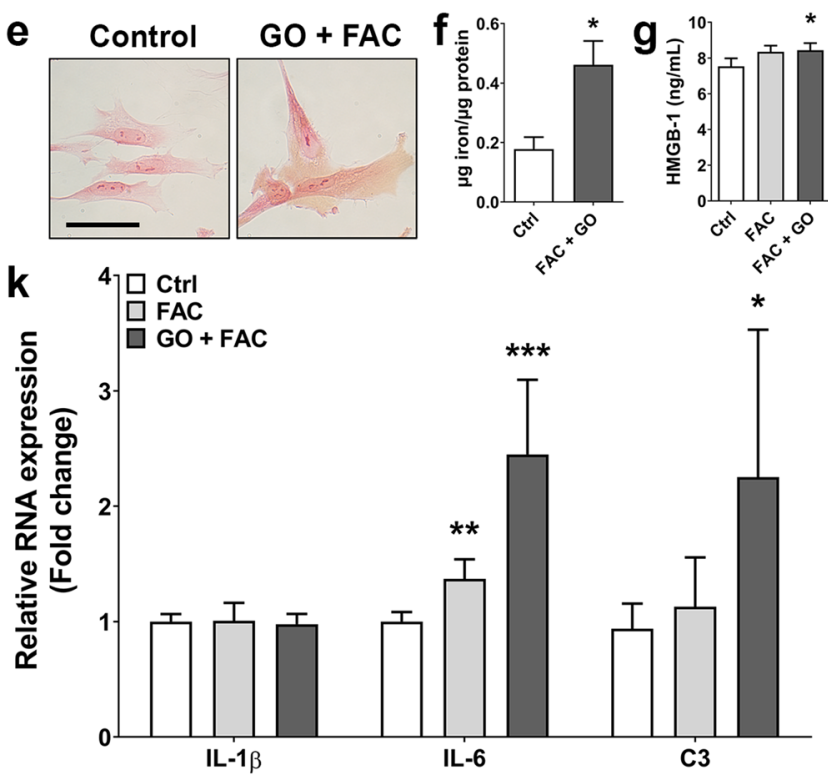

include iron metabolism [44]. This shift in iron handling from microglia to astrocytes is supported by a previous report studying multiple sclerosis brains, which revealed a similar function for reactive astrocytes as iron-storing cells [62]. Besides iron and ferritin, TLE-HS tissue also displayed lower RNA expression of TFRC and higher expression of DMT-1 in epileptogenic tissue. TFRC is involved in transferrin-dependent $\mathrm{Fe}^{3+}$ iron uptake, while DMT-1 facilitates

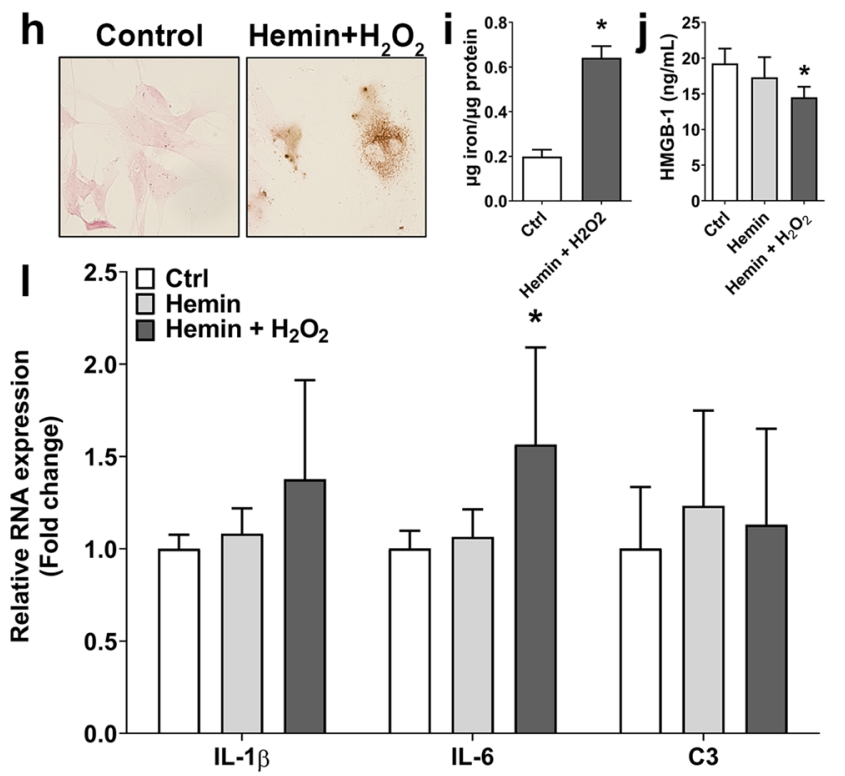

endosomal iron export, but also direct transmembrane entry of $\mathrm{Fe}^{2+}$ into cells. Immunohistochemistry of TFRC and DMT-1 revealed low neuronal TFRC and higher TFRC and DMT-1 expression in astrocytes. DMT- 1 shuttles $\mathrm{Fe}^{2+}$ while TFRC transports transferrin bound $\mathrm{Fe}^{3+}$ [30], thus, indicating either a shift in the brains $\mathrm{Fe}^{2+} / \mathrm{Fe}^{3+}$ ratio or changes in iron handling such as an increased need to rapidly take up $\mathrm{Fe}^{2+}$ or metabolize endosomal $\mathrm{Fe}^{2+}$. Strong DMT-1 and 
4Fig. 7 In vitro, human fetal astrocytes exposed to OS and iron induce glutathione metabolic genes and iron metabolism and promote a proinflammatory phenotype. a-d Human fetal astrocytes exposed to GO $(2.5 \mathrm{mU})$ and FAC $(200 \mu \mathrm{M})$ for $72 \mathrm{~h}$ displayed higher expression of glutathione genes GPx1, GCLC, GSR, xCT, HO-1 and FTH-1 and FTL than GO alone compared to control $(\mathbf{a}, \mathbf{c})$. Additionally, FPN-1 was exclusively higher in astrocytes exposed to GO and FAC (c). Fetal astrocytes exposed to hemin $(10 \mu \mathrm{M})$ for $24 \mathrm{~h}$ only displayed upregulation of FTL while the combination of $\mathrm{H}_{2} \mathrm{O}_{2}(500 \mu \mathrm{M})$ with hemin induced the expression of GSR, HO-1, FTH-1, FPN-1, DMT-1 (b, d). e, f Fetal astrocytes exposed to GO/FAC for $24 \mathrm{~h}$ accumulate intracellular iron. g Stimulation of fetal astrocytes with GO/FAC, but not FAC alone, led to release of HMGB-1 into the culture supernatant. h, i Similar to FAC, exposure of fetal astrocytes to hemininduced iron accumulation. $\mathbf{j}$ However, in contrast to FAC, HMGB-1 release into the supernatant was reduced upon co-treatment of hemin/ $\mathrm{H}_{2} \mathrm{O}_{2}$. k, I RNA quantification revealed higher IL-6 expression upon treatment with FAC or GO/FAC. However, only FAC/GO induced the expression of $\mathrm{C} 3(\mathrm{k})$. Fetal astrocytes stimulated with hemin or hemin $/ \mathrm{H}_{2} \mathrm{O}_{2}$ displayed solely upregulation of IL-6 upon hemin $/ \mathrm{H}_{2} \mathrm{O}_{2}$ co-stimulation. Scale bars: $50 \mu \mathrm{m}$ in e (representative for h). $\mathbf{a}, \mathbf{b}, \mathbf{g}, \mathbf{j}$, $\mathbf{k}$, l Kruskal-Wallis test followed by post hoc Dunn's test. f, i MannWhitney $U$ test. Data are expressed relative to expression observed in controls as bar graphs with SD; $* p<0.05, * * p<0.01$, *** $p<0.001$. $\mathbf{a}, \mathbf{b}, \mathbf{k}, \mathbf{l} n=4$ independent cultures in duplicates, $\mathbf{g} n=5$ independent cultures; $\mathbf{f}, n=4$ independent cultures; $\mathbf{j} n=6$ independent cultures. $\mathbf{e}, \mathbf{h}$ Cells on coverslips were counterstained with Safranin O. Scale $\operatorname{bar}=50 \mu \mathrm{m}$ in $(\mathbf{e})$

TFRC expression in astrocytes suggests higher glial uptake of iron, while overall lower TFRC might be explained by neuronal loss but also reduced expression including other cell types such as endothelial cells. Additionally, higher FPN-1 RNA expression might indicate enhanced cellular iron export [13]. The intimate interaction of astrocytes with the BBB and their consequent improved ability to control iron flux as compared to microglia could be another explanation for the shift of iron sequestration to astrocytes in epilepsy $[46,87,91]$. Interestingly, strong TFRC expression in punctate, astrocytic end-feet around the microvasculature could be detected, which might indicate a shift in control over iron shuttling from endothelium to astrocytes in epilepsy. In addition to SE/TLE-HS tissue, TBI and stroke lesions were studied, since brain tissue from both injuries typically exhibit brain iron overload due to hemorrhages. Notably, iron accumulation and ferritin expression in TBI and stroke lesions was detected in macrophages/microglia acutely, while astrocytes overexpressed ferritin in older lesions. This further confirms astrocytes to be crucial to iron sequestration during chronic iron exposure due to damaged/dysfunctional BBB or increased intraparenchymal iron release of brain cells.

\section{The transcriptome of TLE-HS hippocampi reveals higher glutathione metabolism and altered iron trafficking}

The collected transcriptomic data suggest higher antioxidant capacity, while simultaneously reducing iron import and promoting iron secretion, overall confirming the initial findings. FPN-1-mediated iron secretion is hepcidin (HAMP) and redox dependent [14], mainly mediated by the ferroxidases hephaestin (HEPH) or ceruloplasmin (CP) [30]. CP was shown to be expressed predominantly in astrocytes and its lack thereof promoting astrocytic iron accumulation in aceruloplasminemia $[34,36,55]$. Thus, $\mathrm{CP}$ downregulation might promote iron retention specifically in astrocytes. On the other hand, HAMP downregulation, which promotes FPN-1 internalization [49], and HEPH overexpression support increased iron secretion in other cell types. Interestingly, the transcriptomic data also revealed that of the family of antioxidant peroxiredoxins, solely PRX6 was found to be upregulated in TLE-HS hippocampi. PRX6 constitutes the only glutathione-dependent peroxiredoxin that has high affinity for lipid hydroperoxides $[17,65]$. Thus, the strong expression of PRX6 in astrocytes supports their high glutathione-dependent antioxidant capacity in TLE-HS. Notably, RNA sequencing showed a large heterogeneity between TLE-HS cases revealing distinct sub-clusters. Factors contributing to this heterogeneity between patients might include i.e. age, seizure frequency, epilepsy duration, cellular composition or last seizure before hippocampal resection.

\section{Ictal activity increases the magnetic susceptibility of brain tissue in the seizure-onset zone of epileptic patients}

The analysis of magnetic susceptibility by means of QSM showed a postictal increase in susceptibility within (but not strictly limited to) the presumable seizure-onset zone in patients. In concordance with the current literature [70], this change in magnetic susceptibility might indicate an increased accumulation of brain iron temporally and spatially associated with the epileptic seizure [39]. Notably, magnetic susceptibility of $\mathrm{Fe}^{2+}$ and $\mathrm{Fe}^{3+}$ were shown to be similar, thus not allowing a precise discrimination between oxidation states [15]. Current evidence for acute BBB dysfunction and consequent iron influx upon brain insults such as TBI or SE is strong, while prolonged BBB opening was demonstrated to play a role in epileptogenesis and aggravation of the epileptic condition [84]. Moreover, brain intrinsic alterations in iron handling such as HO-1-mediated iron release or also iron release from iron-sulfur clusters in stressed mitochondria might impact 
the seizure-associated increase in QSM signal [56]. The presented QSM data clearly demonstrate an increased susceptibility as a consequence of seizure activity in vivo, while data from epilepsy brain tissue suggests alterations in iron homeostasis temporally independent of the seizure. This finding likely represents a symptom of ongoing BBB dysfunction in combination with dysfunctional clearance of postictal iron. Here, accumulated iron could contribute to increased excitability by impairing astrocytic function (e.g. reduced potassium buffering) or by stimulating neuroinflammation, as supported by the in vitro data. Accordingly, iron itself might not be ictogenic per se, but affect the progression of epilepsy by lowering the seizure threshold over time.

\section{Strong iron accumulation upon electrically induced SE and spontaneous recurrent seizure activity}

Post-SE rats revealed that the relative iron load was not different between the acute and chronic phase, whereas immunohistochemical staining revealed much stronger iron retention during the acute phase. This finding could be explained by the difference in $\mathrm{Fe}^{2+} / \mathrm{Fe}^{3+}$ ratio since the method for measuring total iron detects both ionization states, whereas the Perl's staining only detects $\mathrm{Fe}^{3+}$. Based on these differences, it could be assumed that more $\mathrm{Fe}^{2+}$ is present during the chronic stage, potentially mediated by an altered brain redox state. Ferritin expression was almost exclusively found in microglia and only occasionally in astrocytes when SRS occurred, though at much lower numbers than in human brain tissue. Thus, higher FTH-1 expression during the latent stage might be attributable to activated microglia, as also shown by previous studies, even before the onset of SRS [23, 29]. Here, FTH-1 upregulation was detected also after the development of SRS, when neuronal loss is minimal, implicating altered iron metabolism in the pathogenesis and progression of epilepsy [23]. Another contributing factor to the increase in iron during the acute stage might also be HO-1, which was strongly overexpressed by reactive astrocytes. In contrast to tissue iron, RNA expression of iron metabolic genes and $\mathrm{xCT}$ was highest in the latent phase. Altogether, these data suggest a strong iron influx acutely post-SE, followed by iron metabolism/removal in the latent stage and, finally, chronic, low iron influx after the development of SRS. Contrary to human tissue, astrocytes appear to play a less important role in iron sequestration in this model which may be explained by the difference in i.e. seizure focus, epilepsy duration and differences in astrocyte competence in handling iron between rodents and humans [96]. Nevertheless, post-SE brain tissue confirmed profound iron accumulation and changes in iron metabolism.

\section{In vitro stimulation of hippocampal brain slices and primary astrocytes with ferric iron implicates seizure-mediated neuronal iron uptake and production of pro-inflammatory mediators in epileptogenesis}

In human and post-SE tissue iron accumulation was associated with seizure activity, but whether seizures also specifically promote neuronal iron uptake and/or iron evokes epileptiform activity remained an open question. Although previous reports demonstrated epileptogenic potential of intracortical iron injections in experimental animals, we did not find evidence for acute ictogenic properties of ferric iron in hippocampal slices $[35,89]$. However, neurons in acute hippocampal slice preparations stimulated with FAC revealed neuronal iron uptake primarily into nuclei and nucleoli, further pinpointing the nucleus as potential site of neuronal iron storage. These findings support that neurons could rapidly take up ferric iron upon excessive, local exposure as also seen in SHSY5Y cells. Moreover, SHSY5Y cells also displayed altered mitochondrial ultrastructure without impaired viability upon FAC exposure. Assuming BBB leakage, iron accumulation in neurons of TLE-HS patients is probably a slow, chronic process that is likely accompanied and influenced by other epileptogenic events such as altered redox status, mitochondrial dysfunction, neuroinflammation, etc. Since $\mathrm{Fe}^{3+}$-citrate is known to be a substantial component of blood [26,54], this way of iron exposure could be feasible. Additionally, seizure-mediated dysfunction of iron clearance and metabolism in brain cells might induce iron accumulation. Hence, we conclude that iron accumulation represents a consequence of seizures. The fact that hemin treatment did not lead to neuronal iron uptake indicates the importance of the iron-donating molecule as iron bound to the protoporphyrin ring of hemin requires enzymatic degradation via HO-1 for release [72]. While HO-1 RNA overexpression could be observed across all models, iron release from heme in hippocampal slices might have required longer incubation times.

Interestingly, stimulation of acute brain slices with epileptiform stimulants Glu or 4-AP plus FAC led to higher uptake of iron. Mechanistically, repetitive stimulation of the NMDA receptor during epileptiform activity could lead to increased DMT-1-dependent or direct NMDA-facilitated uptake of iron into neurons [9, 59]. Additionally, VGCCs, which are also implicated in epilepsy [95], were shown to facilitate neuronal iron uptake [21]. Using inhibitors of VGCCs and NMDA receptors we could not detect a reduction of iron uptake upon treatment with Glu, suggesting other, possibly unspecific routes of entry. Of note, while no ictogenic propensity of FAC was detected on the hippocampal network level, iron was shown to be involved in modulating synaptic excitability in physiological conditions at the cellular level 
[88]. An additional finding in hippocampal slices was the induction of pro-inflammatory cytokine expression upon FAC stimulation and an exacerbation of this effect when paired with 4-AP or Glu. In summary, although iron is not acutely ictogenic in hippocampal slices in the present study, it can drive neuronal iron uptake and promote expression of pro-inflammatory factors, which could reinforce ictogenesis and promote neuronal dysfunction.

Astrocyte cultures stimulated with hemin $/ \mathrm{H}_{2} \mathrm{O}_{2}$ (mimicking acute extravasation of blood components as in epileptogenic injuries) displayed iron uptake and higher RNA expression of iron metabolic genes required for handling excess iron. In contrast, stimulation with FAC/GO (mimicking altered redox balance and iron metabolism in the chronic epileptogenic brain) induced expression of ferritin and FPN-1, but also glutathione synthesis enzymes. Moreover, HMGB-1 release coupled to higher expression of IL-6 and $\mathrm{C} 3$ indicate that chronic iron coupled to OS might promote neuroinflammation. Elevated secretion of HMGB-1 could also be found in SHSY5Y cells treated with FAC/GO, but in contrast to astrocytes also hemin $/ \mathrm{H}_{2} \mathrm{O}_{2}$. Importantly, HMGB-1 disulfide formation is facilitated by OS, which can activate the toll-like receptor 4 (TLR4)-HMGB-1 axis in neurons promoting hyperexcitability, excitotoxicity and seizures [10, 33, 43]. Thus, inflammatory changes in astrocytes coupled to secretion of damage-associated molecular patterns such as HMGB-1 might be associated with astrocytic iron accumulation in epileptogenic brain tissue. Importantly, in conjunction with the proposed iron-catalyzed exacerbation of ROS, astrocytic expression of antioxidant, iron metabolism and pro-inflammatory genes was higher when co-treated rather than with ROS or iron alone. Another link between antioxidant and pro-inflammatory signaling might be the overexpression of PRX6 in astrocytes identified from transcriptomics since PRX6 possesses phospholipase $\mathrm{A}_{2}$ activity [17] which could be involved in the synthesis of inflammatory lipid mediators. Interestingly, previous studies demonstrated that pro-inflammatory activation can promote iron-buffering and resistance to OS in astrocytes. Thus, proinflammatory gene expression might reflect a homeostatic mechanism which, when activated chronically, could ultimately contribute to the progression of the disease [41, 60, 63]. In addition, other blood-borne factors such as albumin could reinforce the iron-mediated pro-inflammatory gene expression we detected and act synergistically as a result of BBB compromise in epilepsy to activate glia.

\section{Conclusion}

In conclusion, iron influx is likely due to a compromised $\mathrm{BBB}$ and changes in intracellular iron handling in chronic TLE-HS and epilepsy models. While the frequency and duration of seizures probably are important, astrogliosis and subsequent BBB dysfunction specific to TLE-HS might be essential for the altered iron accumulation observed. Moreover, the QSM data suggest higher iron load associated with seizures of various etiology. While iron itself does not trigger seizures, its intracellular accumulation is facilitated by paroxysmal activity. Finally, besides higher antioxidant and iron-binding capacity, astrocytes exposed to OS and iron acquire a potentially detrimental pro-inflammatory phenotype. Hence, strategies to reduce iron uptake into susceptible neuronal subtypes as well as into astrocytes, thereby reducing pro-inflammatory responses, might pose novel therapeutic options in epilepsy. While antioxidant treatment targeting Nrf-2 was shown to be beneficial in epilepsy and epileptogenesis, approaches more specifically inhibiting iron-catalyzed lipid peroxidation and ferroptosis have proven beneficial in experimental epilepsy models and might aid to identify novel therapeutic avenues [40, 42, 93]. However, more insights into the treatment window and the exact mechanisms and markers of iron-mediated neuronal damage are urgently needed.

Supplementary Information The online version contains supplementary material available at https://doi.org/10.1007/s00401-021-02348-6.

Acknowledgements We would like to thank Dr. Gabriella Panuccio (Istituto Italiano di Tecnologia, Genova, Italy) for help with setting up the multi-electrode array set-up. We would like to thank Prof. Marzia Perluigi for gifting the SHSY5Y neuroblastoma cell line to us. We acknowledge the Bloemenhove Clinic (Heemstede, The Netherlands) for providing fetal tissues.

Author contributions TSZ, BD, DWMB, MS, GR, AK, and JDM performed the experiments, data collection and analysis. DWMB, WvH, AM, PCvR, JCB, SI, RS, TR, EAvV and EA helped with the selection and collection of human brain tissues and clinical data. JAG and EAvV performed the animal experiments. LF, JvE, SD and JDM performed analysis of RNA sequencing data. NNvW performed electron microscopy. JAG, JDM, EAvV and EA conceived the study and participated in its design and coordination. TSZ, HWK, JDM, EAvV, JAG and EA drafted and prepared the manuscript. All authors read, revised, and approved the final manuscript.

Funding The research leading to these results has received funding from the European Union's Seventh Framework Programme (FP7/2007-2013) under grant agreement no. 602391 (EPISTOP; EA) and no. 602102 (EPITARGET; EAvV, JAG, EA), the Dutch Epilepsy Foundation, project number 16-05 and 20-11 (EAvV) and 20-02 (AM), the European Union's Horizon 2020 research and innovation program under the Marie Sklodowska-Curie grant agreement no. 722053 (EU-GliaPhD; TSZ, EA), the European Union's Horizon 2020 research and innovation program under grant agreement No 952455 (EpiEpiNet) (AE, EAvV, JAG), ZonMw, Programme Translational Research no. 95105004 (EA). GR was supported by a fellowship from "Istituto Pasteur Italia - Fondazione Cenci Bolognetti".

Data availability The datasets generated and analysed during the current study are available on the European Genome-phenome Archive (EGA) data repository. The EGA can be found at ega-archive.org. 


\section{Declarations}

Conflict of interest $\mathrm{AE}$ and $\mathrm{JM}$ receive an unrestricted grant from UCB Pharma. LF, JvE and SD are employees of UCB Pharma.

Ethics approval All procedures with human tissue were obtained with informed consent for the use in research and access to medical records in accordance with the Declaration of Helsinki and the Amsterdam UMC Research Code provided by the Medical Ethics Committee. All procedures performed in studies involving animals were in accordance with University Animal Welfare committee of the University of Amsterdam and performed in accordance with the guidelines of the European Community Council Directives 2010/63/EU.

Open Access This article is licensed under a Creative Commons Attribution 4.0 International License, which permits use, sharing, adaptation, distribution and reproduction in any medium or format, as long as you give appropriate credit to the original author(s) and the source, provide a link to the Creative Commons licence, and indicate if changes were made. The images or other third party material in this article are included in the article's Creative Commons licence, unless indicated otherwise in a credit line to the material. If material is not included in the article's Creative Commons licence and your intended use is not permitted by statutory regulation or exceeds the permitted use, you will need to obtain permission directly from the copyright holder. To view a copy of this licence, visit http://creativecommons.org/licenses/by/4.0/.

\section{References}

1. Aggarwal M, Li X, Grohn O, Sierra A (2018) Nuclei-specific deposits of iron and calcium in the rat thalamus after status epilepticus revealed with quantitative susceptibility mapping (QSM). J Magn Reson Imaging 47:554-564. https://doi.org/10. 1002/jmri.25777

2. Arena A, Zimmer TS, van Scheppingen J, Korotkov A, Anink JJ, Muhlebner A et al (2019) Oxidative stress and inflammation in a spectrum of epileptogenic cortical malformations: molecular insights into their interdependence. Brain Pathol 29:351-365. https://doi.org/10.1111/bpa.12661

3. Aronica E, Boer K, Becker A, Redeker S, Spliet WG, van Rijen PC et al (2008) Gene expression profile analysis of epilepsyassociated gangliogliomas. Neuroscience 151:272-292. https:// doi.org/10.1016/j.neuroscience.2007.10.036

4. Blumcke I, Thom M, Aronica E, Armstrong DD, Bartolomei F, Bernasconi A et al (2013) International consensus classification of hippocampal sclerosis in temporal lobe epilepsy: a Task Force report from the ILAE Commission on Diagnostic Methods. Epilepsia 54:1315-1329. https://doi.org/10.1111/epi. 12220

5. Broekaart DWM, Anink JJ, Baayen JC, Idema S, de Vries HE, Aronica E et al (2018) Activation of the innate immune system is evident throughout epileptogenesis and is associated with bloodbrain barrier dysfunction and seizure progression. Epilepsia 59:1931-1944. https://doi.org/10.1111/epi.14550

6. Bushnell B, Rood J, Singer E (2017) BBMerge—accurate paired shotgun read merging via overlap. PLoS ONE 12:e0185056. https://doi.org/10.1371/journal.pone.0185056

7. Cardenas-Rodriguez N, Coballase-Urrutia E, Perez-Cruz C, Montesinos-Correa H, Rivera-Espinosa L, Sampieri A 3rd et al (2014) Relevance of the glutathione system in temporal lobe epilepsy: evidence in human and experimental models. Oxid Med Cell Longev 2014:759293. https://doi.org/10.1155/2014/759293

8. Chan KS, Marques JP (2021) SEPIA-Susceptibility mapping pipeline tool for phase images. Neuroimage 227:117611. https://doi. org/10.1016/j.neuroimage.2020.117611

9. Cheah JH, Kim SF, Hester LD, Clancy KW, Patterson SE 3rd, Papadopoulos V et al (2006) NMDA receptor-nitric oxide transmission mediates neuronal iron homeostasis via the GTPase Dexras1. Neuron 51:431-440. https://doi.org/10.1016/j.neuron. 2006.07.011

10. Chiavegato A, Zurolo E, Losi G, Aronica E, Carmignoto G (2014) The inflammatory molecules IL-1beta and HMGB1 can rapidly enhance focal seizure generation in a brain slice model of temporal lobe epilepsy. Front Cell Neurosci 8:155. https://doi.org/10. 3389/fncel.2014.00155

11. Chua-anusorn W, Webb J, Macey DJ, Pootrakul P, St Pierre TG (1997) The effect of histological processing on the form of iron in iron-loaded human tissues. Biochim Biophys Acta 1360:255-261. https://doi.org/10.1016/s0925-4439(97)00009-4

12. Croft D, Mundo AF, Haw R, Milacic M, Weiser J, Wu G et al (2014) The Reactome pathway knowledgebase. Nucleic Acids Res 42:D472-477. https://doi.org/10.1093/nar/gkt1102

13. De Domenico I, Vaughn MB, Li L, Bagley D, Musci G, Ward $\mathrm{DM}$ et al (2006) Ferroportin-mediated mobilization of ferritin iron precedes ferritin degradation by the proteasome. EMBO J 25:5396-5404. https://doi.org/10.1038/sj.emboj.7601409

14. De Domenico I, Ward DM, di Patti MC, Jeong SY, David S, Musci $\mathrm{G}$ et al (2007) Ferroxidase activity is required for the stability of cell surface ferroportin in cells expressing GPI-ceruloplasmin. EMBO J 26:2823-2831. https://doi.org/10.1038/sj.emboj.76017 35

15. Dietrich O, Levin J, Ahmadi SA, Plate A, Reiser MF, Botzel $\mathrm{K}$ et al (2017) MR imaging differentiation of $\mathrm{Fe}(2+)$ and $\mathrm{Fe}(3+)$ based on relaxation and magnetic susceptibility properties. Neuroradiology 59:403-409. https://doi.org/10.1007/ s00234-017-1813-3

16. Dixon SJ, Lemberg KM, Lamprecht MR, Skouta R, Zaitsev EM, Gleason CE et al (2012) Ferroptosis: an iron-dependent form of nonapoptotic cell death. Cell 149:1060-1072. https://doi.org/10. 1016/j.cell.2012.03.042

17. Fisher AB (2011) Peroxiredoxin 6: a bifunctional enzyme with glutathione peroxidase and phospholipase A(2) activities. Antioxid Redox Signal 15:831-844. https://doi.org/10.1089/ars.2010. 3412

18. Fisher RS, Acevedo C, Arzimanoglou A, Bogacz A, Cross JH, Elger CE et al (2014) ILAE official report: a practical clinical definition of epilepsy. Epilepsia 55:475-482. https://doi.org/10. 1111/epi.12550

19. Fisher RS, van Emde BW, Blume W, Elger C, Genton P, Lee P et al (2005) Epileptic seizures and epilepsy: definitions proposed by the International League Against Epilepsy (ILAE) and the International Bureau for Epilepsy (IBE). Epilepsia 46:470-472. https://doi.org/10.1111/j.0013-9580.2005.66104.x

20. Friedman A (2011) Blood-brain barrier dysfunction, status epilepticus, seizures, and epilepsy: a puzzle of a chicken and egg? Epilepsia 52(Suppl 8):19-20. https://doi.org/10.1111/j.1528-1167. 2011.03227.x

21. Gaasch JA, Geldenhuys WJ, Lockman PR, Allen DD, Van der Schyf CJ (2007) Voltage-gated calcium channels provide an alternate route for iron uptake in neuronal cell cultures. Neurochem Res 32:1686-1693. https://doi.org/10.1007/s11064-007-9313-1

22. Garton T, Keep RF, Hua Y, Xi G (2016) Brain iron overload following intracranial haemorrhage. Stroke Vasc Neurol 1:172-184. https://doi.org/10.1136/svn-2016-000042

23. Gorter JA, Mesquita AR, van Vliet EA, da Silva FH, Aronica E (2005) Increased expression of ferritin, an iron-storage protein, in 
specific regions of the parahippocampal cortex of epileptic rats. Epilepsia 46:1371-1379. https://doi.org/10.1111/j.1528-1167. 2005.11505.x

24. Gorter JA, van Vliet EA, Aronica E, Breit T, Rauwerda H, Lopes da Silva FH et al (2006) Potential new antiepileptogenic targets indicated by microarray analysis in a rat model for temporal lobe epilepsy. J Neurosci 26:11083-11110. https://doi.org/10.1523/ JNEUROSCI.2766-06.2006

25. Gorter JA, van Vliet EA, Aronica E, Lopes da Silva FH (2001) Progression of spontaneous seizures after status epilepticus is associated with mossy fibre sprouting and extensive bilateral loss of hilar parvalbumin and somatostatin-immunoreactive neurons. Eur J Neurosci 13:657-669. https://doi.org/10.1046/j.1460-9568. 2001.01428.x

26. Grootveld M, Bell JD, Halliwell B, Aruoma OI, Bomford A, Sadler PJ (1989) Non-transferrin-bound iron in plasma or serum from patients with idiopathic hemochromatosis. Characterization by high performance liquid chromatography and nuclear magnetic resonance spectroscopy. J Biol Chem 264:4417-4422

27. Hackett MJ, McQuillan JA, El-Assaad F, Aitken JB, Levina A, Cohen DD et al (2011) Chemical alterations to murine brain tissue induced by formalin fixation: implications for biospectroscopic imaging and mapping studies of disease pathogenesis. Analyst 136:2941-2952. https://doi.org/10.1039/c0an00269k

28. Harrow J, Frankish A, Gonzalez JM, Tapanari E, Diekhans M, Kokocinski F et al (2012) GENCODE: the reference human genome annotation for The ENCODE Project. Genome Res 22:1760-1774. https://doi.org/10.1101/gr.135350.111

29. Hendriksen H, Datson NA, Ghijsen WE, van Vliet EA, da Silva FH, Gorter JA et al (2001) Altered hippocampal gene expression prior to the onset of spontaneous seizures in the rat post-status epilepticus model. Eur J Neurosci 14:1475-1484. https://doi.org/ 10.1046/j.0953-816x.2001.01778.x

30. Hentze MW, Muckenthaler MU, Galy B, Camaschella C (2010) Two to tango: regulation of Mammalian iron metabolism. Cell 142:24-38. https://doi.org/10.1016/j.cell.2010.06.028

31. Honda K, Smith MA, Zhu X, Baus D, Merrick WC, Tartakoff AM et al (2005) Ribosomal RNA in Alzheimer disease is oxidized by bound redox-active iron. J Biol Chem 280:20978-20986. https:// doi.org/10.1074/jbc.M500526200

32. Ingold I, Berndt C, Schmitt S, Doll S, Poschmann G, Buday K et al (2018) Selenium utilization by GPX4 is required to prevent hydroperoxide-induced ferroptosis. Cell 172(409-422):e421. https://doi.org/10.1016/j.cell.2017.11.048

33. Iori V, Maroso M, Rizzi M, Iyer AM, Vertemara R, Carli M et al (2013) Receptor for Advanced Glycation Endproducts is upregulated in temporal lobe epilepsy and contributes to experimental seizures. Neurobiol Dis 58:102-114. https://doi.org/10.1016/j. nbd.2013.03.006

34. Jeong SY, David S (2006) Age-related changes in iron homeostasis and cell death in the cerebellum of ceruloplasmin-deficient mice. J Neurosci 26:9810-9819. https://doi.org/10.1523/JNEUR OSCI.2922-06.2006

35. Jo A, Heo C, Schwartz TH, Suh M (2014) Nanoscale intracortical iron injection induces chronic epilepsy in rodent. J Neurosci Res 92:389-397. https://doi.org/10.1002/jnr.23328

36. Kawanami T, Kato T, Daimon M, Tominaga M, Sasaki H, Maeda $\mathrm{K}$ et al (1996) Hereditary caeruloplasmin deficiency: clinicopathological study of a patient. J Neurol Neurosurg Psychiatry 61:506-509. https://doi.org/10.1136/jnnp.61.5.506

37. Kovac S, Domijan AM, Walker MC, Abramov AY (2014) Seizure activity results in calcium- and mitochondria-independent ROS production via NADPH and xanthine oxidase activation. Cell Death Dis 5:e1442. https://doi.org/10.1038/cddis.2014.390
38. Kwon MY, Park E, Lee SJ, Chung SW (2015) Heme oxygenase-1 accelerates erastin-induced ferroptotic cell death. Oncotarget 6:24393-24403. https://doi.org/10.18632/oncotarget.5162

39. Langkammer C, Schweser F, Krebs N, Deistung A, Goessler W, Scheurer E et al (2012) Quantitative susceptibility mapping (QSM) as a means to measure brain iron? A post mortem validation study. Neuroimage 62:1593-1599. https://doi.org/10.1016/j. neuroimage.2012.05.049

40. Li Q, Li QQ, Jia JN, Sun QY, Zhou HH, Jin WL et al (2019) Baicalein exerts neuroprotective effects in $\mathrm{FeCl} 3$-induced posttraumatic epileptic seizures via suppressing ferroptosis. Front Pharmacol 10:638. https://doi.org/10.3389/fphar.2019.00638

41. Macco R, Pelizzoni I, Consonni A, Vitali I, Giacalone G, Martinelli Boneschi F et al (2013) Astrocytes acquire resistance to iron-dependent oxidative stress upon proinflammatory activation. J Neuroinflamm 10:130. https://doi.org/10.1186/ 1742-2094-10-130

42. Mao XY, Zhou HH, Jin WL (2019) Ferroptosis induction in pentylenetetrazole kindling and pilocarpine-induced epileptic seizures in mice. Front Neurosci 13:721. https://doi.org/10.3389/fnins. 2019.00721

43. Maroso M, Balosso S, Ravizza T, Liu J, Aronica E, Iyer AM et al (2010) Toll-like receptor 4 and high-mobility group box-1 are involved in ictogenesis and can be targeted to reduce seizures. Nat Med 16:413-419. https://doi.org/10.1038/nm.2127

44. Masuda T, Sankowski R, Staszewski O, Prinz M (2020) Microglia heterogeneity in the single-cell era. Cell Rep 30:1271-1281. https://doi.org/10.1016/j.celrep.2020.01.010

45. Mazzuferi M, Kumar G, van Eyll J, Danis B, Foerch P, Kaminski RM (2013) Nrf2 defense pathway: experimental evidence for its protective role in epilepsy. Ann Neurol 74:560-568. https://doi. org/10.1002/ana.23940

46. McCarthy RC, Kosman DJ (2014) Glial cell ceruloplasmin and hepcidin differentially regulate iron efflux from brain microvascular endothelial cells. PLoS ONE 9:e89003. https://doi.org/10. 1371/journal.pone.0089003

47. Meguro R, Asano Y, Odagiri S, Li C, Iwatsuki H, Shoumura K (2007) Nonheme-iron histochemistry for light and electron microscopy: a historical, theoretical and technical review. Arch Histol Cytol 70:1-19. https://doi.org/10.1679/aohc.70.1

48. Meguro R, Asano Y, Odagiri S, Li C, Shoumura K (2008) Cellular and subcellular localizations of nonheme ferric and ferrous iron in the rat brain: a light and electron microscopic study by the perfusion-Perls and -Turnbull methods. Arch Histol Cytol 71:205-222. https://doi.org/10.1679/aohc.71.205

49. Nemeth E, Tuttle MS, Powelson J, Vaughn MB, Donovan A, Ward DM et al (2004) Hepcidin regulates cellular iron efflux by binding to ferroportin and inducing its internalization. Science 306:2090-2093. https://doi.org/10.1126/science.1104742

50. Okubo S, Xi G, Keep RF, Muraszko KM, Hua Y (2013) Cerebral hemorrhage, brain edema, and heme oxygenase-1 expression after experimental traumatic brain injury. Acta Neurochir Suppl 118:83-87. https://doi.org/10.1007/978-3-7091-1434-6_14

51. Panuccio G, Colombi I, Chiappalone M (2018) Recording and modulation of epileptiform activity in rodent brain slices coupled to microelectrode arrays. J Vis Exp. https://doi.org/10.3791/57548

52. Panuccio G, D'Antuono M, de Guzman P, De Lannoy L, Biagini G, Avoli M (2010) In vitro ictogenesis and parahippocampal networks in a rodent model of temporal lobe epilepsy. Neurobiol Dis 39:372-380. https://doi.org/10.1016/j.nbd.2010.05.003

53. Parfenova H, Leffler CW, Basuroy S, Liu J, Fedinec AL (2012) Antioxidant roles of heme oxygenase, carbon monoxide, and bilirubin in cerebral circulation during seizures. J Cereb Blood Flow Metab 32:1024-1034. https://doi.org/10.1038/jcbfm.2012.13

54. Parkes HG, Allen RE, Furst A, Blake DR, Grootveld MC (1991) Speciation of non-transferrin-bound iron ions in synovial fluid 
from patients with rheumatoid arthritis by proton nuclear magnetic resonance spectroscopy. J Pharm Biomed Anal 9:29-32. https://doi.org/10.1016/0731-7085(91)80233-y

55. Patel BN, David S (1997) A novel glycosylphosphatidylinositolanchored form of ceruloplasmin is expressed by mammalian astrocytes. J Biol Chem 272:20185-20190. https://doi.org/10.1074/jbc. 272.32.20185

56. Patel M (2004) Mitochondrial dysfunction and oxidative stress: cause and consequence of epileptic seizures. Free Radic Biol Med 37:1951-1962. https://doi.org/10.1016/j.freeradbiomed.2004.08. 021

57. Patro R, Duggal G, Love MI, Irizarry RA, Kingsford C (2017) Salmon provides fast and bias-aware quantification of transcript expression. Nat Methods 14:417-419. https://doi.org/10.1038/ nmeth.4197

58. Pauletti A, Terrone G, Shekh-Ahmad T, Salamone A, Ravizza T, Rizzi M et al (2019) Targeting oxidative stress improves disease outcomes in a rat model of acquired epilepsy. Brain 142:e39. https://doi.org/10.1093/brain/awz130

59. Pelizzoni I, Macco R, Morini MF, Zacchetti D, Grohovaz F, Codazzi F (2011) Iron handling in hippocampal neurons: activitydependent iron entry and mitochondria-mediated neurotoxicity. Aging Cell 10:172-183. https://doi.org/10.1111/j.1474-9726. 2010.00652.x

60. Pelizzoni I, Zacchetti D, Campanella A, Grohovaz F, Codazzi F (2013) Iron uptake in quiescent and inflammation-activated astrocytes: a potentially neuroprotective control of iron burden. Biochim Biophys Acta 1832:1326-1333. https://doi.org/10.1016/j. bbadis.2013.04.007

61. Pitkanen A, Lukasiuk K, Dudek FE, Staley KJ (2015) Epileptogenesis. Cold Spring Harb Perspect Med. https://doi.org/10. 1101/cshperspect.a022822

62. Popescu BF, Frischer JM, Webb SM, Tham M, Adiele RC, Robinson CA et al (2017) Pathogenic implications of distinct patterns of iron and zinc in chronic MS lesions. Acta Neuropathol 134:45-64. https://doi.org/10.1007/s00401-017-1696-8

63. Rathore KI, Redensek A, David S (2012) Iron homeostasis in astrocytes and microglia is differentially regulated by TNF-alpha and TGF-beta1. Glia 60:738-750. https://doi.org/10.1002/glia. 22303

64. Reinert A, Morawski M, Seeger J, Arendt T, Reinert T (2019) Iron concentrations in neurons and glial cells with estimates on ferritin concentrations. BMC Neurosci 20:25. https://doi.org/ 10.1186/s12868-019-0507-7

65. Rhee SG, Kil IS (2017) Multiple functions and regulation of mammalian peroxiredoxins. Annu Rev Biochem 86:749-775. https://doi.org/10.1146/annurev-biochem-060815-014431

66. Righes Marafiga J, Vendramin Pasquetti M, Calcagnotto ME (2020) GABAergic interneurons in epilepsy: More than a simple change in inhibition. Epilepsy Behav 106:935. https://doi.org/ 10.1016/j.yebeh.2020.106935

67. Ritchie ME, Phipson B, Wu D, Hu Y, Law CW, Shi W et al (2015) Limma powers differential expression analyses for RNAsequencing and microarray studies. Nucl Acids Res 43:e47. https://doi.org/10.1093/nar/gkv007

68. Robinson MD, McCarthy DJ, Smyth GK (2010) edgeR: a Bioconductor package for differential expression analysis of digital gene expression data. Bioinformatics 26:139-140. https://doi. org/10.1093/bioinformatics/btp616

69. Rowley S, Patel M (2013) Mitochondrial involvement and oxidative stress in temporal lobe epilepsy. Free Radic Biol Med 62:121-131. https://doi.org/10.1016/j.freeradbiomed.2013.02. 002

70. Ruber T, David B, Luchters G, Nass RD, Friedman A, Surges $\mathrm{R}$ et al (2018) Evidence for peri-ictal blood-brain barrier dysfunction in patients with epilepsy. Brain 141:2952-2965. https://doi.org/10.1093/brain/awy242

71. Saletti PG, Ali I, Casillas-Espinosa PM, Semple BD, Lisgaras CP, Moshe SL et al (2019) In search of antiepileptogenic treatments for post-traumatic epilepsy. Neurobiol Dis 123:86-99. https://doi.org/10.1016/j.nbd.2018.06.017

72. Schipper HM, Song W, Tavitian A, Cressatti M (2019) The sinister face of heme oxygenase-1 in brain aging and disease. Prog Neurobiol 172:40-70. https://doi.org/10.1016/j.pneurobio. 2018.06.008

73. Schrag M, Dickson A, Jiffry A, Kirsch D, Vinters HV, Kirsch W (2010) The effect of formalin fixation on the levels of brain transition metals in archived samples. Biometals 23:1123-1127. https://doi.org/10.1007/s10534-010-9359-4

74. Shekh-Ahmad T, Eckel R, Dayalan Naidu S, Higgins M, Yamamoto M, Dinkova-Kostova AT et al (2018) KEAP1 inhibition is neuroprotective and suppresses the development of epilepsy. Brain 141:1390-1403. https://doi.org/10.1093/brain/awy071

75. Shekh-Ahmad T, Kovac S, Abramov AY, Walker MC (2019) Reactive oxygen species in status epilepticus. Epilepsy Behav 101:106410. https://doi.org/10.1016/j.yebeh.2019.07.011

76. Shekh-Ahmad T, Lieb A, Kovac S, Gola L, Christian Wigley W, Abramov AY et al (2019) Combination antioxidant therapy prevents epileptogenesis and modifies chronic epilepsy. Redox Biol 26:101278. https://doi.org/10.1016/j.redox.2019.101278

77. Shin EJ, Jeong JH, Chung CK, Kim DJ, Wie MB, Park ES et al (2015) Ceruloplasmin is an endogenous protectant against kainate neurotoxicity. Free Radic Biol Med 84:355-372. https://doi. org/10.1016/j.freeradbiomed.2015.03.031

78. Soneson C, Love MI, Robinson MD (2015) Differential analyses for RNA-seq: transcript-level estimates improve gene-level inferences. F1000Res 4:1521. https://doi.org/10.12688/f1000 research.7563.2

79. Song W, Su H, Song S, Paudel HK, Schipper HM (2006) Overexpression of heme oxygenase-1 promotes oxidative mitochondrial damage in rat astroglia. J Cell Physiol 206:655-663. https://doi.org/10.1002/jcp.20509

80. Stockwell BR, Friedmann Angeli JP, Bayir H, Bush AI, Conrad M, Dixon SJ et al (2017) Ferroptosis: a regulated cell death nexus linking metabolism, redox biology, and disease. Cell 171:273-285. https://doi.org/10.1016/j.cell.2017.09.021

81. Terrone G, Balosso S, Pauletti A, Ravizza T, Vezzani A (2020) Inflammation and reactive oxygen species as disease modifiers in epilepsy. Neuropharmacology 167:107742. https://doi.org/ 10.1016/j.neuropharm.2019.107742

82. Thirupathi A, Chang YZ (2019) Brain iron metabolism and CNS diseases. Adv Exp Med Biol 1173:1-19. https://doi.org/ 10.1007/978-981-13-9589-5_1

83. van Scheppingen J, Iyer AM, Prabowo AS, Muhlebner A, Anink JJ, Scholl T et al (2016) Expression of microRNAs miR21, miR146a, and miR155 in tuberous sclerosis complex cortical tubers and their regulation in human astrocytes and SEGAderived cell cultures. Glia 64:1066-1082. https://doi.org/10. 1002/glia.22983

84. van Vliet EA, Aronica E, Gorter JA (2015) Blood-brain barrier dysfunction, seizures and epilepsy. Semin Cell Dev Biol 38:26-34. https://doi.org/10.1016/j.semcdb.2014.10.003

85. van Vliet EA, da Costa AS, Redeker S, van Schaik R, Aronica E, Gorter JA (2007) Blood-brain barrier leakage may lead to progression of temporal lobe epilepsy. Brain 130:521-534. https:// doi.org/10.1093/brain/awl318

86. Vidal R, Delisle MB, Rascol O, Ghetti B (2003) Hereditary ferritinopathy. J Neurol Sci 207:110-111. https://doi.org/10.1016/ s0022-510x(02)00435-5 
87. Wang XS, Ong WY, Connor JR (2001) A light and electron microscopic study of the iron transporter protein DMT-1 in the monkey cerebral neocortex and hippocampus. J Neurocytol 30:353-360. https://doi.org/10.1023/a:1014464514793

88. White RS, Bhattacharya AK, Chen Y, Byrd M, McMullen MF, Siegel SJ et al (2016) Lysosomal iron modulates NMDA receptor-mediated excitation via small GTPase, Dexras1. Mol Brain 9:38. https://doi.org/10.1186/s13041-016-0220-8

89. Willmore LJ, Sypert GW, Munson JB (1978) Recurrent seizures induced by cortical iron injection: a model of posttraumatic epilepsy. Ann Neurol 4:329-336. https://doi.org/10.1002/ana. 410040408

90. Wirth EK, Conrad M, Winterer J, Wozny C, Carlson BA, Roth $S$ et al (2010) Neuronal selenoprotein expression is required for interneuron development and prevents seizures and neurodegeneration. FASEB J 24:844-852. https://doi.org/10.1096/fj. 09-143974

91. Wu LJ, Leenders AG, Cooperman S, Meyron-Holtz E, Smith S, Land W et al (2004) Expression of the iron transporter ferroportin in synaptic vesicles and the blood-brain barrier. Brain Res 1001:108-117. https://doi.org/10.1016/j.brainres.2003.10. 066

92. Yarunin A, Panse VG, Petfalski E, Dez C, Tollervey D, Hurt EC (2005) Functional link between ribosome formation and biogenesis of iron-sulfur proteins. EMBO J 24:580-588. https:// doi.org/10.1038/sj.emboj.7600540
93. Ye Q, Zeng C, Dong L, Wu Y, Huang Q, Wu Y (2019) Inhibition of ferroptosis processes ameliorates cognitive impairment in kainic acid-induced temporal lobe epilepsy in rats. Am J Transl Res 11:875-884

94. Yumoto S, Kakimi S, Ishikawa A (2018) Colocalization of aluminum and iron in nuclei of nerve cells in brains of patients with Alzheimer's disease. J Alzheimers Dis 65:1267-1281. https://doi.org/10.3233/JAD-171108

95. Zamponi GW, Lory P, Perez-Reyes E (2010) Role of voltagegated calcium channels in epilepsy. Pflug Arch 460:395-403. https://doi.org/10.1007/s00424-009-0772-x

96. Zhang Y, Sloan SA, Clarke LE, Caneda C, Plaza CA, Blumenthal PD et al (2016) Purification and characterization of progenitor and mature human astrocytes reveals transcriptional and functional differences with mouse. Neuron 89:37-53. https:// doi.org/10.1016/j.neuron.2015.11.013

97. Zimmer TS, Ciriminna G, Arena A, Anink JJ, Korotkov A, Jansen FE et al (2019) Chronic activation of anti-oxidant pathways and iron accumulation in epileptogenic malformations. Neuropathol Appl Neurobiol. https://doi.org/10.1111/nan.12596

Publisher's Note Springer Nature remains neutral with regard to jurisdictional claims in published maps and institutional affiliations.

\section{Authors and Affiliations}

Till S. Zimmer ${ }^{1}$ - Bastian David ${ }^{2}$. Diede W. M. Broekaart ${ }^{1} \cdot$ Martin Schidlowski $^{2,3} \cdot$ Gabriele Ruffolo $^{4}$. Anatoly Korotkov ${ }^{1}$. Nicole N. van der Wel ${ }^{5,6} \cdot$ Peter C. van Rijen ${ }^{7}$. Angelika Mühlebner ${ }^{1,8}$. Wim van Hecke ${ }^{8}$. Johannes C. Baayen ${ }^{9}$. Sander Idema ${ }^{9}$. Liesbeth François ${ }^{10}$. Jonathan van Eyll ${ }^{10}$. Stefanie Dedeurwaerdere ${ }^{10}$. Helmut W. Kessels ${ }^{11}$ - Rainer Surges ${ }^{2}$. Theodor Rüber ${ }^{2} \cdot$ Jan A. Gorter ${ }^{11}$. James D. Mills ${ }^{1,12,13}$. Erwin A. van Vliet ${ }^{1,11}$. Eleonora Aronica ${ }^{1,14}$ (i)

1 Department of (Neuro)Pathology, Amsterdam UMC, University of Amsterdam, Amsterdam Neuroscience, Meibergdreef 9, 1105 AZ Amsterdam, The Netherlands

2 Department of Epileptology, University Hospital Bonn, Bonn, Germany

3 German Center for Neurodegenerative Diseases (DZNE), Bonn, Germany

4 Laboratory affiliated to Istituto Pasteur Italia, Department of Physiology and Pharmacology, University of Rome Sapienza, Rome, Italy

5 Department Cell Biology and Histology, Amsterdam UMC, University of Amsterdam, Amsterdam, The Netherlands

6 Department Electron Microscopy Center Amsterdam, Amsterdam UMC, University of Amsterdam, Amsterdam, The Netherlands

7 Department of Neurosurgery, Brain Centre, Rudolf Magnus Institute for Neuroscience, University Medical Center Utrecht, Utrecht, The Netherlands
8 Department of Pathology, University Medical Center Utrecht, Utrecht, The Netherlands

9 Department of Neurosurgery, Amsterdam Neuroscience, Amsterdam UMC, Vrije Universiteit Amsterdam, Amsterdam, The Netherlands

10 Neurosciences Therapeutic Area, UCB Pharma, Braine-l'Alleud, Belgium

11 Center for Neuroscience, Swammerdam Institute for Life Sciences, University of Amsterdam, Amsterdam, The Netherlands

12 Department of Clinical and Experimental Epilepsy, UCL, London, UK

13 Chalfont Centre for Epilepsy, Chalfont St Peter, UK

14 Stichting Epilepsie Instellingen Nederland (SEIN), Heemstede, The Netherlands 